PARADOXES OF

NATURE

AND SCIENCE

Dr.W. HAMPSON 


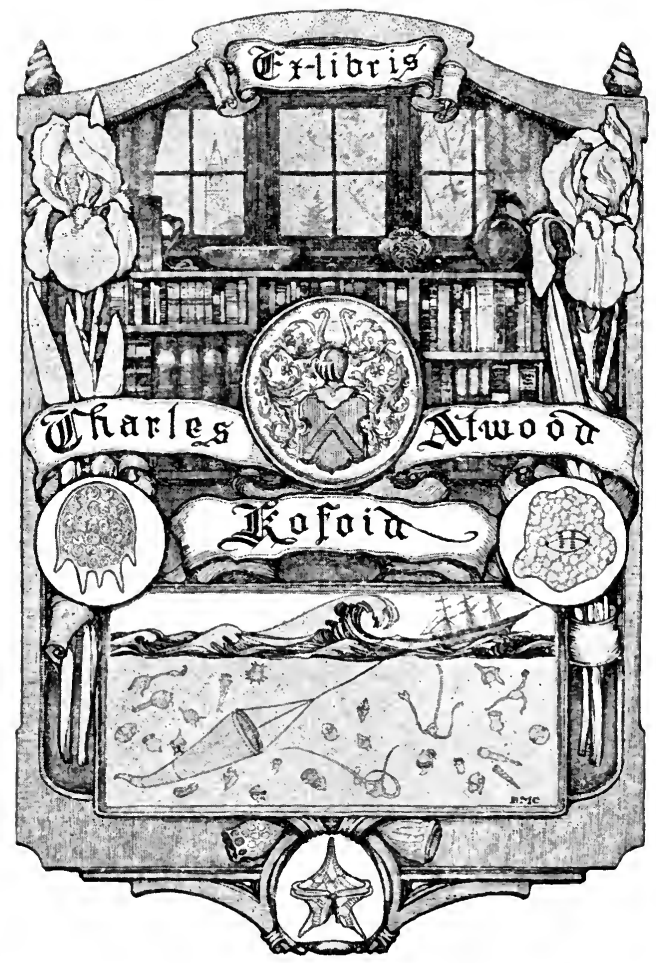




\section{ant 26}

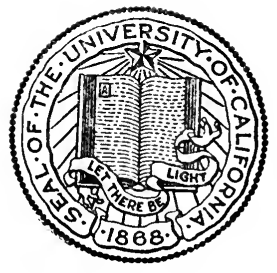

THE LIBRARY

$\mathrm{OF}$

\section{THE UNIVERSITY OF CALIFORNIA}

PRESENTED BY

PROF. CHARLES A. KOFOID AND

MRS. PRUDENCE W. KOFOID 

PARADOXES OF NATURE

AND SCIENCE 

f

H.t. 


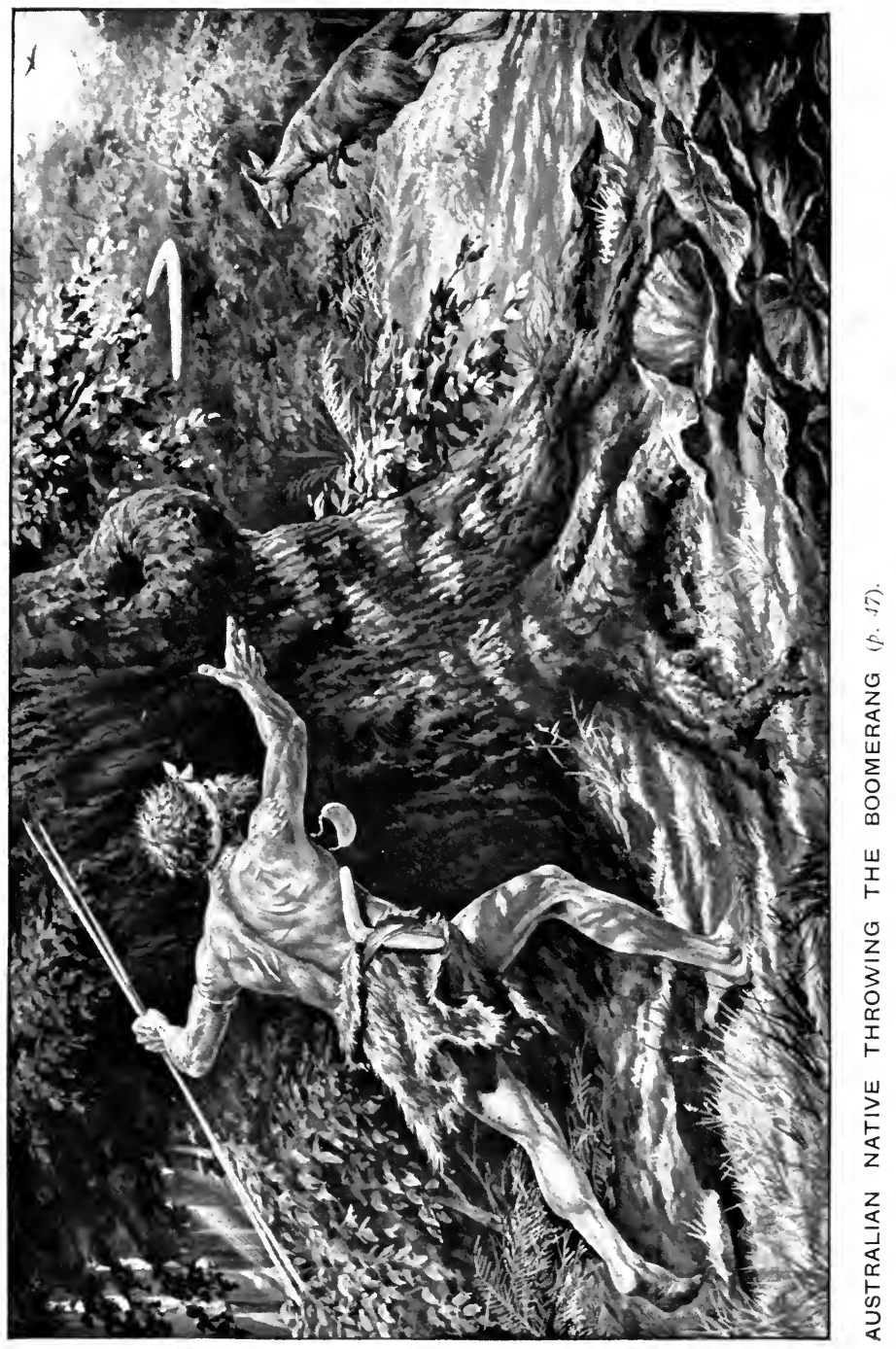




\section{PARADOXES OF NATURE AND

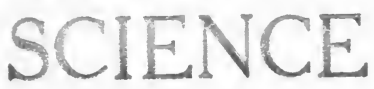

Things which appear to contradict general experience or scientific principles, with popular explanations of the how and why

BY

W. HAMPSON

M.A. Oxon., L.S.A. Lond.

Formerly Open Scholar of Trinity College, Oxford; Lecturer under the London County Council at University College London, 1900-1901; Author of "Radium Explained"

ILLUSTRATED WITH FULL-PAGE PLATES AND DIAGRAMS

CASSELL AND COMPANY, LIMITED

LONDON, PARIS, NEW YORK

AND MELBOURNE. MCMVI

ALL RIOHTS RESERVED 



\section{Q 164}

43

\section{PREFACE.}

NATURE is a great conjurer. With many of her tricks we are so familiar that they do not astonish us ; but on giving them a little consideration we often find that they are really very puzzling performances, and we become as eager to learn the explanation as children at a Christmas conjuring party to hear the performer's account of how he does it, or children of an older growth to learn from the political prestidigitator at the head of the opposite party how he reconciles his action with his principles.

Equally interesting puzzles occur in the course of experimental work in the laboratory; but in this book the choice will be limited, so far as is reasonably possible, to such experiments as can be readily performed, with very simple apparatus, at home; and the form of 


\section{PREFACE.}

experiment illustrated will often depend on the fact that this object is in view.

In both kinds of paradox, the desire to gratify curiosity by seeking the explanation will promote an interest in the intelligent study of the workings of natural forces; and this is no less truly the study of science than much of the rote-work for examinations which is done under that name.

W. H. 


\section{CONTENTS.}

\section{PART I.}

\section{MECHANICAL PARADOXES.}

I.-Carriages and other Means of Transport.

I. A Carriage which on Level Ground is more easily drawn Loaded than Empty

2. When a Train is going at Sixty Miles an Hour, what Part of it is moving backwards? . . . 5

3. A Sailing Boat which moves more swiftly than the Wind which is driving it . . . . .

\section{II.-Spinning Movement}

I. The Mysterious Spinner: Motion without Apparent Cause . . . . . . . . 14

2. Solids defying Gravity: the Gyroscope . • . 23

\section{III.-Rolling and Flying Movement.}

I. The Intelligent Billiard Balls . . . . 36

2. Throwing Balls round a Corner . . . . $4 \mathrm{I}$

3. Boomerangs . . . . . . . . 47

4. Balloons as Air-ships . . . . . . . $\quad$. 62

5. The Way of a Bird in the Air . . . . 70

\section{IV.-Fluid Forces.}

I. A Pound Weight balancing a Hundredweight . $\quad 77$

2. Fluids defying Gravity . . . . . $\quad 85$

3. More Weight without More Material . $\quad$. 92

4. Repulsion and Attraction by the Same Agent . $\quad 98$ 


\section{CONTENTS.}

V.-Fallacies with the Lever.

PAGE

I. The Angular Crank . . . . . . 104

2. The Self-moving Mill . . . . . . III

\section{PART II.}

PARADOXES OF PHYSICAL STATE.

I.-Curiosities of Freezing and Melting.

I. Ice melting while growing Colder . . . . I I7

2. Ice melted without Heat or Cold . . . . I 20

3. Cutting Ice without severing the Parts . . . I 23

4. Ice unmelted in a Vessel of Boiling Water . $~ I 26$

5. Expansion and its Opposite both produced by the

Same Cause . . . . . . . 128

6. Strong Vessel burst by cooling Water in it . $\quad$ I 34

II.-CuRiosities of Steam and Vaporisation.

I. Strong Vessel burst by heating Water in it . .138

2. Explosion or Collapse? . . . . . $\mathrm{I}_{42}$

3. Water boiled by Cold instead of by Fire or Flame. 145

4. More Cooling with less Cold Water . . . 148

III.-Curiosities of Heat Conduction.

I. A Vessel too Hot to boil Water . . . . 152

2. Dipping the Hand into Molten Lead . . . I 55

3. Walking over Red-hot Stones . . . • . 156

IV.-Curiosities of VApour Jets.

1. Passing the Hand through a Live-steam Jet . . I60

2. The Stronger overcome by the Weaker . . . I6I

\section{V.-Curiosities of Volatile Liguids.}

1. Freezing produced by Boiling. . . " . 165

2. Ice as a Heating Agent . . . . . . I7I 


\section{CONTENTS.}

Vi.-Perpetual Motion fallacies.

1. Liquid Air and Perpetual Motion.

2. The Inexhaustible Source of Heat . . . . 178

3. A Clock which is never wound and never stops . I8I

VII.-MAGNETISM.

Pulling without any Cord . . . . . . 186

\section{PART III.}

\section{CHEMICAL PARADOXES.}

I.-Curiosities of Combination.

I. Fire a Source of Water: Picking Moisture out of a

Hot Flame . . . . . . . $20 \mathrm{I}$

2. Water a Source of Fire. . . . . . . 204

3. Paradoxes of Substance and Form . . . . 207

II.-Disintegration.

I. The Philosopher's Stone . . . . . 210

2. Disintegration in General . . . . . 214

\section{PART IV.}

PHYSIOLOGICAL PARADOXES.

I.-The Eyes, and Peculiarities of Vision.

I. A Blind Spot in a Sound Eye . . . . 216

2. The Sane and Sober seeing double. . . . 219

3. Looking through the Hand . . . . . 225

4. Blue and Yellow not producing Green . . . 229

5. Looking at One Colour and seeing Another . . 23I 


\section{CONTENTS.}

II.-The Eyes as False Witnesses.

. 233

2. False Parallels . . . . . . . 237

3. Levels . . . . . . . . . . 242

4. False Continuity . . • . . . . . 246

III.-The Ears as False Witnesses.

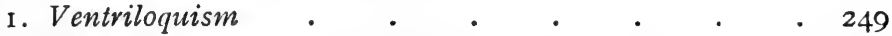

2. False Continuity . . . . . . 256

IV.-The Touch a False Witness.

1. The Hotter feeling the Colder . . . . 259

2. Pain in the Foot when the Leg has been amputated . $26 \mathrm{I}$

3. Immediate Action impossible. . . . . 263

4. False Continuity in Sense of Touch . . . 264

5. Achilles and the Tortoise . . . . . 266

\section{V.-BOdily Structure}

I. Pumps without Pistons: Self-repairing Valves. $\quad 287$

2. The Cab-horse as a Ballet Dancer . . . . 298 


\section{LIST OF ILLUSTRATIONS.}

PAGE

Partial Balance with Loaded Jinrikisha . . 3

Proposed Balance with Empty Jinrikisha . • . 4

Backward Motion of Part of Railway Carriage Wheel 6

How Speed depends on the Set of the Sails • • 9

Construction of Mysterious Spinner • • • • 14

Home-made Gyroscope • • • . . 24

Half-crown Gyroscope $\quad$ • $\quad$ • $\quad$ • 26

Gyroscope resisting a Twist . • • • 29

Secondary Movement caused by a Twist . . 32

Equal Movement transmitted to Equal Numbers of Balls 37

A Projectile deflected from its Course . . . 42

Deflection of Balls from their Course . . • 43

Ordinary Shape of Boomerang . . . . . 48

Vertical Deflection of Boomerang's Line of Flight $\quad 53$

Screw Motion causing Rise in Flight of Boomerang • 55

Variations in Flight of Boomerang • . . 58

Home-made Apparatus for Toy Boomerang . . 60

Soaring of Large Birds identical with Gliding • $\quad 72$

Position and Action of Wings in Flying . . . 74

Principles of the Hydraulic Press • • • 79

Atmospheric pressure, Capillarity, and Siphon Flow . 84 


\section{LIST OF ILLUSTRATIONS.}

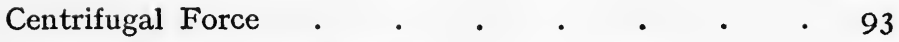

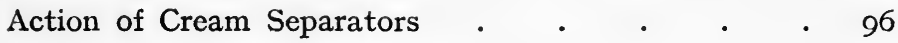

Repelling and Attracting Force of Jets • . . 99

Fallacy of the Bent Crank . . . . . 106

Fallacy of the Automatic Mill . . . . . 113

To Melt Ice by Squeezing : . . . . I2I

Ice re-frozen on Relaxation of Melting Pressure . $\quad 123$

Ice unmelted in Vessel of Boiling Water . • . 127

Expansion and Contraction of Water with Heat and Cold 129

Convection Currents in Water . . . . . 132

Bursting force of Water frozen in Confined Space - 135

Collapse of Flask under Atmospheric Pressure . • 144

Water boiled below Boiling Heat under Reduced Pressure 148

Vaporisation depending on Dryness of Air : the Hygro-

meter . . . . . . . . I49

Water in Spheroidal State on Red-hot Metal . . 153

Principle of the Steam Injector . . . . 163

Cooling due to Rapid Vaporisation of Ether . . 166

Liquid Carbonic Acid frozen by Rapid Vaporisation

through Sparklet Siphon-head . . . . I69

The Radium Clock: Perpetual Motion . . . I8I

Suction by a Pump really Repulsion by Air . . 188

Apparent Attraction in General : Theory of Repulsion 192 Baryta made red-hot by pouring Cold Water over it . 202 Traveller's Food-tin heated by Lime and Water . $\quad 206$

Device to show Existence of Blind Spot in Every Eye 217 Explanation of Blind Spot Experiment • • . 218

The Brain's Interpretation of the Eyes' Vision • • 221 


\section{LIST OF ILLUSTRATIONS.}

PAGE

The Moon as seen by a Man who is "Fou" . . 223

How to see a Hole through the Hand . . 226

Limitations of Sight: Mental Interpretations • . 234

Liability of Interpretations to Error • • • . 236

Apparent Convergence of Cloud Lines • • 238

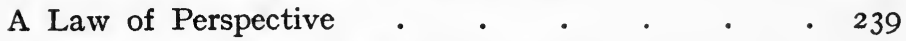

Spherical Shape of the Sky Firmament . • . 24I

Variations in Apparent Steepness of Hills . • . 244

Discontinuity: Flower Petals and Scales of Moth's

Wings . • . . . . . . 247

Experiment of Limitations of Hearing • • • 249

The Nerves and Imperfect Sense of Temperature . 260

A Handicap Race in the Pursuit of Science • . 267

Space and Limits of Divisibility • • • 273

Discontinuity of Motion . . . . . . 279

The Valves in the Veins . . . . . . 290

Mechanism of the Heart-valves • • • 295

Correspondence between Human and Equine Limbs . 300 
한 


\section{LIST OF PLATES.}

Australian Native throwing the Boomerang. Frontispiece Plate I.-A Japanese Jinrikisha . To face page 4 . II.-Canadian Ice-boats . . " 12

" III.-LOOPING THE LOOP . . " 94

" IV.-The Great Glacier on the Canadian Pacific RailWAY . . . . . , 126

"V.-Papa Ita about to Perform his Great Fire-walking FEAT . . . . " 156

"VI.-Railway Lines in Perspective " 240

. Vil.-Comparative Skeletons . " " 298 



\section{PARADOXES OF NATURE AND SCIENCE}

\section{PART I. \\ MECHANICAL PARADOXES.}

I.

CARRIAGES AND OTHER MEANS OF TRANSPORT. I. A Carriage which on Level Ground is more easily drawn Loaded than Empty.

WHEN travellers, returning from Japan, tell us that the jinrikisha man will draw a passenger, in his little carriage (see Plate I.), for a distance of forty miles or more in a day's journey, the statement is now easy to accept, in view of all we have lately learnt of the wonderful endurance of the Japanese. When we are told, further, that the jinrikisha man, even if he were to earn nothing extra for the extra work, would rather convey his passenger back again than draw the carriage home empty, we begin to suspect that we are listening to a traveller's tale.

The statement, however, is justified by the mechanical facts. It is easier, on a level 


\section{MECHANICAL PARADOXES.}

road which is in good condition, to draw the jinrikisha loaded than to draw it empty. The reason is simple and convincing. It depends upon the gain obtained by putting a load upon wheels. It is far easier to draw three hundredweight in a light truck along a railway platform than to carry one hundredweight on the back, making an extra weight for the legs to support. The jinrikisha man, returning with his carriage empty, has to carry his own weight on his legs. It would pay him well to get part of his weight off his legs on to the wheels, even if they had to carry in addition twice as much as they take off his legs. But the jinrikisha is not built so that he can ride it and propel it at the same time, as one does a bicycle or a railway trolley. The only way in which he can transfer part of his weight to the wheels, while drawing the jinrikisha along the roads, is by leaning on the shafts.

But the body of the carriage is so light that the slightest pressure on the shafts sends it up; and to make the shafts able to carry an appreciable part of his own weight, he must counterpoise this by putting a considerable mass in the seat of the vehicle. And the counterpoise must be a good deal heavier than the part of his own weight of which he is to be relieved, since its point of application is nearer to the fulcrum or bearing point, 


\section{MEANS OF TRANSPORT.}

and therefore its leverage is less. A passenger will, in fact, be a convenient weight for the purpose.

In Fig. I, if the passenger's centre of gravity over $\mathrm{A}$ is half as far behind the hub over $\mathrm{C}$ as $B$ is in front of it, $B$ being the point at which the jinrikisha man applies a part of his weight, it is obvious that the leverage at $B$ is twice

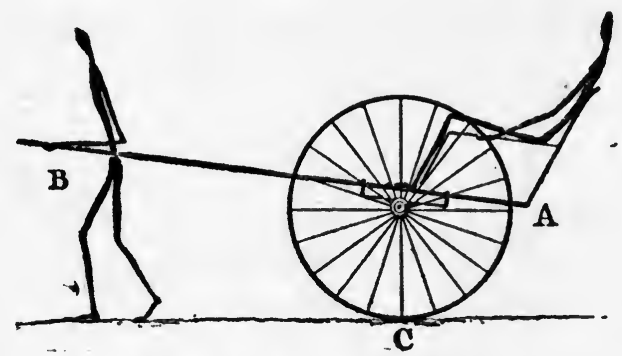

FIG. 1.-PARTIAL BALANCE WITH LOADED JINRIKISHA.

as great as that at A. If, therefore, the man and his passenger be of the same weight, half the man's weight at B balances all the passenger's weight at A. But if half the man's weight is pressing on the shafts at $B$, there is only half left to be carried by his legs. This is a great relief. On the other hand, the extra work of drawing the passenger's weight and half of his own, on light wheels over a good road, is very small, and by no means counterbalances the gain of having his legs relieved of half his own weight. Thus it is actually easier to draw his jinrikisha loaded than empty. 


\section{MECHANICAL PARADOXES.}

Needless to say, the Japanese jinrikisha man does not usually illustrate the virtues of his nation by taking his passenger back for nothing. But if he refuses, it is for commercial rather than mechanical reasons.

This account does not apply to journeys up-hill. In such cases, besides the traction labour there is additional work to be done in lifting a given weight a given height. To double this work by taking a passenger would

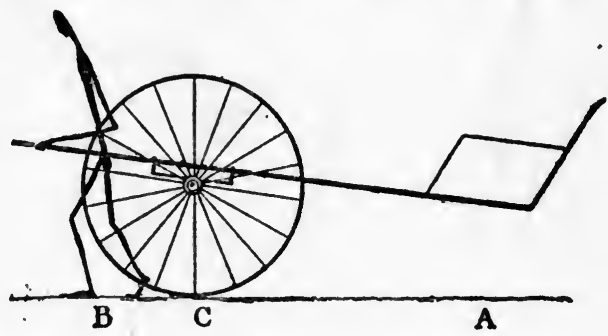

FIG. 2.-PROPOSED BALANCE WITH EMPTY JINRIKISHA.

more than neutralise the man's gain from putting half of his own weight on to the wheels. Similarly when the roads are soft. The traction labour is then increased by the necessity of forcing the wheels to cut to some extent into the ground. For the light jinrikisha itself this effect is trifling; but the addition of a passenger's weight, and half the jinrikisha man's, would make it very serious, and a passenger who was not paying a fare would be unwelcome.

It would be interesting to know whether there have been any attempts to secure the 


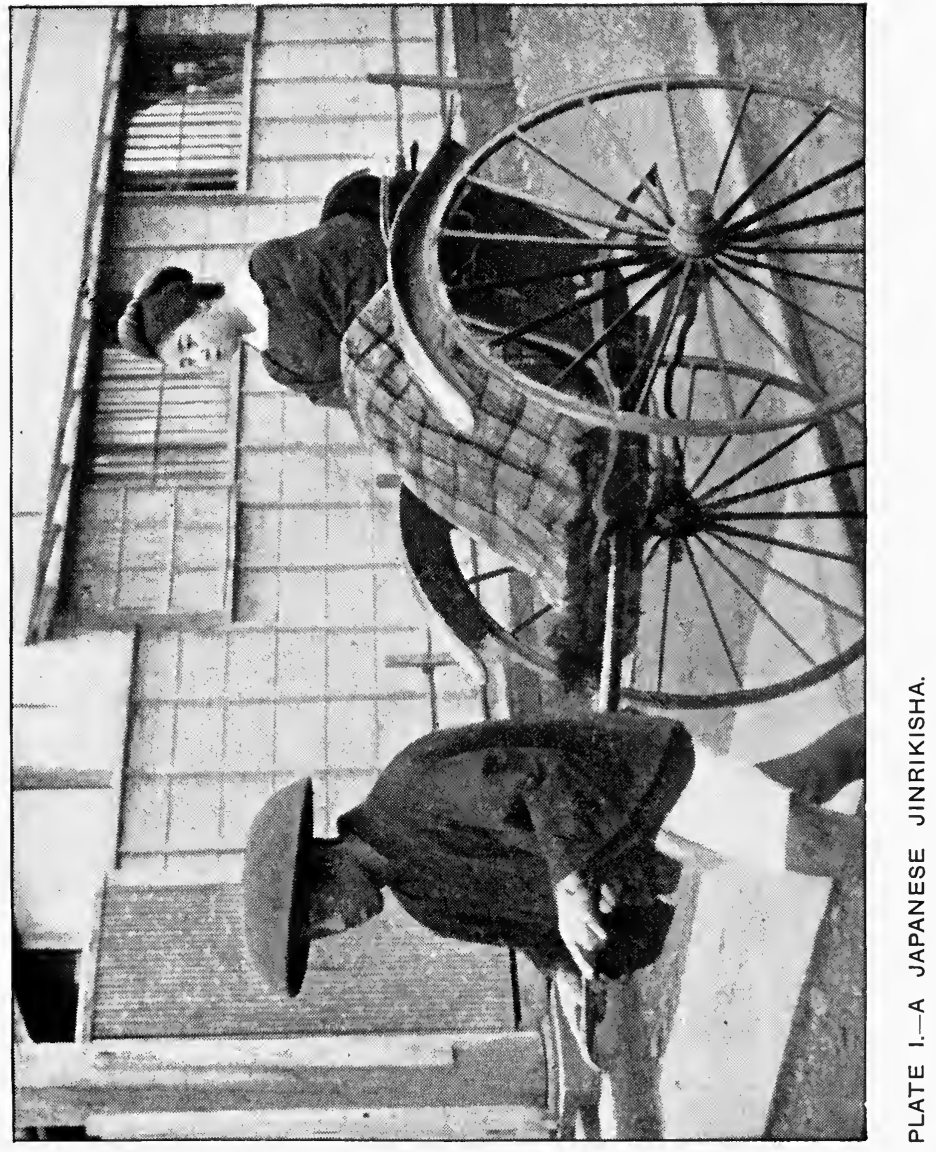





\section{MEANS OF TRANSPORT.}

advantage of diminished weight for the man, when there is no passenger. It appears that this might be accomplished by attaching the shafts in such a way that they could be made to slide in the axle-frame. If the seat body were one-fourth of the weight of the man, it would require four times the leverage to balance him; and with twice the leverage it would balance half his weight. When there is no passenger, let the seat be made to slide backwards, as shown in Fig. 2, till it is three times as far from $\mathrm{A}$ to $\mathrm{C}$ as from $\mathrm{B}$ to $\mathrm{C}$. Then the man can lean three-fourths of his weight on the shafts, in other words relieve his legs of three-fourths of his weight, even when there is no passenger, and without adding to the total weight to be lifted, against gravity, when going up-hill.

2. When a Train is going at SixtyMiles an Hour, what Part of it is moving backwards?

That is, not relatively, but actually backwards. For when an express train is advancing at the above rate, there are always some small portions of every carriage, as well as of the engine and tender, that are actually moving backwards at the rate of something like ten miles an hour.

How does this come about?

Take a circular disc, such as a penny piece, draw a line, such as AC (Fig. 3), from the 


\section{MECHANICAL PARADOXES.}

centre to the edge, and lay it flat on the table against the edge of a thin flat ruler, or some object which is thinner than the disc itself, in such a way that the end $\mathrm{C}$ of the line touches the ruler. Now roll the disc slightly backwards and forwards against the ruler, so that the point $B$ moves an eighth of an inch or less. The most careful observation will not
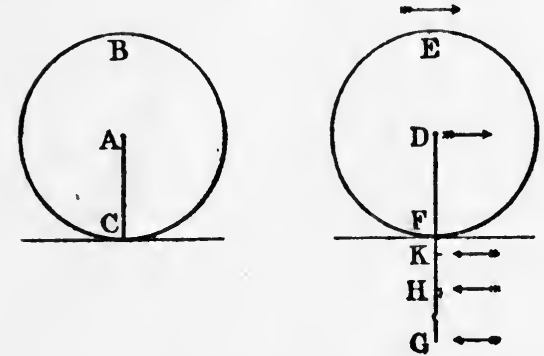

FIG. 3.-BACKWARD MOTION OF PART OF RAILWAY CARRIAGE WHEEL.

detect any movement of the point $C$, at the very end of the line. If the disc be rolled a little further, so that $B$ moves a quarter of an inch or more, the first visible movement of the point $\mathrm{C}$ will be sideways from the edge of the ruler. For some time after this has occurred it will be quite impossible to see any backward or forward movement of this point, lengthways of the ruler.

This fact may be examined on a larger scale by wheeling a bicycle forward till the front wheel is stopped by some vertical obstacle, 


\section{MEANS OF TRANSPORT.}

such as a house-wall. Now put a chalk mark on the lowest part of the wheel and on the ground immediately beneath it. Now back the machine a little from the wall; and when the greater part of it has moved an inch, the marked part of the wheel will not appear to have moved at all. As the machine is slowly backed a little further, the first visible movement of the bottom of the wheel is upwards from the ground, while it is still impossible to see that the chalk mark has backed from the wall to the smallest extent.

It is, in fact, true of all wheels, and at all speeds, that the part immediately in contact with the ground has no movement at all, so that even when a train is travelling at the speed of a mile a minute, each wheel has at every moment a part-namely, the lowest part resting at that moment on the rail-which does not at that moment move forward at all.

This being established, take a bristle, twice as long as the mark $\mathrm{AC}$, and attach it with gum in the position shown at DG, half its length projecting beyond the edge. Now place the disc in the same position as before, with the point $F$ against the edge of the ruler, and the outer half $F \mathrm{G}$ of the bristle reaching over it. Roll the disc very slightly backwards and forwards as before, watching the point $G$ at the outer end of the bristle. It will be seen to move always in the opposite 


\section{MECHANICAL PARADOXES.}

direction to that of the inner end D; so that when $\mathrm{D}$ moves along the ruler one-sixteenth of an inch to the right, $\mathrm{G}$ moves one-sixteenth to the left. $F$ is for the time being the centre of a circle of which $\mathrm{DG}$ is a diameter, and the ends of the diameter move in opposite directions. If a point $\mathrm{H}$ be marked on the bristle, half way from $F$ to $G$, it will move backwards only half the distance, and therefore, since the time is the same, at only half the speed at which $D$ moves forward. If the point $K$ be at one-sixth of the distance from $F$ to $G$, it will move backwards at onesixth of the rate at which $\mathrm{D}$ moves forward.

If $\mathrm{E} \mathrm{F}$ be a wheel, and $\mathrm{D}$ the centre of the axle by which it is attached to a carriage, $D$ will necessarily have at all times the same speed as the carriage itself, while $\mathrm{F}$ is stationary at the moment when it is the bottom point of the wheel; and at the same moment a point $\mathrm{K}$, rigidly connected with the wheel at the stated distance beneath the point on which it is rolling, will move backwards at one-sixth of the speed at which the carriage is advancing, whatever that speed may be.

Such an arrangement we have in the wheel of a railway carriage, which has a flange $\mathrm{O} P$ projecting beyond the rolling surface $\mathrm{MN}$. If the radius $L \mathrm{~N}$ be eighteen inches, and the flange $\mathrm{N} P$ be three inches deep, then that point $\mathrm{P}$ of the flange which is at any moment three 


\section{MEANS OF TRANSPORT.}

inches beneath the rail-top $Q R$ is moving backwards at one-sixth of the speed of the axle $L$, and therefore at one-sixth of the speed of the train.

Thus, when an express train is travelling northwards towards Doncaster at the rate of sixty miles an hour, every wheel of every carriage has at every moment a part of its flange-rim which is travelling backwards towards King's Cross at the rate of ten miles an hour.

\section{A Sailing Boat which moves more swiftly than the Wind which is driving it.}

The wind can drive ships by blowing upon the sails in two different ways. When the
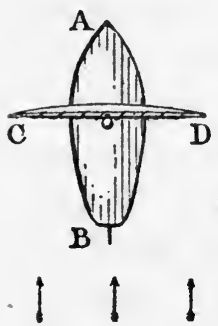

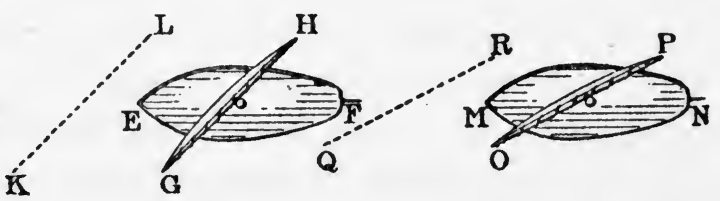

FIG. 4.-HOW SPEED DEPENDS ON THE SET OF THE SAILS.

ship is to go in the same direction as the wind is blowing, the sails can be set square across, and the wind blowing from straight behind blows straight on to the face of the sails, and pushes them and the ship straight onward.

This is shown in the first arrangement in Fig. 4, in which the boat A B, driven by the 


\section{MECHANICAL PARADOXES.}

sail $C D$, is intended to travel in the same direction as the wind-namely, from B towards $A$, as indicated by the arrowheads.

But the second and third arrangements show an entirely different method, such as is employed in windmills and turbines; in which the air is allowed to strike the sails obliquely, because it is not itself moving in the desired direction. If the boat $\mathrm{EF}$ has to travel to the left, with the wind still blowing in the same direction as before, the sail $\mathrm{G} \mathrm{H}$ has to be set obliquely. A portion of air, striking the sail at $G$, and trying to go on to $L$, finds in this sail an intervening obstacle, and cannot proceed without pushing it away. It cannot push the sail straight on, in its own direction, because the ship is set and steered broadside to that direction, so as to be unable to travel freely that way. It is only to the left that the ship can travel easily, when its bow points to the left, and therefore it is to the left that the sail must be pushed away, in order to let the wind get past.1

It is to permit the sail to be pushed to the left that the wind must be allowed to strike it on the right; and since the wind, instead of coming over the stern of the ship, comes over its side, this can only be arranged by setting the sails obliquely, in some such way as is shown at $\mathrm{GH}$.

The speed of the ship will depend to some extent on the degree of the obliquity at which 


\section{MEANS OF TRANSPORT.}

the sails are set. Suppose, for the present, that the air and the sails are absolutely free from friction, so that they slip past each other without any loss of power. Suppose, also, that the ship and the water are equally frictionless, and that no power is spent in lifting the water aside. Then the wind, in going from $\mathrm{G}$ straight on to $\mathrm{L}$, will easily thrust aside the sail to the left far enough to make the way clear. How far this is, depends upon the obliquity of the sail.

When it is set as in the illustration, with the distance $\mathrm{GL}$ equal to $\mathrm{GK}$ or $\mathrm{HL}$, the sail has to be pushed to the left from $\mathrm{GH}$ to $\mathrm{KL}$ in order to leave the way clear for the wind from $G$ to get through past the corner of the sail at L; that is to say, the ship moves to the left as far as the wind moves forward in the same time. In other words, the boat is travelling as fast as the wind. This is the case when the boat is sailing straight across the wind, and the sails are set at an angle of $45^{\circ}$.

But if the sails are set squarer to the wind, as at $\mathrm{O} P$, they have to travel further in order to leave the way clear for the wind to go straight on. Thus, while the wind goes from $O$ to $R$, the sail in front of it has to go from $\mathrm{OP}$ to $\mathrm{QR}$; and if the distance $\mathrm{OQ}$ or $\mathrm{PR}$ is twice the distance $\mathrm{OR}$, the ship has to go twice as far as the wind goes in the same time; that is, it travels twice as fast. 


\section{MECHANICAL PARADOXES.}

In reality, however, the sails and wind are not free from friction. Still less are the ship and the water. Much force is required to overcome this friction, and to lift aside the water in the formation of waves. The result is that the sails do not move quite freely sideways; the wind does not go straight on, but is to some extent deflected along the face of the sails; and the actual speed of the ship does not correspond to the proportions of the diagram. Nevertheless, there is a kind of sailing frame so contrived that nearly all the most serious friction-that between ship and water-is got rid of, while the wave-making power is abolished altogether.

This is the so-called ice-boat, which is used for sporting purposes on the great lakes of the United States and Canada (see Plate II.), when their surface is frozen over in severe winters. These ice-boats consist of a frame mounted on runners resembling large skates, which slide upon the ice, and furnished with a mast which supports a sail to obtain driving power from the wind, much as an ordinary boat does.

Now the friction between the smooth runners and the hard smooth ice is almost nil. The power lost in lifting water aside and making waves is in this case actually nil. And so the ice-boat approaches the conditions of the third diagram sufficiently to be really 


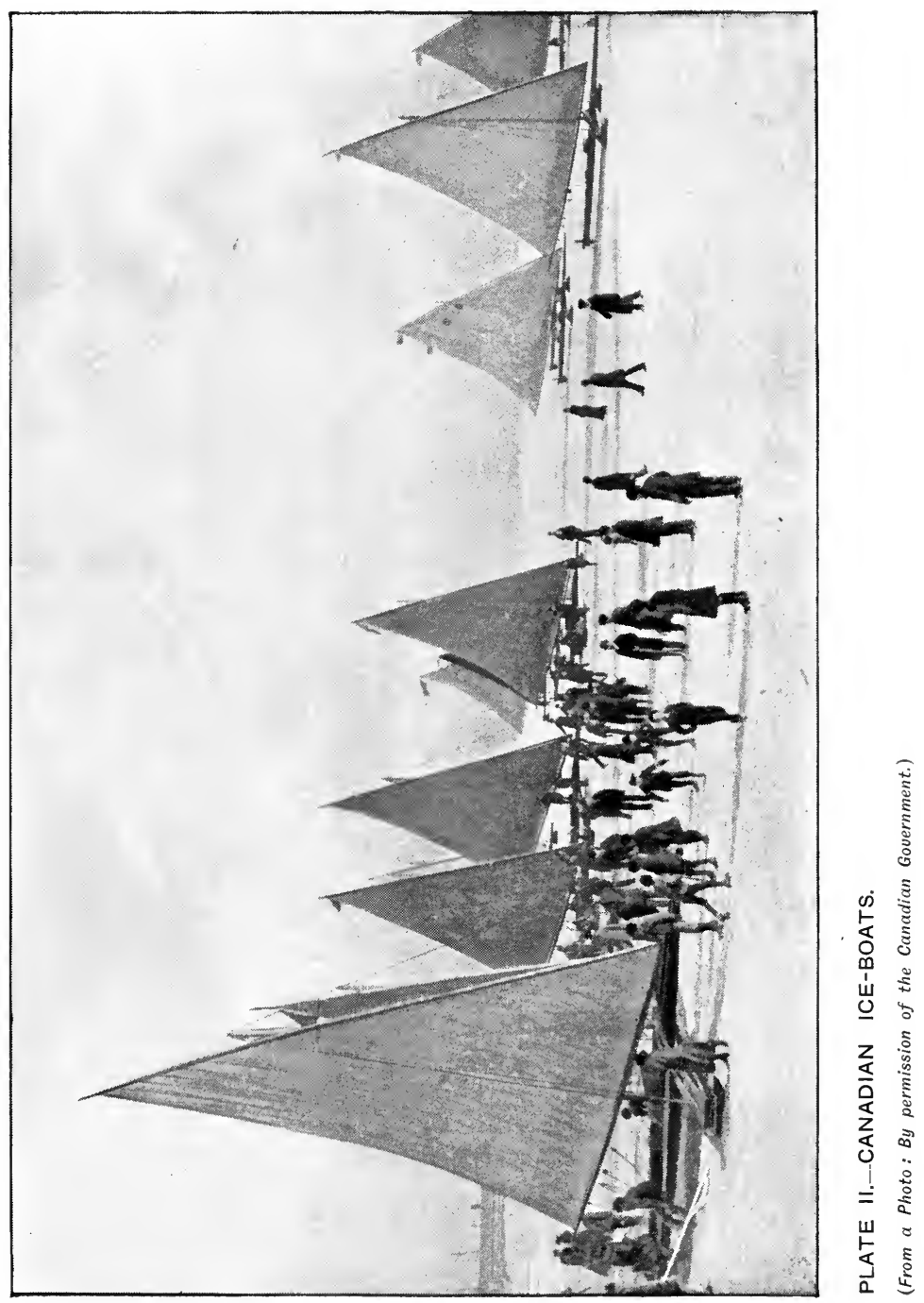





\section{MEANS OF TRANSPORT.}

capable of travelling faster than the wind which drives it.

It is obvious that a wind blowing straight over the stern, in the desired direction of travel, could not drive the boat faster than it is going itself; and so arises the curious result that in some cases a cross-wind is more favourable to speed in the boat than a wind straight behind of equal velocity. 
II.

SPINNING MOVEMENT.

I. The Mysterious Spinner; Motion without Apparent Cause.

THE author once had occasion to test the air of a room at various points for slight downdraught and up-draught by some delicate and sensitive test. For this purpose he devised an appliance which, while it illustrates a point

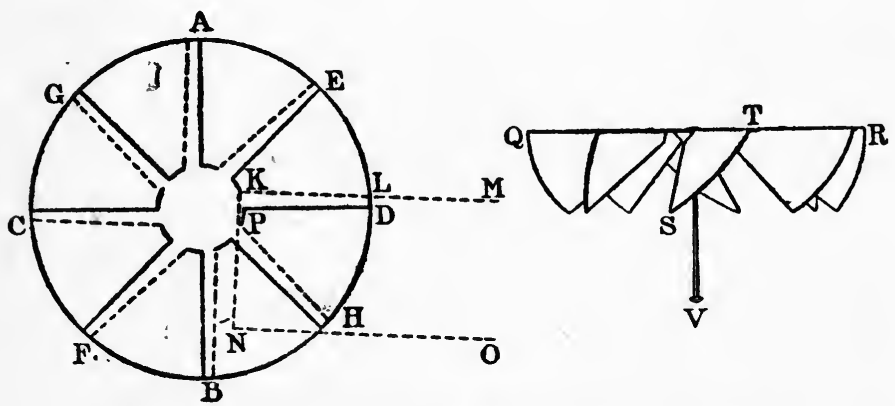

FIG. 5.-CONSTRUCTION OF MYSTERIOUS SPINNER.

of great and paradoxical interest, can be readily made by anyone at home. Its construction will therefore be described fully, so as to ensure success.

Draw lines A B and C D, as in Fig. 5, at right angles to each other with pencil on a piece of note-paper. Draw two others E F 


\section{SPINNING MOVEMENT.}

and $\mathrm{GH}$ bisecting the angles already made. With the point of intersection as centre, draw a larger circle $\mathrm{ACH}$, of about two inches diameter, and a smaller one of about half an inch diameter. If this is done with compasses, the point of the leg must not be allowed to make a hole in the paper at the centre. To avoid this, a small flat piece of indiarubber or tin or leather may be laid on the point where the lines intersect, and the leg of the compass can be placed upon it. When the circles are marked out, draw lines in the position of the dotted lines on the diagram.

Now, with scissors or penknife, cut round the larger circle. Then cut down the thick lines, as far as the smaller circle, and from the inner end of each cut make another cut halfway to the inner end of the next cut. The triangular flaps, E K L, and the others like it, are now to be folded up so as to slope at an angle of $45^{\circ}$ to the table. This can best be done by placing over the radial part which is to remain unbent, $\mathrm{KPDL}$, a flat ruler, in the position $\mathrm{MKNO}$, with its edge along the dotted line $\mathrm{K} \mathrm{L}$. Holding this edge firmly down, put the end of a table knife under the flap E K L, bend it up, and press it with the back of the knife-blade against the edge of the flat ruler, so as to produce a sharp crease along the dotted line $\mathrm{KL}$. Leave the flap sloping up at an angle of about $45^{\circ}$. Bend 


\section{MECHANICAL PARADOXES.}

up the other seven flaps to the same angle with a similar crease. Take a lead pencil with a dull rounded point, not sharp, but not very wide and flat. Hold it perpendicularly with its point on the intersection point of the lines at the centre of the disc, having placed a few folds of fairly soft paper, such as newspaper, underneath, and twirl it in the fingers, while pressing moderately, so as to make a small conical pivot cup in the centre; but do not pierce a hole through. The disc, taken up, turned over, and viewed sideways, will then present the appearance shown at $Q R$.

Take an ordinary pin, and make the point very slightly dull by rubbing it gently on an oil-stone, or some similar surface. Take care that there is no little hook or tag of sharp metal left sticking to the point, which should be rounded and smooth, though fine.

Hold up the pin in the position shown at $\mathrm{V}$, with its head between the ends of the finger and thumb, and place the disc upon it, with the vanes on the lower side, and the point of the pin in the little pivot cup.

This simple apparatus is now a very delicate anemometer. Its weight is very little, and the area of contact between its centre and the supporting pivot is extremely small and is well lubricated by the polished surface of blacklead left by the pencil. It will therefore turn with very great ease. The slightest 


\section{SPINNING MOVEMENT.}

draught of air upwards or downwards, acting upon the obliquely set vanes in the same way as on the sail of a windmill, or as the sail of the ice-boat described in the last section, should cause these vanes to revolve. In an up-draught, the air, striking upwards against the lower surface of the oblique vane $\mathrm{ST}$, will drive it from right to left, while the vanes at the back are similarly driven from left to right. A down-draught, on the other hand, striking $\mathrm{TS}$ on the upper surface, will drive it to the right, while the back of the disc is driven to the left.

As soon as you mount the disc on the pinpoint, and hold it up steadily, you find that it begins at once to revolve, the front turning to the left. Apparently just where you standthere is an up-draught, which was perhaps too slight for your previous observation.

Go to another part of the room, where you expect to find no draught at all, and hold the disc steadily in position there. It begins again to revolve, and in the same direction as before. Apparently there is an up-draught there also. If you try yet other parts of the room you get the same result.

If a window or ventilator be open to a strong wind, and swung at such an angle as to direct the blast downwards, you then get a powerful local down-draught, which at once sets the disc spinning in the opposite direction. 


\section{MECHANICAL PARADOXES.}

But without such special and violent interference, making your observations in a room in which, so far as you could previously tell, the air was everywhere absolutely still, you are surprised to find at every point evidences of a distinct draught upwards. Apparently the air is rising bodily through the floor, at every part of it, floating upwards in the whole extent of the room, and going away through the solid substance of the plaster all over the ceiling $!$

Or is there some other mysterious agency at work to keep the spinner revolving ? The author had one made of thin sheet aluminium, with four larger vanes instead of eight smaller ones. Each vane had its outline cut in such a way as to resemble a bird with wings and tail outspread, and attached to the centre by the central end of the inner wing. The obliquity of the vanes, instead of being obvious, as in the paper spinner previously described, was disguised as an artistic set of the wings and tails to imitate the natural attitude of birds in some of the movements of flight. This, on being tried, behaved in the same way as the paper spinner. In every part of a room where the air was expected to be calm and still, it kept slowly revolving. Investigators of the phenomenon were much puzzled. Civil engineers and other scientific men were unable to give a satisfactory explanation. Some 


\section{SPINNING MOVEMENT.}

suggested magnetic fields or electric discharges from the points of the vanes.

The key to the explanation is found by supporting the pivot-pin in some other holder than the hand. Take a narrow strip of stiff cardboard, and fix the pin near one end by driving it through up to the head. Fix the strip so as to project over the edge of a sideboard or other object by laying the edge of a book on it, the pin pointing upwards at a distance of two inches or so from the sideboard. Next place the spinner in position on the pin-point and retire a little distance away. In a still room, the spinner now fails to move. Hold the hand just under it, and it begins to revolve. Clearly the motive power comes from the hand beneath.

The fact is, that the hand is usually warmer than the surrounding air. The temperature of the blood deep beneath the surface of the body is about $98^{\circ} \mathrm{F}$. The air of a room is often $60^{\circ}$, more or less. But the hands are always cooler than the body-blood simply because they are always losing heat in warming the air. Heat makes things expand; and so the heat of the hands, passing to the air in contact with them, causes it to expand. Expanded air is less dense, and therefore less heavy. It is consequently out-balanced and driven upwards by the heavier unwarmed air around it, just as the hot, expanded, light air from 


\section{MECHANICAL PARADOXES.}

a fire is driven up the chimney by the colder, denser, heavier air of the room. Thus we get a constant up-current of air from the hands and face. This is so slight that in ordinary circumstances it passes undetected. But if a good deal of the skin is exposed when it is hot and the air very cold, the up-draught due to the warming and expansion of the air is easily observed.

Thus, when a bald-headed gentleman, who lives a good way from the station, has made himself very hot on a frosty morning by hurrying from a late breakfast, and finds that his train, being unusually punctual, has left him to wait for the next, he will not unfrequently pass the time during this wait by mopping up the perspiration. At the moment between the removal of his hat and the application of his handkerchief, clouds of vapour, condensed by the cold air, may be seen rising up in a column from his head, clearly showing the direction of the up-current which is caused by the heat of his head warming the air, and so making it expand and grow lighter.

Thus it is seen that the heat from the body, or a part of the body, is quite sufficient to make up-currents of air capable of being employed to turn a little windmill.

Up-currents produced in this way by some local source of heat, and balanced by corresponding down-currents produced in a similar 


\section{SPINNING MOVEMENT.}

way by local sources of cold, form systems of circulation known by the name of convection currents, which play a very important part in the natural history of our earth. A good instance of currents of air caused by local cooling is that offered by the windows of a room, in connection with which it will be worth while to explain the paradoxical unfairness of a story not seldom told to the disadvantage, once more, of an elderly gentleman.

In the days when large clear sheets of plate glass were new and rare, such a gentleman, visiting for the first time in a house furnished with this glass, was seated near a window which had no cross-bars from top to bottom. After a time he clapped his hand to the top of his head, which was not protected by hair, and, his sight also being none of the best, complained that he had caught cold from the draught through the open window. It was explained to him that the window was really closed; but having imagined that it was open and that he had caught cold from the draught through it, he did, as a matter of fact, endure all the distresses of a bad cold for the next fortnight. This is told as a remarkable instance of the effect of imagination-the wonderful power of the mind over the body. He had caught cold from his imagination!

The story does not necessarily illustrate any such thing. Although the window was 


\section{MECHANICAL PARADOXES.}

shut there may have been a distinct cold draught from it. If the room was fairly warm and the outside air cool, there certainly would be. For the cold outside air cools the glass. The cold glass cools the air inside which comes into contact with it. The cooling makes it contract, become dense and heavy, and consequently sink downwards and move towards the centre of the room while other masses of air move in the upper part of the room towards the window to be cooled in their turn. Thus are established the convection currents, of which one part is the cold draught from the window, which may well have given the old gentleman his cold, in spite of the fact that the window was shut.

The same convection currents on a large scale are set up in an assembly hall which has a blank wall on one side and a row of windows on the other. On a cold night the cool air outside cools the glass windows, which cool the adjacent air inside. This inside air, contracting with the cold and so becoming denser and heavier, sinks and crosses over the lower part of the room, where it is warmed by the heat of the assembled people and perhaps by artificial heating. On the side opposite the windows it rises upwards, and higher up crosses over to the windows to be cooled and made to descend again. If the roof also is largely of. glass or other thin material the cooling 


\section{SPINNING MOVEMENT.}

effect is much stronger, and so are the convection currents, which are commonly known, under these circumstances, as draughts. So powerfully can these causes act that on the platforms of some large halls the flame of a spirit-lamp on the table, instead of burning upwards, is blown straight across horizontally even when there is no open window, door, or other aperture in the neighbourhood.

When we consider what striking air movements we get in the convection currents due to such moderate and limited causes, and compare with them the tremendous power of the sun's fierce heat over millions of square miles in the tropics, and the huge areas of severe cold round the poles, we have no reason to be surprised at the force of the most terrible storms of wind, which are only convection currents on a grander scale. The action of the breezes which drive ships and windmills is, both in origin and in operation, exactly similar to the small up-current from the hand which causes the revolutions of the mysterious spinner.

2. Solids defying Gravity: the Gyroscope.

Of all the purely mechanical paradoxes, the most surprising is the one which shows a solid substance with a support under one side only, and yet not falling down. 


\section{MECHANICAL PARADOXES.}

A very good gyroscope top to illustrate this can be got for half-a-crown, and a fairly good one for a shilling; but any one who is handy with a fretsaw or keyhole saw can make a good substitute for himself.

Take a flat piece of board without any warp in it, and mark out a circle five, six, or seven inches in diameter. Saw carefully round this mark, bore a hole in the centre, and insert

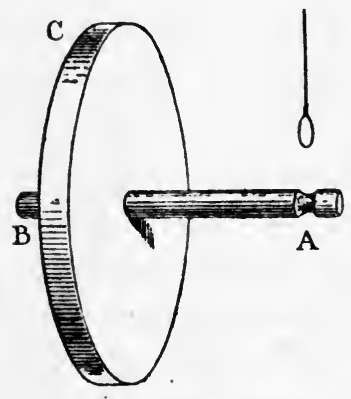

FIG. 6.- HOME-MADE GYROSCOPE. an axle projecting three or four inches on one side and two on the other. A wooden penholder will make a very good axle. The axle must be set as truly perpendicular to the wheel and as truly central as possible. Near the end of the axle, on its longer projection, cut a deep nick as at A, Fig. 6 ; and take or make a wire ring which will only just go over the axle. Push it on as far as the nick, then squeeze it to an elliptical form, so that it will not come off again, and finally tie to it a string about as long as from the ground to an upper window-the longer the better, so that there may be more time to watch the effect. The apparatus is now ready.

Wind up the string (a fine one, or strong thread) on the axle, giving it a few turns over itself at the beginning, to fix it for winding. 
SOLIDS DEFYING GRAVITY.

The most convenient way of winding will be to turn with the right hand by the short projection $\mathrm{B}$, guiding the string with the thumb and first finger of the left hand; and resting the knob A on a table-edge or other support. When it is wound, lean out of the window, hold the end of the string in the left hand, and the wheel by $\mathrm{C}$ in a vertical position. With the string tight between the axle and the left hand, give the wheel a smart turn with the right hand to start it unrolling, and then let it go on unwinding the string as it descends spinning.

To the surprise of those who have not watched the spinning of the gyroscope, the wheel, though supported only at one end by the string, instead of falling, as might be expected, into a position with the axis vertical (the string end above and the other end, with the weight of the wheel, beneath), will continue much in the position shown in the figure, spinning faster as it descends, until all the string is unwound, when it will continue spinning for some time supported by the wire ring in the nick on the axle, and looking like a visible contradiction of the most widely manifested and best established natural law-that of universal gravitation.

To start the wheel spinning nicely, it is advisable to have the string at the beginning of the spin wound close against the wheel, and 


\section{MECHANICAL PARADOXES.}

not call upon it for a display of its paradoxical properties until its spin is well established. A mere loop on the string will do instead of the wire ring, but will make a little more friction, and will not last so long.

When the wheel is not spinning, if we attempted to get it to remain with the axis horizontal while supported by the string at one end only, the attempt would be a ludicrous

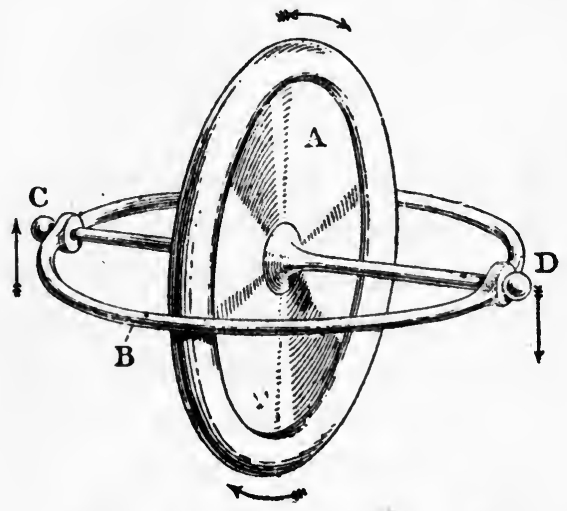

FIG. 7.-HALF-CROWN GYROSCOPE.

failure. How does the spinning make it possible to perform what looks like a miracle ?

Before attempting to make this clearer to the non-mathematical, we will briefly consider a few of the properties of the gyroscope in a somewhat less simple form, one which can be set spinning and held while spinning in the hands.

Such a gyroscope is shown in Fig. 7, in which $\mathrm{A}$ is the spinning wheel with a heavy rim, 


\section{SOLIDS DEFYING GRAVITY.}

and $B$ a circular frame in which the ends of the axle are supported on pivots in screw-knobs which admit of adjusting the tightness of the bearings. It can be spun by a string passed through a hole near one end of the axle, and wound round the axle.

Hold the gyroscope, while spinning briskly in a vertical position, by the two knobs, which are therefore level. Try to tilt the instrument by raising one knob, C, and depressing the other, D. The spinning wheel will offer a great resistance to this twist, and very likely will twist itself in another way, with a most uncanny appearance of perversity, out of the grasp of one who is experimenting with it for the first time. It behaves almost as if it were alive, and offers what seems like an intentional resistance to twisting. It can be lifted and lowered quite easily, for its weight remains unaltered; it may be moved from side to side or backwards and forwards just like any inert body, provided that its plane of rotation, and therefore its axis of rotation, be kept looking in the same direction. But any attempt to make it face another way round is stoutly resisted, and in the struggle it often twists itself out of the experimenter's grasp. The larger and heavier the gyroscope, and the more vigorous its spin, the more powerful is the resistance that it makes.

Now when the gyroscope is spinning with a vertical plane of rotation, and therefore a 


\section{MECHANICAL PARADOXES.}

horizontal axis, it may be supported, as we have seen, at one side of the axis only, either in our original simple experiment with a string, or in a well-made gyroscope by placing the knob at one side of the frame in a cup-shaped hollow on the top of a small pillar-stand. When it is in this position the force of gravity, in trying to pull it down, necessarily tends to give it a twist. Since one end is supported, the spinner as a whole can only come down by the dropping of the unsupported end, which involves a twisting of the spinner so that one face would look more downward and the other more upward.

Such a twisting its spin enables it, as we have seen, to resist with considerable force, so that rather than be twisted it can remain with its axis horizontal, though supported only at one end.

We must now turn to the question: How does its spin enable the gyroscope to maintain its position against gravity ?

To begin with, it does not quite do so. It only comes so near doing it that, unless we look closely, we do not notice the slight failure to keep truly horizontal, which, however, goes on increasing, and the more rapidly as the spin gets slower.

What we have to account for, then, is simply a strong tendency to keep the axis horizontal. 


\section{SOLIDS DEFYING GRAVITY.}

In a subsequent section we shall have occasion to refer to centrifugal force, which is really the result of the tendency of motion to resist interference. It is a general law of nature, to which we have hitherto found no exception, that a moving body tends to keep moving straight on at the same speed, and resists any interference. The force with which it can so resist depends on its weight and its speed. In a spinning mass every particle of the circumference is at any given moment moving at right angles to the radius, and tends to go on in that direction. If suddenly set free, the particles will go on in that direction, which is called mathematically a tangent to the circle. We see this in the stone of a sling, which, after being whirled round the head, and

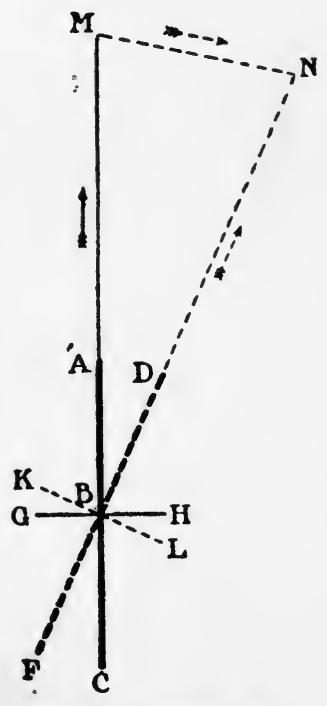

FIG. 8.-GYROSCOPE RESISTING A TWIST. then suddenly released, does not continue its whirling motion, but continues that part of the whirl in which it was moving at the moment of its liberation - namely, the tangent to the circle of whirling. So, also, with muddy wheels which are rapidly revolving. The drops of mud fly off at a tangent to the circumference, 


\section{MECHANICAL PARADOXES.}

clearly showing that this was the direction in which they were tending to fly at the moment of liberation, and clearly showing, too, what is the direction in which every particle in the rim of a spinning wheel is tending to fly at each moment.

In Fig. 8, let $\mathrm{A} \mathrm{BC}$ be a view, edge on, of a gyroscope which is spinning so that the back is going up and the front down. The top at $\mathrm{A}$ will be coming forwards and the bottom at $\mathrm{C}$ going backwards. The particles at the back, on the level of the axle $\mathrm{GH}$, will then be moving directly upwards, and will tend to fly straight up in the direction B M.

Now tilt the gyroscope so that it lies in the plane D B F and its axis is in the direction $\mathrm{K} \mathrm{L}$. The particles at the back will now tend to fly in the direction B N. Suppose that the rim of the instrument is spinning at the rate of roo feet per second. Then if the rim suddenly broke into small fragments, those at the back would fly roo feet in the direction $\mathrm{BN}$ in one second, whereas, before the tilt, they would, on the supposition of breaking up, have flown roo feet per second in the direction BM. The effect of the tilt, then, is to give to these fragments, in addition to the flight BM which they get in virtue of the spin, a further flight from $\mathrm{M}$ to $\mathrm{N}$ in virtue of the tilt. When B M is roo feet per second, suppose $\mathrm{MN}$ represents 30 feet per second. 


\section{SOLIDS DEFYING GRAVITY.}

It will then require an additional power equal to a considerable part of the original power exercised in the spinning, embodied in the spin, and expressed by the flight $\mathrm{B} \mathrm{M}$, to be exercised in the tilting, and expressed by the additional flight $\mathrm{MN}$.

The tilting will require a power equivalent to that required for interfering with a number of particles in their flight from $B$ to $M$, so that they shall fly to $N$. Since the possibility of the flight is involved in the spin, the power necessary to interfere with the flight is involved in changing the plane of the spin. This is an effort of power which is intelligible to anyone. Anyone can realise that power is required to alter the direction of flight in a body which has already started. If we want to change the direction of a shower of bullets after they have left the magazine rifle, by holding in front of the rifle an obliquely placed shield to deflect them from their original course, it is easy to understand that we shall have to exercise a powerful sideway thrust upon the shield in order to hold it against the bullets so as to change their direction. After the gyroscope has been spun, every fragment of its rim is in the position of a bullet which has already left the rifle and is on its way. To alter the tilt of the gyroscope is therefore equivalent to changing the direction of the potential flight of the fragments of its rim. 


\section{MECHANICAL PARADOXES.}

The spinning gyroscope resists this tilting as energetically (for its speed) as a bullet resists being turned out of its path, simply by virtue of the great law of inertia, the strong tendency possessed by all moving things to resist interference with their motion.

It has been mentioned that when the gyroscope is held by the knobs and an attempt

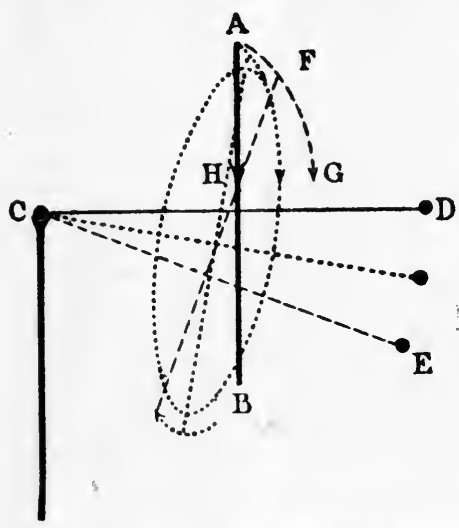

FIQ. 9.-SECONDARY MOVEMENT CAUSED BY A TWIST. made to tilt it by raising one knob and depressing the other, it not only resists this tilting, but seems to wrestle and twist itself in another way in the effort (not always an unsuccessful one) to wrest itself out of the experimenter's grasp and escape to the ground.

This apparently extra twist which the gyroscope gives itself is really the consequence partly of the tilt given by the operator, and partly of the gyroscope's resistance to disturbance of its movement.

Fig. 9 will help to explain this. Let A B be the gyroscope, seen, as in the last figure, by a person in front of its edge, and let the direction of the spin again be such that the 


\section{SOLIDS DEFYING GRAVITY.}

top A is coming forward, the bottom B is going backward, the front is going down, and the back up. Let the knob $\mathrm{C}$ at the left extremity of the axis be resting in a small cup on a pillar support.

Depress the other knob $\mathrm{D}$, or leave gravity to depress it, tilting the right hand end of the axle downwards towards $\mathrm{E}$ and the top of the gyroscope to the right towards F. If the top of the gyroscope were previously still, this tilting would give it a movement in the direction of the dash line towards G. But it was not previously still. In virtue of the spin of the gyroscope the top part had a movement directly forwards and then downwards in the direction towards the arrowhead $\mathrm{H}$. And this movement it is not willing to resign in favour of the movement towards G. Like all other moving things, it tries hard to keep to its original direction of movement towards $\mathrm{H}$. The most that it will agree to, except under constraint of great violence, is a compromise in the form of a movement in the direction of the dot line towards the middle arrowhead.

In doing this it is coming down to the right of its original direction; and it cannot do this unless the front rim of the gyroscope goes round to the right-that is to say, unless the right-hand end of the axis goes backwards.

Thus it happens that if we press D downwards towards E, it tends, apparently of its 


\section{MECHANICAL PARADOXES.}

own accord, to go backwards at the same time. And since a spinner supported at one end only is constantly being depressed by gravity, so also it is constantly having its axis turned horizontally round its fixed end, and in that direction in which the bottom of the gyroscope is spinning at the time.

So in the first experiment in which a spinner was let down from an upper window, unwinding a long string, it was no doubt observed that besides the vertical spin maintained by the unwinding of the string, there was a horizontal movement of the whole axis round its supported end, which the experimenter doubtless attributed to the unwinding of the string. But it will be noticed that if the string be wound, and consequently the gyroscope spun, in the opposite way, the axis will also turn the other way round, always in the same direction as the bottom part of the gyroscope is spinning.

The direction in which the axis turns can also be reversed by putting the support under its other end. The direction of movement of the bottom part then points the opposite way round the new point of support.

This turning of the axis is called in mathematics a movement of precession; but having once mentioned this fact we will not admit so technical-looking a word again.

There is a very remarkable feature about this turning of the axis which must not be passed over. 


\section{SOLIDS DEFYING GRAVITY.}

When the spinning gyroscope is supported at one end and consequently the axis is turning round the point of support, if we take a pencil, and, holding it vertically, push the revolving knob round a little faster than it is going of its own accord, that end of the axis rises; if we put the pencil in front and retard it, that end sinks. This is another form of that compromise between movements which we have seen to be responsible for the turning movement in the first instance. We can thus cause the free end of the axis to rise or sink without any direct pushing up or down, by simply hastening or retarding the turning movement round the point of support.

This explains how it is that a top rises to an upright position.

When it is a little sloping, gravity pulls at the outer-that is, the upper end-and so causes the top to turn round the centre of support, the point. But the point, rubbing on the ground and so advancing in a circuit, hastens this turning movement at the opposite end of the axis. As we have seen, a hastening of the turning movement causes the freethat is, the upper-end of the axis to rise, and so the top constantly tends to regain a vertical position. 
III.

ROLLING AND FLYING MOVEMENT.

I. The Intelligent Billiard Balls.

ArRANGE three billiard balls (A, B, C, Fig. Io) in a row along the cushion at the side of a billiard table in close contact with one another. Place another, $D$, at a distance of about six inches from the end of the row, but in a similar position beside the cushion.

Now push the ball D lightly and smoothly along the cushion in the direction of the other balls, till it reaches a position near to them, as at $\mathrm{E}$, by which time it will have acquired a certain speed. Let it run the rest of the distance along the cushion by itself and strike the ball $\mathrm{C}$ a smart stroke full on the nearest side. When all movement is over, the final position of the balls will be as shown at $a, b, c$, and $d$. D will have come to rest approximately in the position in which it was at the moment of striking the other balls, as at $d$. B and $\mathrm{C}$ will remain apparently just as they were, without the smallest movement, as at $b$ and $c$. A, however, will suddenly run away in the direction of D's previous movement to $a$. It will appear to start instantly at the moment 
when D strikes and stops, and it will appear to start with the speed with which D finished, so that it will run as far against friction as $D$ would have done, if, instead of striking $C$, it had been uninterrupted.

Now how is it that only A moves? And how is it that, in all variations of the speed of $\mathrm{D}$, or of the number of balls in the stationary row, A knows just how fast to start, and so how far to go? D loses the whole of its
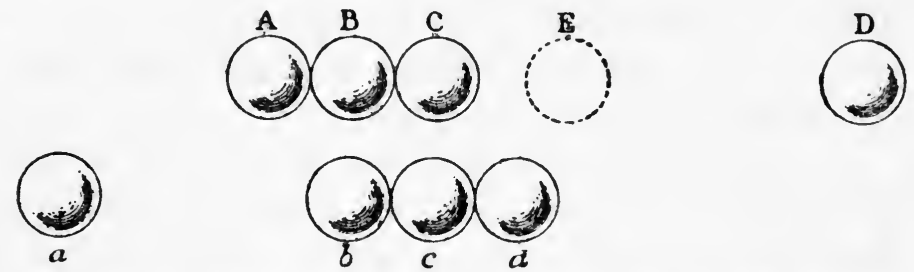

FIG. 10.-EQUAL MOVEMENT TRANSMITTED TO EQUAL NUMBER OF BALLS.

energy of movement, which has finally been transferred to A. But this cannot have happened without $B$ and $C$ having moved also. How is it that they do not share in the final movement? Why is this final movement not divided equally between $A, B, C$, and $D$, all of them moving together, though much more slowly, and for a shorter distance than when the movement is all concentrated in $\mathrm{A}$ ?

But this is not the most surprising part of the paradox. If there be a longer row of stationary balls, four, five, six, or seven, and if 


\section{MECHANICAL PARADOXES.}

instead of a single striking ball, two or three be employed, one behind the other, all moved together and made to strike together, the balls which are struck will display a still greater degree of intelligence. They will always appear to know what was the number of balls which struck them, and will depute the same number of their own row to respond by moving off at the other end.

This seems a very puzzling display of intelligence on their part. When two or three balls strike instead of one, the total striking energy is two or three times as great, supposing the striking speed to remain the same. Accordingly, it would not be surprising it all the balls in the row displayed the influence of this twice or three times greater energy. Or granting that all the energy must for some reason be conveyed to and displayed by the last ball of the row, it would be natural that it should start off with a force two or three times as great.

But that the intervening balls should be able in some way to tell those at the end of the row that only one had struck and only one must move, and to despatch two or three when two or three had been the number of the striking balls, this seems indeed a truly mysterious puzzle.

It must be remembered that the energy of moving bodies depends upon their mass 
INTELLIGENT BILLIARD BALLS.

and their speed, and that the amount of energy conveyed can be varied by varying either the mass or the speed. But in the present case we are supposing that only the number-that is, the mass-of the striking balls is varied, while the hand always moves them up to the striking point so far as possible at the same speed. The velocity of the hand, then, being approximately constant in our trials, the velocity of movement with which the stroke is delivered is constant. The ball which is struck being prevented from moving freely, partly by its own inertia, and partly by that of the balls in front, receives the energy of the striking movement partly in the form of limited movement of its whole mass, partly in the form of compression waves transmitted through its substance and that of the other balls.

For the balls are elastic, and their elasticity, though of much less amplitude than that of indiarubber, is quite as real. This may be easily shown-preferably with other people's balls-by bouncing them on a stone floor.

Now the speed with which the wave of compression is transmitted depends on the speed of that movement of the striking ball which is transformed into compression waves, and not on the mass, or number of balls, behind it. And the energy of the compression waves is re-transformed at the other end into movement of balls whose velocity corresponds to 


\section{MECHANICAL PARADOXES.}

that of the compression wave and is therefore (apart from friction losses) equal to the velocity of the striking balls which produced the compression wave. The velocity of the balls starting from one end is therefore (except for friction losses) that of the balls which struck at the other end.

But the amount or extent of compression between the moving balls at one end and the balls resisting movement at the other end varies with the compressing force-that is, for a given velocity-with the mass or number of the striking balls. And since this energy must all be represented finally in the movement of balls at a velocity which is, as we have seen, identical with the velocity of the striking balls, the mass of these moved balls which take up in starting at the definite speed the definite quantity of energy must equal the mass of the striking balls which gave up that quantity of energy when stopped at that speed. Therefore the number of balls moved must equal the number of balls which struck.

As to the details of force-application which decide the movement of the last ball that moves, and the inability to move of the ball preceding it, without the help of mathematical figures they might be made fairly intelligible in the following way.

Suppose the number of striking balls to have been two. As the last ball at the other 


\section{INTELLIGENT BILLIARD BALLS.}

end moves off at the speed, as has been shown, of the striking balls, it takes away, in moving off at that speed, half of the energy given up by the two striking balls in being stopped at the same speed. Therefore, the ball before the last, in delivering to the last ball the blow which started it off at that speed, delivered only half of the energy which had been delivered to it by the striking balls through the intervening ones which remain practically stationary.

Retaining the other half of that energy, it has retained enough to start itself at the same speed. As it has no obstacle in the form of a stationary ball beyond it, it starts, and follows the last ball, to which it had itself transmitted the necessary starting power.

But the ball preceding it-the third ball from the end-in starting the two last balls at the speed of the striking balls, has given up to them the whole of the energy transmitted from the latter, and has none left to start itself. It remains, therefore, at rest.

A similar explanation applies whether the number of balls in motion be more or less than two.

\section{Throwing Balls round a Corner.}

We are familiar enough with this operation when the corner is a vertical one. Every boy knows that if a snowball is to hit a policeman over the lowest tunic button from a 


\section{MECHANICAL PARADOXES.}

distance at which it is possible to perform the experiment in safety, it must be aimed at least as high as the top of his helmet, in order to allow for the inevitable drop during its flight. Rifles and guns have to be sighted for a point considerably higher than that which they are intended to hit, so that, as in Fig. II, it is possible for a bullet fired from A to hit a man at B who is out of the rifleman's sight, the ball passing over the roof of an intervening cottage, in the direction of the curved line

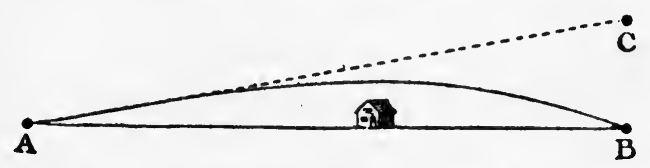

FIG. 11.-A PROJECTILE DEFLECTED FROM ITS COURSE.

from A to B. But it was fired in the direction of the dotted straight line from $A$ to $C$, so that it may be said to have turned a corner downwards. The reason why it did this instead of continuing its flight in the direction in which it started, is that there was a force constantly acting upon it to pull it downwards-namely, the force of gravity, measured by its weight.

If gravity could act horizontally the bullet could be made to turn a corner sidewaysthat is, in the ordinary sense. And though gravity cannot act in this way, there are other forces which can. The wind, for instance, blowing sideways across the firing range, acts 


\section{THROWING ROUND A CORNER.}

as a constant force, driving the ball away from its original direction, and this produces an effect so serious that riflemen have to make the most careful allowance for it.
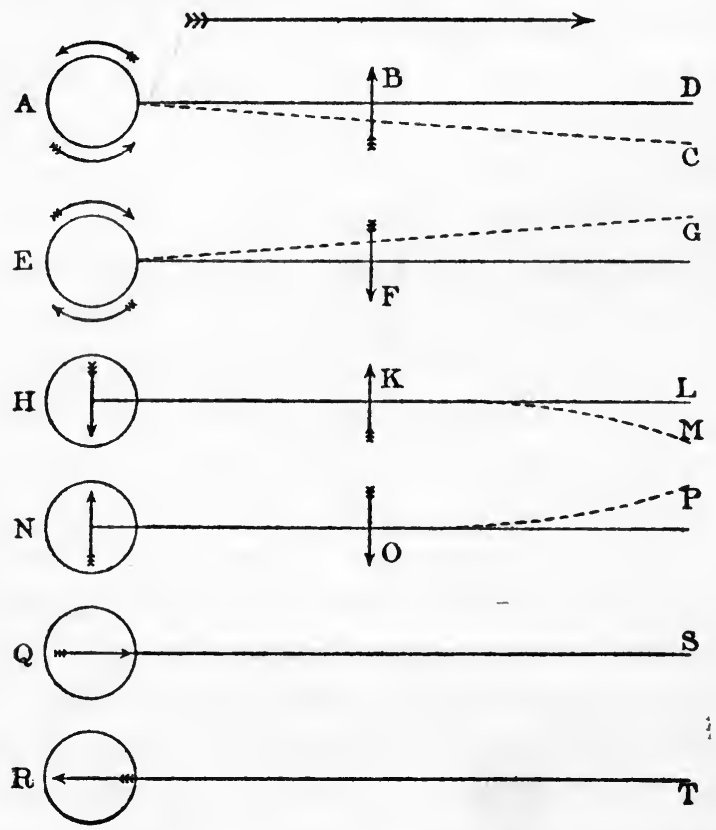

FIG. 12.-DEFLECTION OF BALLS FROM THEIR COURSE.

These are outside forces. Can any force be impressed upon the ball itself that will take it definitely out of the direction in which it starts? This also is possible, and is accomplished by giving the ball a certain spin. The effect is most commonly seen in the games of cricket, lawn-tennis, and baseball. 


\section{MECHANICAL PARADOXES.}

In Fig. I2 let the view always be downwards from above on to the top of the ball, and let the ball in each case be supposed thrown from the left side of the page towards the right, in the direction of the large arrow at the top of the figure.

Let the ball $\mathrm{A}$ at the moment of throwing receive a horizontal spin about a vertical axis, as shown by the small arrows. Then its front face, as it flies, will move towards the left of the thrower, as shown at B, and will tend to brush the air in front of it, against which it is forcibly pressed, in that direction. But action and reaction are equal and opposite. Standing in a boat, if you push someone who is standing on the pier, you not only make him move backwards from you, but you also move yourself and your boat backwards from him. The same thing happens if you push someone while sitting in a swing: you cause movement in yourself as well as in the person you push. A nearer parallel is that of oars pushing the water. This results in the boat moving in the opposite direction. So, when the wings of birds and insects beat the air downwards and backwards, it results in their own movement upwards and forwards.

In the same way, when the face of the ball drives the air in the direction of $B$ to the left, the ball itself has to move along the dotted 


\section{THROWING ROUND A CORNER.}

line to the right at $\mathrm{C}$, instead of going on in its original direction to $\mathrm{D}$.

If the ball receive the opposite horizontal spin as at E, then its face, which is pressed against the air in front, moves in the direction $\mathrm{F}$, and drives the air in that direction. Consequently the ball itself, moving, as before, in the opposite direction, goes to the left along the dotted line to G.

Next let the ball at the moment of being thrown receive a vertical spin sideways about a horizontal axis, the arrow at $\mathrm{H}$ showing the direction of its upper surface, and that at $\mathrm{K}$ the direction of its lower surface.

At first this spin will not deflect the ball from its line of flight $\mathrm{HL}$. But when it has travelled some distance, and had time to acquire considerable falling movement, its lower surface presses the air more forcibly than its upper surface, and, pushing the air aside in the direction $\mathrm{K}$, is itself deflected in the opposite direction to $\mathrm{M}$.

Similarly a spin in the opposite direction, the upper surface moving as at $\mathrm{N}$, and the lower as at $O$, results in the ball being deflected towards $P$.

There are yet two other chief ways in which a ball may spin during its flight. In these the plane of spinning is vertical and directed in the line of flight.

$Q$ shows the upper surface of the ball spinning forwards towards the same point $S$ to 


\section{MECHANICAL PARADOXES.}

which the ball is thrown. At $\mathrm{R}$ the spin is in the reverse direction.

In the case of spinning like that at $Q$ it is clear that the front of the ball, which presses hardest against the air, is moving downwards and so throwing the air downwards. Consequently the reaction tends to keep the ball up - that is, to prevent it from falling so fast as it otherwise would. In other words, it has a longer and more shooting flight than it would otherwise have at the same speed. In $\mathrm{R}$ the opposite is the case; the reaction from the front friction due to its spin helps the force of gravity to pull it downwards, so that it drops more rapidly than gravity alone would make it drop.

In various games with balls these spins play an important part in deceiving the batsman as to the probable flight of a ball. The effect is usually complicated by combining two of the spins described above ; and in cricket and tennis it is further complicated by the influence of spin on direction at the moment of bouncing. In cricket the break off the ground is more important than the swerve in the air, developing later and more suddenly, so as to be more difficult to see, and producing a greater change of direction in a given distance.

This section, however, is concerned only with the swerve produced by spin during the flight through the air. It is this effect of 


\section{BOOMERANGS.}

spin that plays the most important part in baseball, as the batsman has to take the ball in its first flight without previous bouncing. Some of the throwers in this game have great skill, and make an especial feature of spins $\mathrm{H}$ and $\mathrm{N}$, giving balls which appear to fly straight for a great part of the way and develop an unexpected swerve at the last.

These men can throw a ball so that in an unbroken flight, without any bouncing, it can pass round the corner of a house out of sight of the thrower.

\section{Boomerangs.}

Among the various weapons and contrivances of savage races none has aroused more interest than the boomerang of the native Australians (see Frontispiece), and the reason for the exceptional interest with which it has been regarded is the paradoxical and almost miraculous nature of its reported performances. It has been said to describe circles, loops, and a figure of eight in the air, to hit the quarry and then return to the hunter who threw it, to fly round a house and come back on the other side, to come back and drop behind the thrower.

The boomerang varies a great deal in its form, but the following is an account of its average construction. 


\section{MECHANICAL PARADOXES.}

It is made of a flat thin piece of hard wood (see Fig. I3), which has fairly pointed ends and fairly sharp edges, and a bent or crescentic outline as seen upon the flat, though as viewed towards the edge it is in one plane. The figure shows a common shape, seen from above; and below it is a view of the thin edge. The angle, as seen in the upper view, is very unsettled, and is often determined in detail by the direction of the grain of the wood.

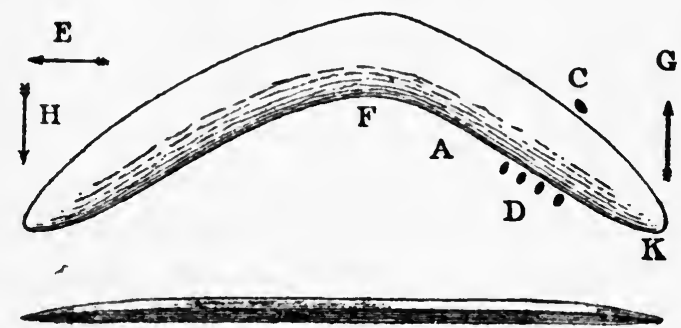

FIG. 13.-ORDINARY SHAPE OF BOOMERANG.

The two blades, or limbs, are not always exactly in one plane, but often have a slight twist in their set, so that while the front edge of one limb looks slightly upwards, that of the other will look a little downwards.

The performance of this weapon depends entirely upon the manner in which it is used. In its flatness it resembles a leaf, a piece of card, a sheet of tin, or a bird's wing; and so far as its flatness is concerned, it might be expected to behave like any of these. Now, 


\section{BOOMERANGS.}

if we watch the three first objects, the inanimate flat things, as they fall from a sufficient height, we observe that instead of gliding steadily and smoothly downwards, with the same thin edge always in front, they come down with many varieties of irregular movements. Of the falling leaves in autumn many will keep rolling over in the same direction during the whole of their fall. Others will have a swinging movement, dipping down, across, and up, with one edge first, and then with the opposite edge in front dipping down, across, and up, in the opposite direction, but a little lower. Others, again, have a twirling motion, sometimes keeping almost horizontal, at other times with one end lower than the other, forming a funnel-shaped or conical curve by the spin.

None of these would be a suitable movement for a flat weapon to tend towards assuming after it had left the guidance of the hand. If it could maintain, as a bird's wing does, something like a horizontal position, it might, like a bird, float with a steady movement through the air, and, having the advantage of the air's support to delay its fall, could travel much further with the same starting impetus.

To avoid the irregular movements and turning over, to keep the thin edge always presented in the direction of the forward 


\section{MECHANICAL PARADOXES.}

movement, something must be done by the thrower at the moment of despatching it.

He causes it to revolve in an almost horizontal plane-that is, on an almost perpendicular axis.

We have seen, in the section on gyrostatic movements, that a revolving body strongly resists attempts to change the plane or axis of its revolution. You may move it backwards or forwards, sideways, upwards, or downwards quite easily, without any resistance other than that due to its weight. But if you attempt to give it a twist, so that it shall be spinning in a different plane, it resists this change with an energy acting quite differently from that of gravity.

In this spin, then, we have a means ' of promoting steady motion by checking in the beginning any tendencies towards deviation.

The influence is much like that of steadying the front wheel of a bicycle. This wheel is so constructed that it has of itself a tendency to run straight, and if the machine be ridden carefully the wheel does run straight. But without such care, whenever' the slightest roughness in the road, wind on one side, or unevenness of pressure, disturbs the balance, the tendency of the wheel to set this right again, and to continue too far the movement by which it sets it right, causes an error on the other side, the over-correction of which 


\section{BOOMERANGS.}

causes a greater error on the original side, and so on till a real wobble is set up. A hand resting lightly on the handle-bar, not consciously guiding or straightening the machine, but unconsciously checking each irregular movement before it has had time to develop, leaves the wheel free to follow its own general tendency to keep straight.

So the force of the thrower gives the boomerang a general tendency to move in a given direction. The way in which its edges, of slightly irregular shape, cut the air would cause it to begin irregular movements which, allowed to become excessive, would result in movements of alternate swings or continual turning over, such as we see in falling leaves or slips of paper, or in thrown cards. The steadying action of the gyrostatic influence due to the spin, like the hand on the steering-bar of a bicycle, checks such irregularities at the beginning, and so leaves the boomerang free to follow the course impressed upon it in the throw.

Before leaving the spin of the boomerang, we must consider how its crescent shape helps in producing the spin which is so essential in maintaining the steadiness of its flight.

We know that it is difficult to throw any ordinary stick-such as a walking-stick-by one end without giving it such a motion that it turns end over end during its flight. 


\section{MECHANICAL PARADOXES.}

This result of ordinary stick-throwing, however, would not be sufficient for the gyroscopic spin of the boomerang-thrower. The shape of the implement enables him to intensify this spin considerably at the moment of despatching it.

Look again at the outline of the boomerang in Fig. 13. Suppose it to be thrown in the general direction of the arrow $\mathrm{E}$, from right to left. Suppose it to be just on the point of leaving the hand, which is underneath it, with the thumb at $\mathrm{C}$ and the fingers at $\mathrm{D}$. As it is moving to the left, any obstacle at A in front of the hinder horn would prevent that horn, A K, from moving straight forwards in the direction of the arrow $\mathrm{E}$. To get past the obstacle at $\mathrm{A}$ the rear end must move sideways in the direction of the arrow $G$, and in this direction the rear end is forced by the impetus already acquired by the whole weapon. But the centre of gravity of a weapon of this shape is about the point $F$, and a sudden movement given to one end of a long object tends to make it revolve about its centre of gravity, the other end moving in the opposite direction. Therefore, when the rear end is pushed towards $G$, the front end will move in the direction of the arrow $\mathrm{H}$.

Now at the moment of discharge, when the thumb is relaxed at $C$, the fingers remain as an obstacle at $\mathrm{D}$, and in order to get past 


\section{BOOMERANGS.}

them the boomerang has to spin in the direction of the arrows $G$ and $H$. The spin is further assisted by a final push of the fingers in the direction of the arrow G. The spin due to the presence of the fingers as an obstacle at $\mathrm{D}$ is additional to, and intensifies, the spin which the boomerang, like all sticks thrown from one end, acquires from the swing given to it in the act of throwing.

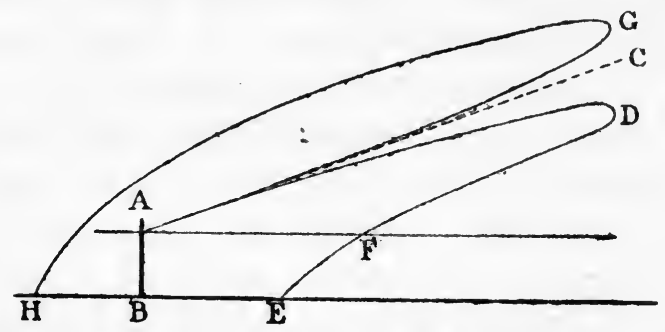

FIG 14.-VERTICAL DEFLECTION OF BOOMERANG'S LINE
OF FLIGHT.

The steady flight of the boomerang being accounted for by the gyroscopic action of the spin given to it at the moment of throwing, there remain to be considered some of the peculiarities of flight which have earned for it its special reputation.

First, then, the boomerang can return to the thrower.

Let A B (Fig. I4) represent the thrower, and the dotted line $\mathrm{AC}$ the direction in which the boomerang is thrown. Now, if A C were a plane surface of polished and lubricated 


\section{MECHANICAL PARADOXES.}

metal, sloping after the manner of a houseroof, and the boomerang were thrown up the slope, when it had gone as far as its impetus would carry it, it would then simply turn and slide down again to the spot from which it started, being supported all the way by the metallic plane on which it was sliding.

Well, the boomerang is supported, though on nothing so rigid as a metallic plane. Owing to the fact that it is started with its flat sides up and down, and that its spinning movement keeps it in that position, it can rest on the air like a paper kite, an aeroplane, or the wings of a soaring bird. Like all these, however, it is not rigidly supported; the air yields, and it slowly descends, so that, instead of keeping to the direction in which it was thrown, marked by the dotted line A C, it follows that of the continuous line, and at $\mathrm{D}$, still slowly dropping, it turns and slides down backwards on the air almost as if on the metallic slide, except that it is all the time falling through it as well as sliding down it. Thus it reaches the level $\mathrm{F}$, at which it started, considerably in advance of its starting point, but, continuing, strikes the ground at $E$, almost at the feet of the thrower. In this behaviour the boomerang simply imitates the performance of the cards which a trick showman throws up towards the gallery in such a way that they fall back to the stage. At the moment of throwing he 


\section{BOOMERANGS.}

gives to each of them, with practised skill, a strong whirling spin, so that the gyroscopic influence keeps them with their flat surfaces in the same sloping plane, and they can slide up the air, and down it again, with a steady motion.

This is the action of the simple boomerang, with the edge which cuts the air evenly bevelled

A

B

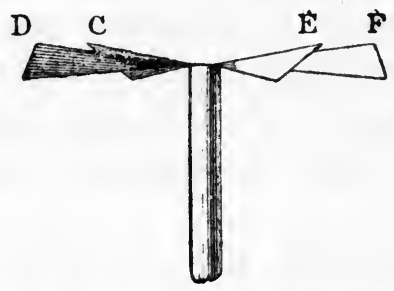

FIG. 15.-SCREW MOTION CAUSING RISE IN FLIGHT OF BOOMERANG

on both sides all the way along. Boomerangs are not all made on this simple plan, however. If they are carefully examined, it will be seen that some of them have the cutting edge nearer to one side than to the other-above or beneath the plane of a central horizontal section. Thus the one shown in Fig. I5 has a twist of such a nature that at the end $\mathrm{A}$ the cutting edge is nearly in a line with the upper surface, and at the end B nearly in a line with the lower. The reverse is the case with the opposite edges, invisible in the figure, because at the back; 


\section{MECHANICAL PARADOXES.}

at the $\mathrm{A}$ end the back cutting edge is beneath, at the $B$ end it is above.

It can be readily seen that such a boomerang is on the plan of the spinning toy shown in the same figure. This toy has oblique vanes, and, supposing it to be spun so that those on the left advance and those on the right recede, then the upper edges of the vanes, C, D, E, F, are the leading edges, and cut the air on such a slope that they tend to climb up it and all rise together. The spinning is done by means of a string wound round the stem in a suitable holder, and if the spin be strong enough and the toy large enough, it will fly up to the ceiling or even as high as a house.

A boomerang with its vanes constructed on the same plan, though it has only two of them, and they are much heavier in proportion to their area, will behave to some extent in the same manner if spun in the same way. If the boomerang in Fig. I5 be so spun that the end A comes forward and the end B goes back, since A slopes upward towards the front and B slopes upward towards the back, each end will tend to rise-that is, the whole boomerang will tend to rise, and with a force proportionate to the vigour with which it is spun.

Thus, recurring to. Fig. I4, the rising tendency of such a boomerang might counteract the falling tendency due to gravity, and instead 


\section{BOOMERANGS.}

of taking the course ADFE, it might fly out to $\mathrm{C}$ in the actual direction in which it was thrown, and, coming back in much the same line, fall at the feet of the thrower. Or, if still more strongly spun, it would actually rise above this line, and travel by way of $A \mathrm{G} \mathrm{H}$, falling behind the thrower himself.

The boomerang can do more surprising things still, describing circles, ellipses, and more complicated figures.

To understand how these variations may arise, we must remember that the boomerang is not impressed with a spinning motion only, but with a very energetic forward motion as well. We will suppose the forward motion of the boomerang in Fig. I5 to be actually forward from the reader, that is, into the page, and the spin to be as described before-that is, the end $\mathrm{B}$ going forward into the page, and the end $\mathrm{A}$ coming towards the reader.

Then it is clear that whichever end is at the right for the time being will cut the air forward much more swiftly and forcibly than the end which is at the left. For the righthand end has the forward motion of the whole weapon increased by the forward motion of the spin, whereas the left-hand end has the forward movement of the whole weapon diminished by the backward movement of the spin.

Now the oblique under-surface on the right 


\section{MECHANICAL PARADOXES.}

striking the air so much more forcibly than on the left, the right-hand side of the boomerang has the stronger tendency to rise, and does rise more than the left-hand end. But it is a curious and striking law of gyroscopic action that when an external force twists in one direction the plane in which a body is spinning, the spinning forces in the body itself resist
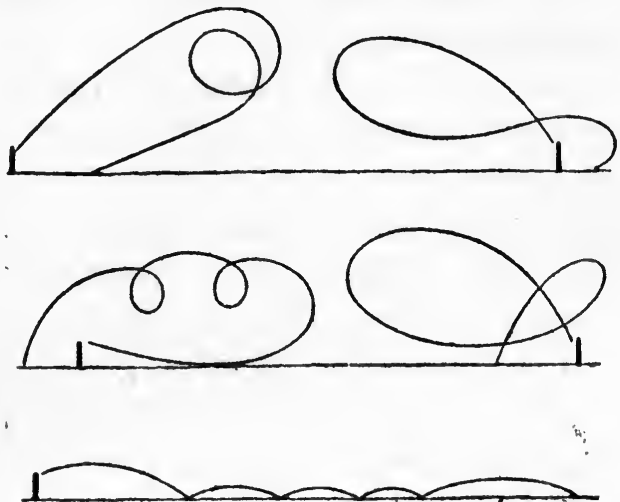

FIG. 16.-VARIATIONS IN FLIGHT OF BOOMERANG.

the simple change and insist on a compromise depending on the direction of the spin.

In the case under our consideration this law operates so that whereas the greater raising effect of the oblique vanes cutting the air more forcibly on the right tends to raise the right side of the boomerang, the additional gyroscopic effect of this twisting the plane of rotation upwards on the right is to twist it upwards also at the front; and the resulting 


\section{BOOMERANGS.}

effect of these two tendencies is a rising of the right front quarter.

This alteration in the plane of rotation causes a further change in the form of an alteration of the general direction of flight. For with its front raised higher than its back, it no longer presents its cutting edge to the air. Its under surface meets the air obliquely, the right forward quarter being the higher; and the result is that it tends to turn upwards and to the left. The tendency to turn upwards is resisted by gravity, but it does turn to the left.

The causes being persistent, the result is continuous and cumulative, so that the boomerang makes a partial or complete circuit, or more than one complete circuit.

The rising of one side can become so excessive that the weapon turns over, and this and other modifications due to the gyroscopic spin produce further complications of the flight of the boomerang, which it would be tedious to attempt to explain further in detail. Fig. I6 shows some of the varieties of flight actually performed, including a curious ricochet movement along the ground. The upright line represents the thrower, and the boomerang starts from near the top of this line.

In suburban districts, where babies and old ladies abound, and the police are at hand to see that their rights are respected, it would 


\section{MECHANICAL PARADOXES.}

not be possible, even if we had boomerangs, to practise with them sufficiently to be able to emulate the performances of the Australian aborigines. In the open fields in the country such practice is a very entertaining pastime, and if its devotees were allowed to practise at any motorist whom they might find filling the country and smothering other travellers with dust, the sport would be more exciting as well as more useful than golf. As with the

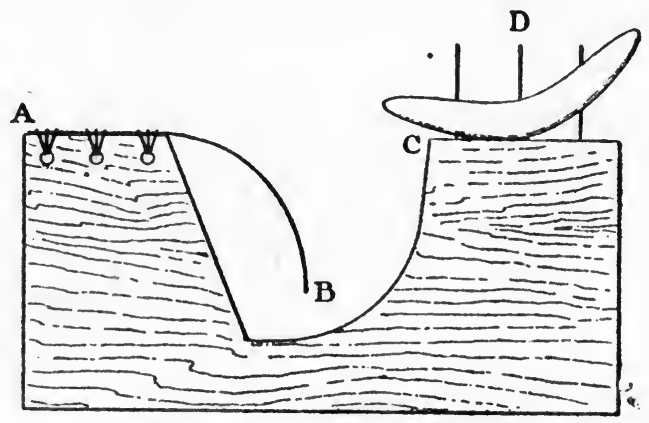

FIQ. 17.- HOME-MADE APPARATUS FOR TOY BOOMERANG.

shooting of tigers in India or wolves in Russia, the sportsman, in following his own amusement, would be promoting an object of public utility.

In default of such opportunities a good deal can be done by cutting a boomerang out of a visiting card, and flicking it off one hand with the thumb and fingers of the other. 


\section{BOOMERANGS.}

But better and more instructive effects can be obtained by a home-made little implement such as that shown in Fig. I7. It is made of a half-inch board, about ten inches by five, with a piece sawn out of one side. A B is a piece of old whalebone, or its modern steel equivalent, which can be got by making application in the proper quarter at a suitable time and in an unostentatious way. This is tied or wired to the board at one end, and the other is left just long enough to clear the board at $\mathrm{C}$, where, on being released from a bent position, it will strike one end of a small card or thin tin boomerang in such a way as to give it at the same time a forward movement as a whole and a strong spin in the plane of flight.

By varying the size and weight of the boomerang, the strength and weight of the spring, and the degree of twist at the angle of the weapon, a great many of the effects described above can be easily obtained on a lawn, in the backyard, or even in a fair-sized room.

At $\mathrm{D}$, in the figure on the preceding page, are shown three short pieces of wire or beheaded nails driven into the edge of the board in such a way that they are behind the middle line. Their front edges then form a convenient support for the small weapon before firing at various angles. 


\section{MECHANICAL PARADOXES.}

\section{Balloons as Air-ships.}

For a considerable number of years now a good many people have been engaged in attempts to work out the problem of navigating the air in, on, or under balloon air-ships. For the most part they are not inventors. They do not contrive or even try to contrive original applications or combinations of natural forces or mechanical arrangements, which will open an entirely new chapter of human possibilities. They are merely using over again devices and schemes which have been used a hundred times before, introducing the latest improvement in light strong engines, the latest development in light strong cords and silk, the very best varnish, and so on with a thousand other details, producing, and sometimes not producing, a slightly better result by the careful combination than had been produced before.

Montgolfier, and the others who first thought of inflating with light gas an air-bag huge enough to lift a man, were inventors. Those who first thought of replacing the air-bags by aeroplanes to act as kites or birds' wings do, were inventors. Those who thought of making the gas-bag cigar-shaped, so as to move end-on with less resistance to the air, were also inventors. But these principles having been invented, it is not invention to apply to them the latest improvements in mechanical 


\section{BALLOONS AS AIR-SHIPS.}

contrivances, which is the chief business of airship designers.

The fact is that their object is impossible, and will never be realised.

To make a balloon that shall travel somewhat faster and be a little safer than others is, of course, quite possible ; and many people appear to think that when one of the so-called inventors has accomplished this, he is on the high road to success. But their professed object is to " conquer the air," to devise a contrivance that shall supply not merely a possible but a practical means of navigating the air, something that shall come within measurable distance of being as safe, as regular, and as economical in the air as a good ship is at sea.

To accomplish this by balloons is impossible.

Many of the paradoxes hitherto considered have been actualities, things accomplished either naturally or artificially in actual fact. The present section is concerned with a paradoxical idea; and our interest will be in examining this idea, to see how impossible of realisation is a scheme upon which many men have spent and are spending a great deal of time, money, and ingenuity.

Swimming in a fluid like air, and swimming on a fluid like water, differ from travelling on the ground not only in the manner and means of support, but also in the fact that the fluid 


\section{MECHANICAL PARADOXES.}

which supports the traveller may be, and often is, in rapid motion itself.

When this is the case, the contrivance for travelling is at the mercy of the supporting fluid, unless it can travel through the fluid as fast as the fluid itself is likely to travel. And to have real independence of movement it must be able to do a good deal more. It must be able to move through the fluid much faster than it is ever likely to find the fluid moving.

A ship, for instance, which could only travel at the rate of four miles an hour would be liable to be dashed upon rocks or banks by ocean currents of six miles an hour. And if a river flowed at the rate of six miles an hour, a steamer which could not go more than five miles an hour would never be able to travel any way but down stream ; and if it were only capable of six miles an hour, all it could do against the stream would be to remain stationary opposite the wharf. To be able to travel freely up and down the river it must be able to travel through the water a good deal faster than the water itself travels through the country.

The same condition is equally imperative for a machine which is to travel by swimming in and through the air. It must not only be able to rise and keep aloft as long as necessary, but to avoid destruction it must be able to travel through the supporting fluid as fast as 


\section{BALLOONS AS AIR-SHIPS.}

the fluid itself travels-that is, it must be as swift as any wind which it is expected to be out in. And to have free and independent motion in any direction at any time it must be swifter through the air than the air itself is over the earth. Allowing that, as ships do, they lie by in safety as far as possible in times of hurricane, they must be a good deal swifter than strong winds, and even storms. To have to wait for days, and even for weeks, as they do now, till the wind has dropped to something like a calm before venturing out, is hardly to have accomplished the "conquest of the air." As well might a mouse boast of its conquest of the cat on the ground that, having waited till she was asleep, it had then crept out of its hole.

Is there, then, any probability that balloon air-ships will ever be able to travel fast enough not merely to escape destruction by winds, but even to perform their appointed journeys in spite of them ?

If success is to be attained, air-ship engineers are undoubtedly on the right lines in making the balloon of an elongated cigar-shaped form, so that in moving in the direction of its length it may receive as little resistance as possible from the air in front of it. But there are limits to what can be done with advantage in this direction, and all that can profitably be done has been done. The spherical shape 


\section{MECHANICAL PARADOXES.}

is the one that offers least surface and least weight of structural materials in proportion to volume, and is therefore the one that gives the greatest floating power. The further this shape is departed from the greater the loss of floating power, and the limits of improvement in this direction have already been reached.

The limits have also been reached, and, for safety, exceeded, in the direction of lightness in the frame, the cords, and the gas-bag; and though reductions may yet be made in the weight of the motor, so little, proportionally, remains to be done in this direction that the volume necessary to give the balloon its floating power can never be substantially reduced.

Now this volume is such that balloons with practicable floating power can never be driven fast enough to be even safe in strong winds, much less to have free and independent movement. In a hurricane the wind moves at a speed approaching one hundred miles an hour, and a balloon should be able, for safety, to neutralise a wind of fifty miles an hour; that is, to travel at the same speed itself. To have voluntary movement in any direction, against even strong winds, it should have a speed of its own equal to that of an express train, fifty, sixty, or seventy miles an hour.

Many birds, such as pigeons and swifts, have such a speed. But they do not float 


\section{BALLOONS AS AIR-SHIPS.}

by their lightness and volume, as a balloon does. A bird, with its pointed beak, wedgeshaped head, gently swelling neck, chest, and body, is admirably adapted for swiftly cleaving the air, better than any machine can be which, like a balloon, has to sustain itself by floating. And, with its wings edge on, a bird presents a remarkably small front to the air in the direction of movement.

How different it would be if birds sustained themselves, not by beating the air with wings, but by being light enough for their size-that is, large enough for their weight-to float! A little bird weighing an ounce and a quarter would then have to occupy a cubic foot of volume, and allowing that it was cigar-shaped, and that its length was ten times its diameter, it would still present a front end of more than twenty-eight square inches surface-an enormous object for a little bird of one and a quarter ounces weight to drive swiftly through the air.

Or take the case of a bird which can only just contrive to fly at all-a goose weighing ten pounds. For such a goose to rise by mere buoyancy it would have to occupy a space of I30 cubic feet. With the cigar-shape again, and the length ten times the diameter, the front end area to be driven through the air would be over six square feet. It is difficult to imagine, and would be impossible to construct, any motor, physiological, mechanical, 


\section{MECHANICAL PARADOXES.}

electrical, or thermodynamic, powerful enough to drive such a surface at the rate of fifty, sixty, or seventy miles an hour, and yet light enough to come within that part of the goose's ten pounds of weight which is not taken up by the framing and structure of the bird in its hypothetically swollen form.

For it must be remembered that the air pressure increases more than proportionally with the area exposed.

The air-pressure itself on large surfaces becomes so enormous as to be destructive for a thing which, like a balloon, has to be built with a construction light enough to let it float in air. Imagine our goose with a great part of its ten pounds of weight taken up by muscle tendons and bones powerful enough to force so large a body through the air at sixty miles an hour, and having only the remainder of its ten pounds available to make the frame and covering of a bulk of I3o cubic feet strong enough to stand the tremendous pressure of being driven at express railway speed! To state the problem is to see how insoluble it is.

The paradox of the balloon air-ship, then, may be stated briefly as follows:

To be independent, or even safe, in a fluid as swift as the winds, it must itself be as swift as an express train.

To resist the air-pressure at so high a speed it must be very strong, and therefore heavy. 


\section{BALLOONS AS AIR-SHIPS.}

To float by its own lightness, it must be very large for its weight, and therefore weak.

To move swiftly with so large a bulk it must have powerful and therefore heavy motive apparatus.

It must be, in four words, heavy and light, weak and strong.

The problem of conquering the air by balloon air-ships is therefore beyond solution.

Not that the more general problem, that of constructing practicable air-ships, is insoluble.

But it must be attacked by means which are not inconsistent with each other to the extent of being paradoxical.

Nature herself is a useful guide to the only possible method of solution.

The only natural instances of floating in the air are such as that of the dandelion seed or the small spider suspended by a long thread which it has itself spun, and which is blown out by the wind. But these are cases of merely passive floating, at the mercy of the air, which, if it blows out to sea, will inevitably take the passengers there too, unless they touch ground first. And, indeed, these are not even cases of floating, in strict exactness. In an absolutely still air these objects would all fall straight to the ground. They only travel because currents of air, some of them being accidentally up-currents, carry them up and away faster than their very small weight carries them down. 


\section{MECHANICAL PARADOXES.}

Nature's active and independent travellers through the air all employ one or both of two proceedings-either, like birds, bats, and insects, they actively beat the air with their wings, or like most large birds and many small ones, they occasionally perform a soaring movement with wings outspread and motionless, or nearly motionless, gliding through the air from a position of greater height or swifter movement.

Some of the movements of birds will be considered more fully in the next section. Meantime, we may note that the air-ship engineers who get their aerial support after the manner of soaring birds by means of aeroplanes - that is, large smooth surfaces gliding through and resting upon the air-avoid the necessity for having a very large volume, and are left with difficulties which, though great, are not beyond human ingenuity to solve, since they involve no incompatibles. Travelling by such machines is never likely to be over-safe or reasonably cheap, but they will probably be very useful in war and meteorology, and for emergency work generally.

\section{The Way of a Bird in the Air.}

Since the days of the ancient Hebrews " the way of a bird in the air" and "the way of a fish in the sea" have been standing puzzles 


\section{FLIGHT OF BIRDS.}

to those who like to understand what is going on around them. It is still very puzzling that small fishes should be able to dart so swiftly with apparent ease through a medium so resistent as water is to motion at high velocities.

But the flight of birds, though it has points that still need clearing up, can for the most part be explained in accordance with the accepted principles of physical science. There is so much in it, however, that is contrary to ordinary expectation that it may be strictly and literally called paradoxical.

One point which has been much discussed is the soaring of large birds, the means by which they keep aloft in the air for hours together without any apparent motion of the wings. This seems at first sight puzzling; but it is capable of explanation under known laws.

In the first place a bird with a large area of wings outspread sinks very slowly, just as a parachute does, because it offers so large an area, in proportion to its weight, over which the air can resist its downward movementin other words, support it.

But when the bird is gliding forward this resisting or supporting action of the air is more effectual to uphold it than when it is sinking straight down. For, in the latter case, the air which it has moved downwards in the previous part of its fall joins its downward impetus to the weight of the bird in moving 


\section{MECHANICAL PARADOXES.}

the air beneath to let it fall further; whereas when the bird is gliding rapidly forward, the air above it is previously undisturbed by itself, and there is only its own weight to press upon the supporting air beneath.

With such a gliding movement, therefore, the wings may be quite motionless, and the falling of the bird will be extremely small.

Cases have been observed, however, where no falling could

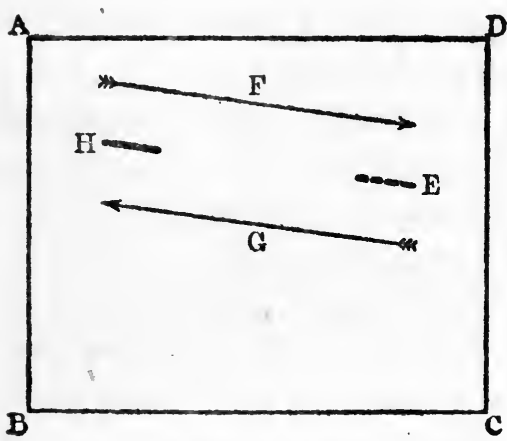

FIG. 18.-SOARING OF LARGE BIRDS IDENTICAL WITH GLIDING.

$p$ be noticed at all, and no gliding apparently took place.

These observations are of a nature that makes it difficult to verify them exactly. At a great height small differences of height and considerable changes of position can easily escape notice. But for cases where there really is no motion of the bird, the following explanation is quite adequate.

The behaviour of clouds, and facts observed by means of balloons and kites, show that there are many movements of the upper air not represented by corresponding movements of the air beneath. A moderate breeze in the 


\section{FLIGHT OF BIRDS.}

upper air, with a very slight rise in direction, will easily remove our difficulty.

If $\mathrm{A}, \mathrm{B}, \mathrm{C}, \mathrm{D}$ (Fig. I8) represents a block of the upper air, in which the bird $\mathrm{H}$ is quietly gliding, E may represent the position to which it would have moved through perfectly still air after a definite interval, say one second, the direction and distance being represented by the arrow F. Suppose that there is a breeze moving in exactly the opposite direction at the same speed, as indicated by the arrow $G$. It is obvious that this breeze will carry the bird backwards and upwards just as far as its own gliding had taken it downwards and forwards, and so its actual position would be unchanged.

Another puzzle in bird movement which is not often explained is how birds get such rapid forward movement without beating their wings backwards against the air. When an oarsman propels his boat forwards he beats his oars backwards against the water, and the reaction drives the boat on. A paddle steamer does the same with its paddles, and a duck or swan with its feet. But if we carefully watch any bird such as a rook, peewit, or seagull, whose wings move slowly enough for the nature of their movements to be observed, we cannot detect the slightest backward and forward movement of the wings; it appears to be purely up and down. Such a movement of 


\section{MECHANICAL PARADOXES.}

wings seems appropriate enough for keeping up, if that were all that had to be done. But it is at least equally important to move rapidly forward. How is this accomplished without backward beats upon the air ?

First look at a diagram of the flying bird, as seen from straight in front, Fig. I9, A and
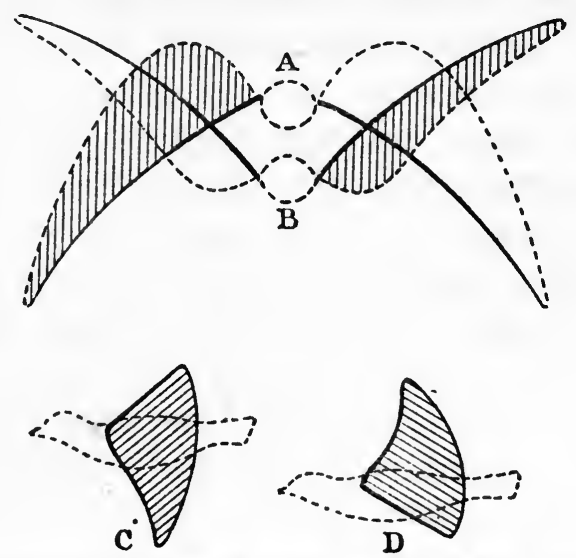

FIG. 19.-POSITION AND ACTION OF WINGS IN FLYING.

$B$, in which the front edges of the wings are shown with continuous lines, their rear edges with dotted lines, and the upper surface on the left side, and the lower on the right side, by parallel bars.

In the position $\mathrm{A}$ it is seen that the reaction from the down-beat, which is nearly finished, has caused the body to rise. At B the up-beat is nearly finished, and while lifting the wings up, the body, unsupported, has fallen. There 


\section{FLIGHT OF BIRDS.}

is thus a continual up and down movement of the body in its progress forward.

$\mathrm{C}$ and $\mathrm{D}$ are diagrams of the same positions as seen from the side, the parallel bars in $\mathrm{C}$ showing the slope of the upper surface and those in $\mathrm{D}$ the slope of the under surface.

The bars of slope in $\mathrm{C}$ show that when the wing beats downwards in the position $\mathrm{A}$ or $\mathrm{C}$, the lower surface strikes the air obliquely, not squarely, because the wing is in an oblique, not a square, position. Now we know what happens when the air is struck obliquely by the oblique surface of a fan. The air is driven not merely round with the fan, but forwards from it, the combined movement being not far from perpendicular to the striking surface.

So the wing, beating downwards with a surface which looks backwards as well as downwards, drives the air backwards as well as downwards. By reaction the wing is thrust forwards as well as upwards, carrying the bird in the same direction. Thus we get the forward movement of the bird out of the purely downward beat of the wing.

In the diagrams the slope of the wing backwards, which produces this movement, has been considerably exaggerated for the sake of clearness. In reality it is much less, a very slight obliquity being sufficient to produce the forward movement. In fact, as we saw in the case of the ice-boat's sails, the smaller 


\section{MECHANICAL PARADOXES.}

the obliquity the greater the forward speed in comparison with that of the wind in that case, of the wings in this, so long as the resistance is not too great. Consequently it is often impossible, without the closest observation, to see that obliquity in the wings of birds which produces the forward movement.

In the return or up beat, shown at B and $\mathrm{D}$, the wing surface is purely passive, being merely carried forwards and upwards by the front edge, which cleaves a way for it through the air till it gets into position to act in the next down beat. 
IV.

FLUID FORCES.

\section{A Pound Weight balancing a Hundredweight.}

WHEN those who have not studied the physical sciences or had much experience of practical mechanics are told that a hydraulic press is a machine which will enable one man to lift a weight of fifteen tons, or that a large one, worked by mechanical power, will lift two thousand tons, it seems to them that there must be some extremely clever, recondite, and almost supernatural use made of physical forces to produce so tremendously large a power out of a small one.

In reality, the result is obtained by a very simple application of forces almost universally present and active.

All depends upon the fact that water, in common with all other fluids, possesses the property of transmitting pressure equally in all directions.

A piece of iron or stone, on the other hand, is without this property. It is pressed by gravity downwards, and can only transmit the pressure downwards to things beneath. Things at its side are not pressed by its weight. 


\section{MECHANICAL PARADOXES.}

Or if it be pressed sideways, it can only transmit this pressure sideways to objects beyond it in the direction in which the pressure is exerted upon it.

Indiarubber, having in an imperfect degree some of the properties of fluids, can transmit some of the pressure put upon it in new directions. Thus, if a round ball of solid indiarubber be placed in a square box whose sides it just touches, and be then forcibly pressed upon, it will swell sideways and transmit sideways to the sides of the box some of the pressure put upon it.

But a fluid when pressed upon transmits the full pressure equally in all directions. A little consideration will provide familiar illustration of this. How is it that water tends so powerfully to force open a dock gate or lock gate, or to burst the dam of a reservoir ? The water at a given distance down the inside of the gate is pressed downwards by its own weight and by the weight of the water above it. This pressure it transmits not only downwards to the water beneath it, and eventually to the bottom, but also sideways, on three sides to the water adjacent, and on the fourth side to the dock gates, so that the pressure against the gates is greater the deeper we go from the surface.

How is it that a ship floats in the dock or in the sea? The weight of the water beside it, 


\section{FLUID FORCES.}

pressing downwards, is transmitted sideways, and then beneath the ship is transmitted upwards.

One of the effects of this principle, expressed as proverbial philosophy, is that water will find its own level; because it is only when it has done so that the pressures at every point on any level transmitted in all directions are equal, and balance one another.
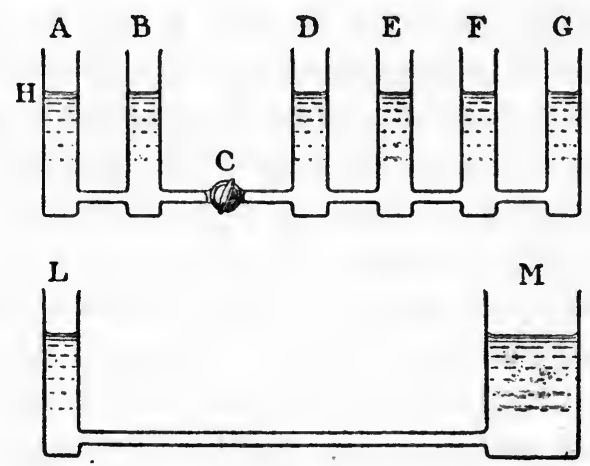

FIG. 20.-PRINCIPLES OF THE HYDRAULIC PRESS.

Let us then take the arrangement in Fig. 20 for letting water find its own level.

$A$ and $B$ are two barrels or cylinders, whose inside sectional areas are just equal to one square inch each. D, E, F, and $G$ are four similar barrels. All six barrels communicate by small tubes connecting them at the bottom.

At first the tap C is closed, so that only $A$ and $B$ communicate, and water is poured into one of them. It speedily finds its level. 


\section{MECHANICAL PARADOXES}

For in whichever barrel it stands a little higher it weighs more, since they are of the same diameter. It therefore presses harder on the water near the bottom, and this greater pressure is transmitted across and upwards in the other tube, lifting the water in this latter tube till it is at the same level, and therefore has the same weight, and makes the same pressure, in both.

But it is not merely the pressure from the water that is transmitted in every direction. On each water-surface there is a weight of nearly fifteen pounds of air, and the pressures from these weights of air are also transmitted, and balance each other. To prove that this is so, it is only necessary to fit pistons into each barrel, above the water. Then if the piston in A be lifted a little, it lifts the weight of air from the water in $A$, while the equal weight of air still pressing the piston on to the water in $\mathrm{B}$ has its pressure transmitted so as to lift up the water in $\mathrm{A}$ and make it follow the piston.

On the other hand, if the piston in $A$ be forced down a little, the extra pressure is transmitted down, across, and up, so as to lift the piston in $B$ with the fifteen pounds of air resting upon it.

If now the tap C be opened, any of these actions upon $\mathrm{A}$ will have exactly the same kind of influence upon the five barrels $B, D, E, F$, 


\section{FLUID FORCES.}

G, as it had upon the one barrel B. Pour water into A; it will find its level in all, the atmospheric pressure as well as that of the water itself being transmitted in all directions so as to procure a perfect balance. Fit them all with pistons, and the whole five will respond to an exactly equal extent, just as the one did. And if we put a one-pound weight additional on each piston, the whole five will remain exactly balanced at the same level by universally transmitted pressures.

Here we come upon the key to the explanation of the hydraulic press. The pressure transmitted is equal for equal areas of pressuresurface. Any weight on the one square inch of water in $A$ balances an equal weight on each of the square inches in $B, D, E, F$, and $G$. Therefore one pound on the water in $A$ can balance five pounds distributed over the other five water-surfaces. And so a pound and a half at $\mathrm{A}$ would more than balance, would actually raise, five pounds at $B, D, E, F$, and $\mathrm{G}$.

But it is clear that we should not change the relation between the one barrel and the other five if we combined these latter all in one larger barrel, whose section area was five square inches like theirs added together, and whose weight of air-pressure on the top would therefore be equal to theirs, as well as its weight of water for the same height of column. 


\section{MECHANICAL PARADOXES.}

This arrangement is shown at $M$, and it is, in fact, found by experiment that if $L$ be one square inch and $M$ five square inches, one pound at $L$ balances five pounds at $M$, and a pound and a half at $\mathrm{L}$ lifts five pounds at $\mathrm{M}$.

On the same principle, if the area at $M$ be one hundred times that at $\mathrm{L}$, or Ioo square inches, then a pressure of one pound at $\mathrm{L}$ will balance roo pounds at M. And any other pressure applied at $\mathrm{L}$ would be multiplied in the same proportion. Now a man can without difficulty exercise a pressure of sixty pounds. And if he apply this pressure on a pump-handle whose power end is six times as long as its work end, so that the working leverage is six, he can thus put a pressure of 360 pounds on the piston. Pumping water into $\mathrm{L}$ at this pressure, when $M$ is one hundred times the area of $\mathrm{L}$, he can make the water in $\mathrm{M}$ lift a weight of 36,000 pounds-that is, sixteen tons.

One man, by pumping at a handle, lift sixteen tons! It sounds magical at the first time of hearing. It seems like cheating Nature. But Nature is a very careful banker, and has never had the worst of a bargain yet. She never cashes a cheque for an amount in excess of the deposits and the security.

You cannot get out of any machine in one form more power than in some other form or forms is put into it. Indeed, you cannot get quite so much. Whatever power you put 


\section{FLUID FORCES.}

into a machine, Nature takes toll of it by converting a portion into friction, which is lost to you as power. That is the banker's commission. So that the total which comes out of a machine as power is always less than that which was put into it.

If, then, by using a pressure of sixty pounds a man can get a machine to lift sixteen tons, we may be sure that there is some compensating circumstance to be looked out for which will reduce the apparently magical gain to a balance of powers. This compensation is in the distance through which the weight is lifted as compared with the distance through which the power is exerted. When a man develops with the hydraulic press six hundred times the pressure that he exerts on its handle, the lift will be through only the six-hundredth part of the distance. If the stroke of his pump-handle be two feet six inches, the weight of sixteen tons will only rise one-twentieth of an inch per stroke. It will take twenty strokes to raise it one inch, and six hundred strokes to raise it the height of the stroke itself. Also the operator will have to press each time with a force a little greater than sixty pounds, to make up for what is lost in friction.

How the necessity for this compensation arises can easily be seen from another glance at Fig. 20 .

When a piston forces the water down below $\mathrm{H}$ in the barrel $\mathrm{A}$, and so forces it up in the 


\section{MECHANICAL PARADOXES.}

other five barrels, the extra height of water in these five can only be filled up from the diminished height of water in A. The sum total, therefore, of the increased heights in the five must equal the total of the fall in $\mathrm{A}$. That
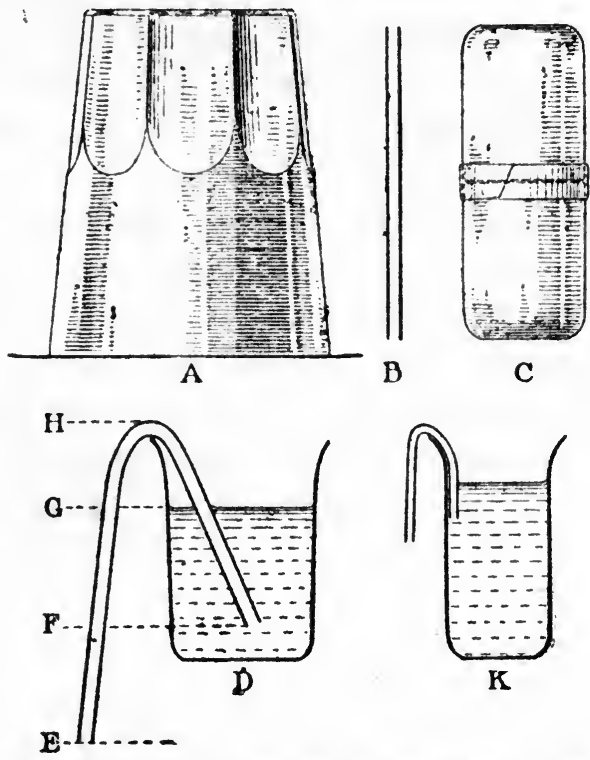

FIG. 21.-ATMOSPHERIC PRESSURE, CAPILLARITY, AND SIPHON FLOW.

is to say, the rise in each one of the five is onefifth of the fall in A. And when the five barrels are all combined in one, as at $M$, whose total area. equals theirs added together, then again the weight is lifted at $M$ one-fifth of the distance through which the piston falls at $\mathrm{L}$. 


\section{FLUID FORCES.}

To sum up :-

If the piston of a hydraulic press is to lift a weight in some definite proportion to the pressure applied at a force-pump handle, the area of the lifting cylinder, multiplied by the leverage, must have the same proportion to the area of the force-pump barrel.

\section{Fluids defying Gravity.}

Let a tumbler be filled with water and covered with a piece of light cardboard or stiff paper. While the paper is held lightly in position, let the tumbler be inverted, and the support then withdrawn from the paper, as in Fig. 2I, A. It will remain in position, and the water will not fall out of the tumbler while the latter is held up without any support underneath it.

The explanation is that gases, like liquids, are fluids, and transmit pressure equally in all directions. The air, then, transmits in all directions the pressure due to its own weight, and it thus presses upwards beneath the under surface of the card with a force of nearly I5 lb. to the square inch, forcing the card against the water. But the column of water on the upper surface of the card, inside the tumbler, if the tumbler be of ordinary height, weighs only about $2 \mathrm{oz}$. to the square inch, so that the air underneath presses the card upwards 


\section{MECHANICAL PARADOXES.}

about a hundred times as forcibly as the water presses it downwards. No wonder the water does not force the card away and fall out! When an accident does happen, and the water falls, it is simply because in reality the card has moved sideways, or twisted, and so failed to distribute the atmospheric pressure evenly. The sole duty of the paper or card is to secure this even distribution of pressure.

A narrow tube, such as $B$, filled with water, will hold it without any paper beneath it, if the upper end be simply stopped by pressing the finger over it. Its section area is too small to let the pressure be unevenly distributed, so that no bubbles of air can pass upwards; and the atmospheric pressure easily holds up the water.

If two tumblers be filled under water, say in the bath, and while still under water be placed end to end, as at $C$, and have their joint wrapped with a strip of paper, they may then be placed vertically one over the other, as shown, and lifted out of the water. The whole arrangement can then be held by the upper tumbler if care is taken to keep them vertical, and the lower tumbler, with the water contained in both, will be held up by the atmospheric pressure beneath it.

For this experiment it is well to take bedroom tumblers, with perpendicular sides, and 


\section{FLUIDS DEFYING GRAVITY.}

then it will be easier to fit the strip of paper smoothly. The function of the paper, again, is not to hold the glasses together by its strength, but simply to distribute the air-pressure evenly, and prevent bubbles from entering at some points while water passes out at others. To bring out the point of the experiment, therefore, it is well not to use strong, good paper, or the result might be ascribed to the wrong cause. Accordingly, it is a good plan to choose some halfpenny evening paper whose texture is as weak as its principles, and so filled with rubbish that in its case, as in theirs, a little washing almost reduces the whole to pulp. We shall be sure, then, that we are not attributing to atmospheric pressure what is due to the strength of the paper.

Beginners in experimentation may be warned that it is not in the preliminary task of working up an experiment to a successful issue that the chief danger of failure lies. This arises by preference after success has been privately obtained, and when the experimenter is showing the phenomenon to intended admirers. The wise experimenter, therefore, will demonstrate, as well as practise, the last two principles in and over the bath. Then, in case of a tumbler or its contents circumventing the atmospheric pressure, there will be no damage of glass-ware, tablecloths, or carpets to account for to those in authority. 


\section{MECHANICAL PARADOXES.}

The tube B is supposed to be too small for water to run down and air to run up at the same time-say, a quarter of an inch diameter. Now, the pressure of the air being nearly fifteen pounds to the square inch, its pressure upwards against the water in the lower end of such a tube would be about three-quarters of a pound. But a column of water of that size would have to be 34 feet high in order to weigh three-quarters of a pound. It is clear, therefore, that if a tube of that length were filled with water and its upper end were closed, the atmospheric pressure would hold up the water inside it. The same pressure would have no difficulty in holding up the water in tubes of a few feet or inches, such as are commonly used for experiments.

If a tube of this size were bent in something like the shape shown at $D$, and its lower ends were both open, the atmospheric pressure pressing anything into the one end would balance the same pressure at the other. If the whole tube were full of water, and the whole height of the one leg from the top of the bend to the lower opening were exactly equal to the height of the other-that is, if their lower openings were on a level-the waterpressures also in the two legs would exactly balance, and the tube would remain full with both ends open.

Practically it would be as impossible to 


\section{FLUIDS DEFYING GRAVITY.}

secure such exact equality in the length of the legs, the filling of the lower orifices, the wetness of the ends adjacent to these orifices, and the stillness of the air in their neighbourhood, as to balance a poker on its point. We could not avoid some slight inequality which would destroy the balance in so mobile a substançe.

Let us, then, go on to the case where the orifice of one leg is distinctly lower than that of the other, as at $\mathrm{E}$ and $\mathrm{F}$. In this case the atmospheric pressure upwards in the two legs is once more balanced, and so is the weight of water-pressure between the levels $\mathrm{H}$ and $\mathrm{F}$, in which the two water columns are of the same height. The water between these levels in the two columns therefore neutralises, by its downward pressure, equal portions of the upward pressure of the atmosphere in the two columns, and leaves the balance undisturbed. But the water between the levels $\mathrm{E}$ and $\mathrm{F}$ in the left leg is unbalanced, and neutralises an additional part of the atmospheric pressure upwards in the left leg. The resulting pressure upwards in the right leg being greater than that in the left, the water is driven upwards in the former and runs down and out of the latter, with a force which depends upon the height of the unbalanced column of water-F E at first, but more afterwards as the column of water in the right leg shortens upwards. 


\section{MECHANICAL PARADOXES.}

If the shorter end be placed in a beaker of water, as at $\mathrm{D}$, the difference of pressures in the two legs is increased from the start, since to the height $\mathrm{FE}$ of the column of water, which causes the movement by neutralising part of the atmospheric pressure upwards in the left leg, is to be added the height of the water column $\mathrm{GF}$ between the water level in the beaker and the bottom of the right leg. The pressure of this column, transmitted in all directions, presses upwards in the lower end of the right leg, and so its effect is added to that of the atmosphere, which presses upwards in the same way, its pressure now being not direct, but on the surface of the water in the beaker, which transmits it to the tube as well as everywhere else.

The total moving force, then, is measured by the height of the water column EF, which shows the excess by which the weight of water in the left leg diminishes the upward atmospheric pressure in that leg as compared with the corresponding diminution in the right, plus the height of the water column G F, whose pressure is added to the atmospheric pressure in the right leg. The two together make the height $\mathrm{G} \mathrm{E}$, between the delivery point and the surface of the water in the beaker. This force obviously lessens as the level in the beaker falls, whereas, when we had to do with water in the tube alone, the moving force went on increasing. 


\section{FLUIDS DEFYING GRAVITY.}

This is the well-known action of the siphon, by which water actually runs uphill in getting out of the beaker by the bend of the tube.

There is another case of water running uphill in consequence of a special operation of capillary attraction. If the tube $B$ is placed in water, so that the upper end projects above the surface, it will be seen that the water level inside it stands higher than outside. This is in consequence of the combined action of surface tension and the proximity of an encircling solid substance which can be wetted by the liquid. The smaller the tube the higher the water rises inside.

Now the siphon $\mathrm{D}$ has to be started by first inverting it and filling both legs, or by putting it in position and then applying suction at the lower end of the outside leg. But if the tube be fine enough-a capillary tube, because its bore is as fine as a hair (Latin, capillus)-and if the bend be not too high above the level of the water, the liquid can surmount the bend by capillary attraction, and then as it goes down the outer leg, having the weight of its own increasing column to help it, it gains power of movement, and acts as an ordinary siphon of very small bore and great friction.

A piece of cloth or wick may be regarded as a collection of very fine capillary tubes, since it contains a great many surfaces in close 


\section{MECHANICAL PARADOXES.}

proximity to each other. These, acting in the way described, can draw up oil to feed the flame of a lamp. If a piece of cloth be arranged as at $\mathrm{K}$, one end dipping into water which nearly fills a vessel, and the other end hanging down outside, it can act as a siphon, the weight of the liquid in the part outside favouring the action much as it does in an ordinary siphon. If a vase nearly full of water be arranged with leaves or petals in the position shown at $\mathrm{K}$, the arrangement acts as a capillary siphon, and speedily makes a considerable pool on the mantelpiece or table.

These are further cases of water running uphill in defiance of the force of gravity.

\section{More Weight reithout more Material.}

The ordinary meaning of the word "weight" is an earthward-tending force which can be used as a measure of the quantity of material. It depends upon the mutual attraction between the material and the earth, and to make it an exact measure of quantity careful observation must be made of the latitude, the height, the density of the fluid in which weighing takes place, and so on.

Another way of measuring quantity of material is to note the energy with which it strikes if stopped when moving. Here, again, to be exact, we must observe the rate of motion, 


\section{WEIGHT AND MATERIAL.}

the heat developed on striking, the resistance of the fluid through which motion takes place, and so on.

This latter method of measuring quantity depends on the fact that any material particle in motion tends to keep moving straight on at the same speed, unless interfered with by resistance of air, gravity, or some other cause. When the speed and all other circumstances are the same, then the force with which material tends to resist stopping appears to be proportional to the number of ulti-

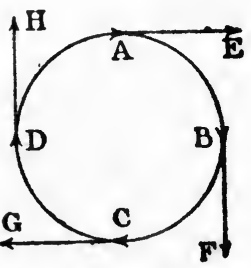

FIG. 22.-CENTRIFUGAL FORCE. mate corpuscles or small particles of which it is made up -that is, its total quantity, just as the weight does. This tendency to resist stopping, or any interference with or modification of its motion, is called the inertia of the material.

Now when anything is moving in a circle, its tendency at any moment is, in accordance with this law of inertia, to go straight on-not curvingly on, in continuation of the circle, but straight on, in the line which mathematicians call the tangent at the point where it is at the moment.

Thus, referring to Fig. 22, if a body be revolving in the circular path $A, B, C, D$, in the clockwise direction, when it is at $\mathrm{A}$ it has a tendency to continue in the direction $\mathrm{AE}$, at $\mathrm{B}$ 


\section{MECHANICAL PARADOXES.}

in the direction $B \mathrm{~F}$, at $\mathrm{C}, \mathrm{C} \mathrm{G}$, and at $\mathrm{D}, \mathrm{D} \mathrm{H}$. And these are the directions in which loose particles do fly off, as may be seen in the sparks from an emery wheel. But if the body went from A along A E, it would be going further from the centre of revolution. Consequently, it requires a constant pull towards the centre to tie it down to the circular path. This tendency of revolving bodies to go further from the centre is commonly called centrifugal force; and, for a given speed of the revolving body, the force is greater as the circle is smaller.

The strength of this force may be seen in the tendency of rapidly revolving grindstones and emery wheels to burst, so that they have to be specially bound in order to prevent accidents.

It may be illustrated also by taking a can or small bucket, half filled with water, and swinging it higher and higher until it goes right overhead and completes the circle. This can be done without a drop being spilled, because the centrifugal force throws the water upwards away from the centre against the top-nominally the bottom-of the bucket. The experiment is made easier by taking a very small can and swinging it by a piece of string.

But, instead of the string, other means may be taken of holding the object at the same distance from the centre while it revolves. 


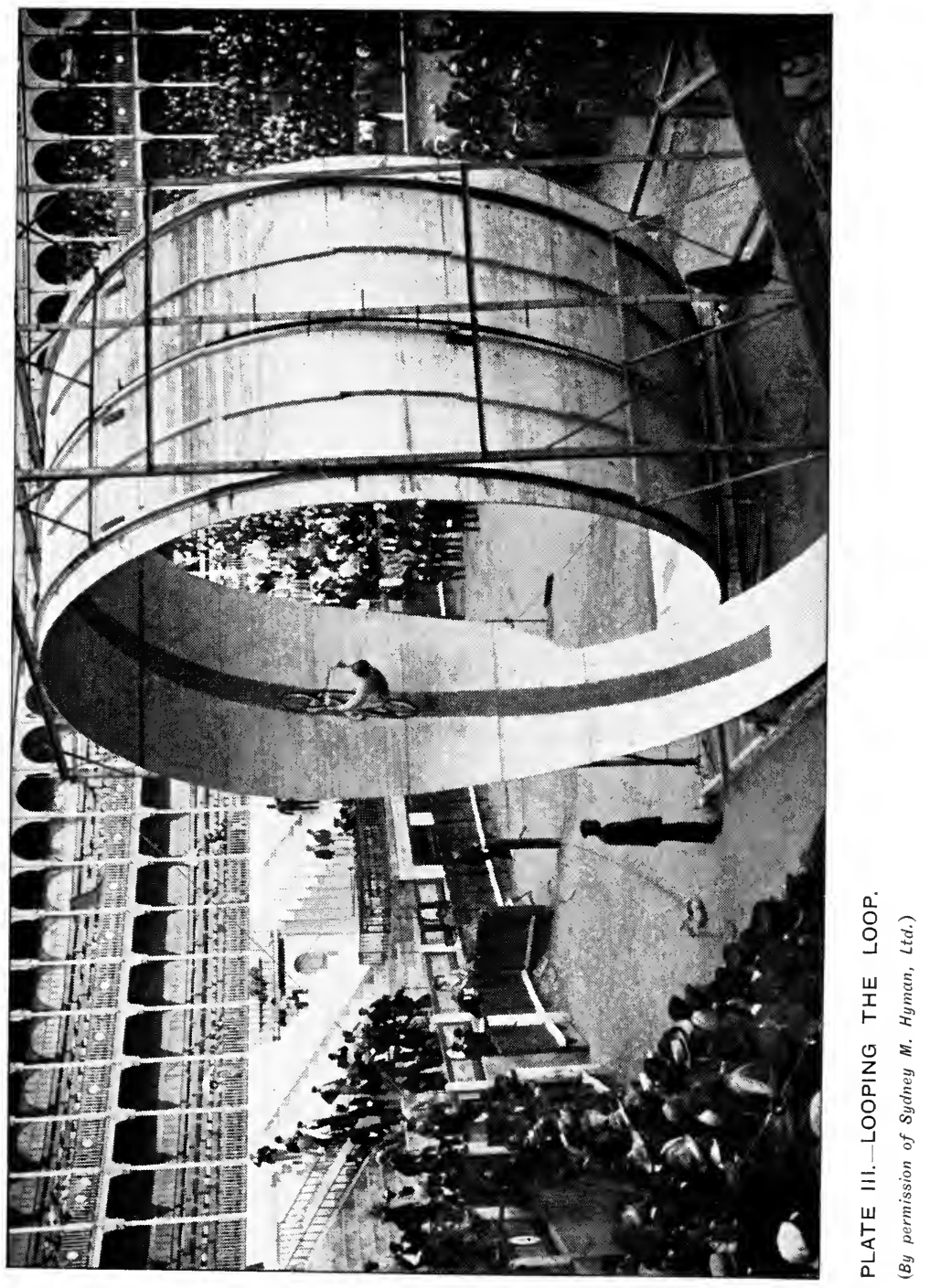





\section{WEIGHT AND MATERIAL.}

It may be placed upon wheels and obliged to follow the inside of a circular path, as in the case of a bicycle or small car which is used for the performance called looping the loop (see Plate III.). The necessary speed is obtained by running previously down a steep descent somewhat higher than the circle to be traversed; and this is sufficient to carry the car or bicycle right round a track on the inside of a vertical circle, the passengers or rider crossing over at the top with their heads down and their feet up, held up by centrifugal force against their inverted seats, and in perfect safety so long as the mechanical arrangements are all flawless and the cyclist retains his nerve.

So far as this performance is a demonstration of scientific truth, its purpose would be equally well served by having dummy riders, but perhaps its "drawing" power would be less.

Advantage is taken of this centrifugal force to separate more quickly things which separate slowly by weight. Such means are employed for the separation of crystals and precipitates from their solutions; of water from washed linen, again because it is heavier; and of cream from the watery part of milk, because it is lighter. But where the difference of weight is not great, the process of separation is slow. If a pint of cream weighs eighteen ounces, while the same volume of water weighs twenty, the difference, two ounces, is the floating power 


\section{MECHANICAL PARADOXES.}

on which we depend to bring the cream to the top. But this is so small a force to separate so intimate a mixture that it takes many hours before even a partial separation has taken place.

If we could make the eighteen ounces of cream weigh eighteen pounds, and so with the twenty ounces of water, the floating power

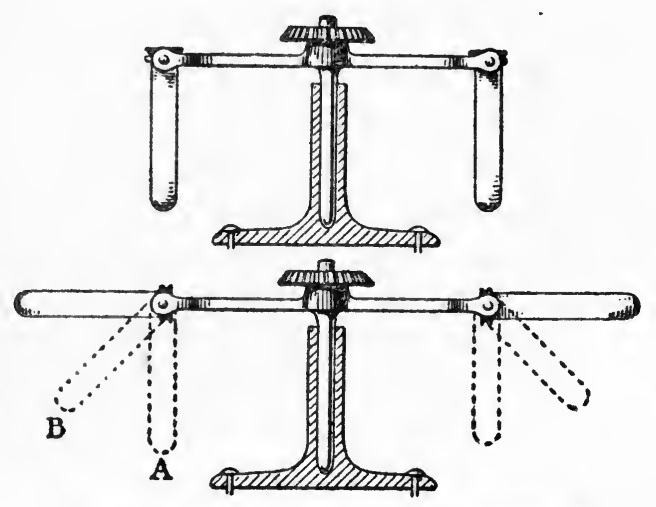

FIG. 23.-ACTION OF CREAM SEPARATORS.

of the former would be equal to the pressure of two pounds, and its small particles would quickly rise to the surface.

Practically this is what is done by the centrifugal separator, of which a simple form as arranged for laboratory work is shown in Fig. 23. A frame, with about six or ten arms, is arranged to be made to rotate horizontally with great rapidity by a simple hand-wheel 


\section{WEIGHT AND MATERIAL.}

connection not shown in the diagram. At the end of each arm is a swivel ring into which a test-tube, containing the substances to be separated by weight or its substitute, can be dropped. To avoid shaking, equal weights should be placed opposite to each other.

When the apparatus is spun horizontally, centrifugal force causes the test-tubes to swing outwards from the position $\mathrm{A}$. When they swing as far as B, so as to make an angle of forty-five degrees, they are half-way between the vertical and the horizontal position. The vertical force of gravity is just balanced by the horizontal force of centrifugal action. One ounce of material inside each tube, in addition to its one ounce of vertical weight, due to gravity, has acquired one ounce of horizontal weight due to centrifugal action.

Now the centrifugal force increases in proportion to the square of the velocity, so that when the machine is spinning so as to carry round the test-tubes twice as quickly, their contents have four times the centrifugal force, or four ounces of horizontal weight, urging them away from the centre. And when the machine is carrying the tubes four times as swiftly, each ounce of material in them, besides its own ounce of vertical weight, has one pound of horizontal weight. Thus a very small original difference between the weights of two of the things in a test-tube becomes a very consider- 


\section{MECHANICAL PARADOXES.}

able difference in their centrifugal weights when they are spinning round, and the heavier one rapidly forces its way to the outer endthat is, the bottom of the test-tube.

In machines made on this principle, though different in detail, large quantities of milk are separated every day, the watery part of the milk being driven to the outer part of the circuit, while the lighter cream remains nearer the centre. The same system is used in large laundries, for rapidly extracting the water from wet clothes, and in apiaries to throw out honey from the cells of the honeycomb without destroying the latter, as formerly, by chopping and crushing them.

4. Repulsion and Attraction by the Same Agent.

If a steam-pipe, connected with a boiler in which steam is being raised, be pierced with a small hole, the steam will rush out in a fine jet. The speed at which the steam enters the inner end of the hole is something like $I, 400$ feet per second; but as it passes along the fine channel it expands, and occupies, after expansion, a greater volume. But when two gallons of anything have to go through an orifice in the same time as one gallon, it is clear that each part of the two gallons must travel twice as fast as each part of the one gallon; and since each gallon of steam passing the inner end of the hole becomes by its 


\section{REPULSION AND ATTRACTION.}

expansion two or more gallons as it passes the outer end, it follows that each part of it in the expanded state must move more rapidly than in the unexpanded state. So it comes to pass that as it leaves the outer end of the small hole, the steam has acquired a velocity of several thousand feet per second.

Light as steam is, when it moves with this enormous velocity, it can exercise consider-

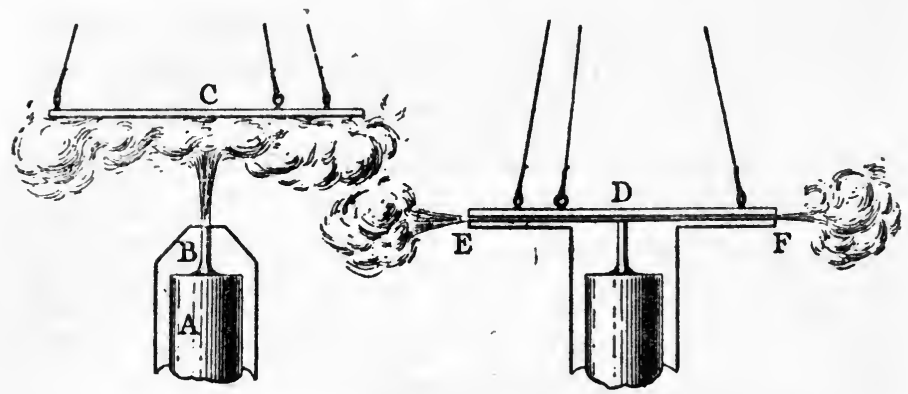

FIG. 24.-REPELLING AND ATTRACTING FORCE OF JETS.

able force, as is shown in the driving of turbines by such jets.

The illustration (Fig. 24) shows another way in which its power can be manifested. A is a pipe communicating with a steam boiler. Its upper end is blocked by metal pierced with the fine hole $B$. The steam enters the lower end of this fine hole at a speed of something like I,400 feet per second, and as it passes along, expands, leaving the upper end in a jet of several thousand feet per second. When this 


\section{MECHANICAL PARADOXES.}

jet strikes an obstacle, it tends to drive it forcibly away. If a light disc, for instance, be suspended above the jet in the position shown at C (Fig. 24), this disc will be driven away and prevented from falling down on the jet at $B$.

But if, instead of being presented to the jet at some distance, as in that instance, the disc be placed quite closely over another disc, which is pierced with a small hole for the steam-jet, we get from these changed conditions a very different result. The upper disc now, instead of being repelled by the jet of steam, appears to be attracted by it. It is, at any rate, pulled down by it into close contact with the lower disc, as at E D F, so that to separate the two discs requires considerable force exerted through the strings by which the upper disc is suspended.

Now, how is it that exactly the same set of circumstances can produce two such opposite results, the only change in the conditions being the provision of a second disc for the jet to shoot through and the lessening of the distance from which it shoots against the first disc ?

In the first case, we may consider that the pipe A forms part of the boiler, and that boilerpressure in the steam extends to the inner end of the small hole $\mathrm{B}$, throughout the length of which it is continually diminishing till it comes 


\section{REPULSION AND ATTRACTION.}

down to atmospheric pressure just as it leaves the outer end of the hole.

In the second case, the outer end of the small hole is so nearly closed by the disc placed over it that the boiler may be considered as including the small hole itself, and boiler-pressure extends to its outer end, just beneath the disc at $D$. It might seem then, so far as that goes, that the upward pressure beneath the disc should be greater in the second case, instead of less, being, in fact, the boiler-pressure itself, instead of the mere flight-energy obtained by steam particles through expansion from boiler-pressure to a lower pressure.

However, the boiler-pressure beneath the disc is limited to a very small area just at its centre, where it is almost closing the small hole ; while the expansion from that area gives rise to a very different state of things in the rest of the space between the two discs.

For, just as the steam from $A$, expanding through $\mathrm{B}$, gains a rapid forward movement towards $C$, so the steam just beneath $D$, expanding laterally, gains a rapid horizontal movement outwards between the two discs from the centre towards every part of the circumference. At the centre the way upwards is blocked by the upper disc, so that the only direction in which the particles of steam can start moving as the steam expands, and gain rapid movement, is horizontally. 


\section{MECHANICAL PARADOXES.}

It is, therefore, in the horizontal direction, instead of upwardly against the disc, that the rapidly flying particles of steam can deliver a blow and exercise force. In this direction the steam's motion is strong enough to drive out and keep out the air from between the two discs, and to do this by virtue of its flying energy only, without itself exercising, except just at the centre, much fluid pressure vertically between the two discs.

Now, when the air and the air-pressure are thus removed from between the two discs, there is nothing to force them apart against the atmospheric pressure on their other sides. Upon the upper surface of the upper disc and beneath the lower surface of the lower disc, the air exerts its full pressure in the ordinary way. This amounts to almost fifteen pounds against every square inch of surface, either upwards or downwards. If the upper disc be a little more than two and a quarter inches across, its area will be four square inches, and the weight of the atmosphere pressing downwards upon it will be about sixty pounds. With similar force it is pressing upwards beneath the under surface of the lower disc, so that the two discs are being forced together by this very considerable pressure on their outer surfaces.

In between the discs, as we have seen, the air-pressure is kept back toward the circumference by the impact of the expanded steam. 


\section{REPULSION AND ATTRACTION.}

The pressure then between the discs, tending to separate them, is limited to the atmospheric pressure round the outer part, beyond the line to which it is driven back, the boiler-pressure over a very small area at the centre, and the very moderate vertical pressure of the expanded steam as it rushes from the centre outwards. These pressures, assisting one another to separate the discs, are decidedly less than the atmospheric pressure all over the outsides, tending to drive them together.

Thus the net result of the jet's action is that when the discs are originally at a distance, it is able to keep them at a distance, against a considerable force tending to bring them together, whereas, when they start together, it is able to hold them together against a considerable force tending to move them apart. 


\section{V.}

FALLACIES WITH THE LEVER.

I. The Angular Crank.

A PUBLIC benefactor, whose claim on the gratitude of the community has not been fully recognised, is the inventor and patentee. For many years now he has been repairing in thousands and thousands per annum to the neighbourhood of Chancery Lane, with his contribution to the public funds of $£$ I for a provisional specification, and $£ 3$ more for a complete specification. Sometimes he makes further donations, as fee for enlargement of time for completing, fee for amendment of specification, fee for lodging objection to other people's patents, and other special fees under thirty or forty different headings. If a patent survives four years, $£ 5$ more has to be paid to keep it alive a fifth year, $£^{6}$ more for the sixth year, and so on till $\mathrm{II}_{4}$ is required for the fourteenth year. These payments, however, beyond the first $£ 4$, are frequently not made, unless the patentee be encouraged by the receipt of royalties. No such taint of self-interest attaches to the original 


\section{ANGULAR CRANK.}

payments for taking out the patent. These are the outcome of generosity unalloyed-an offering to the Chancellor of the Exchequer which saves him from having to demand its equivalent from the general public, and so enables him to keep down our income-tax in peace time to the modest proportion of one shilling in the pound.

Of all the parts of a bicycle none has been more tempting to the inventor than cranks and crank-movements. Endless devices have been made by introducing special mechanisms into the crank to give to the foot some other than a plain circular movement, usually with the object of obtaining for the foot greater leverage against the resistance of the work. Then, to save the foot from having to take an inconveniently large sweep, it was often contrived that the pedal should return from the bottom to the top of the stroke at a shorter distance from the crank axle than that at which it descended.

One inventor, whose device the author saw exhibited at a show, considered that he had solved the problem of giving the foot greater leverage without an inconveniently large sweep, and by a method much simpler than the complicated mechanisms referred to.

His crank is shown in Fig. 25 at A B C, C being the point for the attachment of the pedal, and the position of the driving wheel 


\section{MECHANICAL PARADOXES.}

and chain being indicated by dotted lines. The distance from $\mathrm{A}$ to $\mathrm{C}$ is the length of an ordinary straight crank.

The inventor's argument was as follows: A longer crank gives a greater leverage to the foot; therefore, since the length of the crank limb A B is made greater than the distance $\mathrm{A} \mathrm{C}$, which is the length of an ordinary

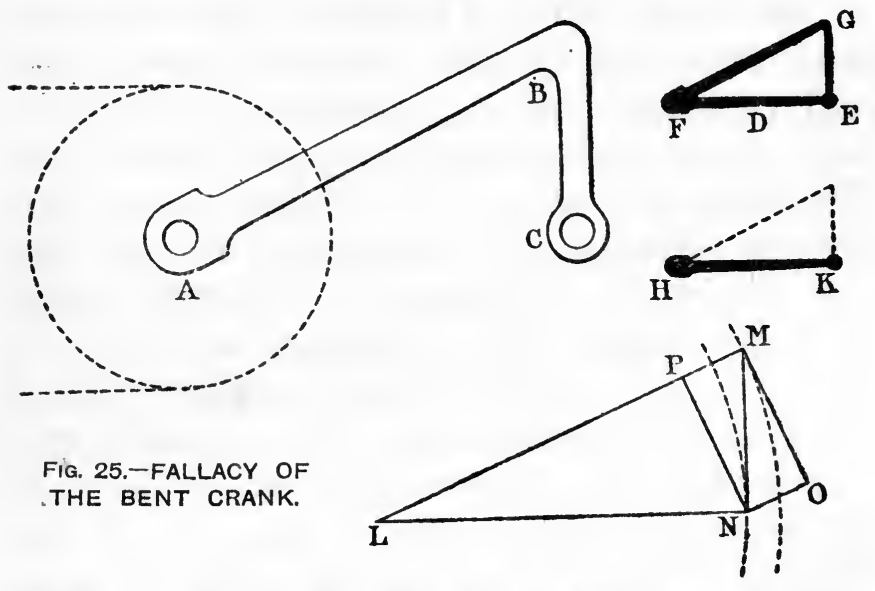

crank, a pedal placed at B would allow the foot to exercise greater turning force. But to move round a circle with the radius A B would oblige the foot to take an inconveniently large sweep; so the arm BC is fixed at an acute angle with $A B$, so that a pedal fixed at its end $C$ will be at the usual distance from the crank axle A. This shorter arm is in such a position that when the long arm is beginning the most effective part of the stroke, BC is 


\section{ANGULAR CRANK.}

vertical, and the downward pressure of the foot at $C$ is directly transmitted in full to the point $\mathrm{B}$, where it acts in turning the arm $\mathrm{A} \mathrm{B}$ just as powerfully as if the pedal itself were fixed at $\mathrm{B}$. Thus the foot at $\mathrm{C}$ gets the benefit, for the most effective part of the stroke, of the greater leverage at the greater distance A B, while actually moving round a circle with the smaller radius $\mathrm{A} \mathrm{C}$.

To those who have a little mechanical instinct, or a little practical acquaintance with the facts of mechanical work, the fallacy of this claim is too obvious to need any explanation. To most others the following consideration will show that it is not in accordance with common-sense.

The one essential which determines the leverage of a crank is its length-that is, the distance between the crank axle and the pedal, and it makes no difference to the power result what is the shape of the metal connection between the two ends so long as it is strong enough to be rigid.

It may be quite straight, like an ordinary bicycle crank. It may be $\mathrm{S}$ shaped, like the grindstone cranks in the carts of travelling knife-grinders ; or it may be solid right round the circle, in the form of a disc, as is often seen in the donkey-engines used for raising luggage on board ship. But the shape is of no consequence whatever for the power-leverage, for 


\section{MECHANICAL PARADOXES.}

which the only important point is the distance from axle to connecting-rod.

Take, for instance, the inventor's bent crank A B C. Since it is of rigid metal, C will always remain at the same distance from A. We may, therefore, add a rigid metal connection between $\mathrm{A}$ and $\mathrm{C}$, as $\mathrm{D}$ at $\mathrm{F} \mathrm{E}$, without in any way interfering with the power previously transmitted through $\mathrm{F} \mathrm{GE}$. We may then make a further modification, removing altogether the limbs F G and $G E$, since the bar $D$ will now keep $E$ in its previous relation to $F$. In other words, a straight crank $\mathrm{H} \mathrm{K}$ will have exactly the same effect as the bent crank A B C, provided the distance from $\mathrm{H}$ to $\mathrm{K}$ be the same as that from $\mathrm{A}$ to $\mathrm{C}$.

The last suggestion should appeal to those who have an eye and an imagination for mechanical truth; but for those who can follow a simple proof, that is also available.

The inventor's theory is that a force applied vertically at $C$ through $C B$ exercises a greater leverage at $B$ through the arm A B than it would do at $C$ if there were only a straight crank A C. Let $\mathrm{L} \mathrm{MN}$ have the same angles and proportions of parts as ABC. The force is applied vertically at $\mathrm{N}$ and communicated to $\mathrm{M}$ by the arm $\mathrm{MN}$, which is rigidly connected with the arm L M. There is, therefore, a vertical pressure at $\mathrm{M}$ equal to that applied at $\mathrm{N}$. Let the magnitude of the force be represented 


\section{ANGULAR CRANK.}

by the length of the line $\mathrm{MN}$. Let $\mathrm{L} \mathrm{N}$ be horizontal, and the angle L N M therefore a right angle.

Now, the force applied vertically at $M$ is not applied in the direction of turning, which is the tangential direction $\mathrm{MO}$. The whole force represented by the length of $\mathrm{MN}$ is therefore not employed in turning.

To find how much is so employed, complete the parallelogram $\mathrm{PO}$, whose diagonal is $\mathrm{MN}$, and one of whose sides, $\mathrm{M} \mathrm{O}$, is in the tangential direction-that is, the direction of turning at the point $M$, and therefore at right angles to L M. Then, by the parallelogram of forces, it is seen that the actual force applied by the foot, of magnitude and direction $\mathrm{M} \mathrm{N}$, is compounded at the point $M$ of two forces, one of direction and magnitude $\mathrm{M} \mathrm{P}$, wasted in compressing the crank L M, and the other of magnitude and direction $\mathrm{MO}$. This latter, therefore, is the portion of the foot's pressure which is employed at $\mathrm{M}$ in turning the crank, with the advantage for turning of the longer leverage.

This, of course, gives as much turning effect as a greater force employed with the shorter leverage at the point $\mathrm{N}$. How much greater would the latter have to be to produce the same turning effect as the force $\mathrm{MO}$ applied at $\mathrm{M}$ ? Obviously, as much greater as the lever $\mathrm{L} \mathrm{N}$ is less than L M. Since the triangles are rightangled, and have one of their acute angles in 


\section{MECHANICAL PARADOXES.}

common, it can be shown that they are similar, and therefore $\mathrm{L} \mathrm{N}$ has to $\mathrm{L} \mathrm{M}$ the same proportion as $\mathrm{MO}$ has to $\mathrm{MN}$. M N, therefore, is as much greater proportionally than $\mathrm{MO}$ as $\mathrm{L} \mathrm{N}$ is less than $\mathrm{LM}$; so that $\mathrm{M} \mathrm{N}$ represents the magnitude of a force which, applied tangentially - that is, vertically - at $\mathrm{N}$, would have the same turning effect as $\mathrm{M} \mathrm{O}$ applied tangentially at $\mathrm{M}$.

But $\mathrm{M} \mathrm{O}$, as we have seen, is the tangential component at $\mathrm{M}$ of the force $\mathrm{M} N$ applied vertically at $N$ and transmitted to $M$ in the bent crank L M N. Whether, therefore, the footpressure at $\mathrm{N}$ be applied directly to the straight crank $\mathrm{L} \mathrm{N}$, or indirectly through $\mathrm{MN}$ to the angle at $\mathrm{M}$, in both cases it exercises exactly the same turning effect, $\mathrm{MN}$ at the shorter leverage, or its equivalent $\mathrm{MO}$ at the longer leverage.

Yet the inventor who showed this crank was able to print recommendations from people who had actually used it, testifying to the increase of power that it had given them in their riding, so that they had been in some cases enabled by it to ride hills which they had vainly tried to mount before.

What is the explanation of this paradoxical result ?

Partly, it is that which applies to many quack remedies: more favourable circumstances at the time of trial. The machine may be a new one, more perfectly made in other respects. 
The roads may be in a smoother, harder, and cleaner condition than usual. The wind may be more helpful, and the fact not duly noted. The rider himself may be in more vigorous health.

More important, probably, than any or all of these causes is the mental state of the rider, and its influence on his bodily vigour.

$\mathrm{He}$ has become interested in the new invention. He hopes it may be a success. Perhaps he has already pronounced in its favour on theoretical grounds, is confident that it will prove a great benefit, and anxious to justify his opinion in a practical trial. Inspired by this confidence and determination, he actually is able to make more resolute and sustained efforts than ever before, and rides up a hill that has been previously insurmountable.

The remarkable influence of the mind upon the body is well known, and this is simply another instance of it. The rider does not understand that the cause of his extra strength is psychological rather than mechanical, and the inventor gets the benefit of the confusion. Let us not grudge it to him. The benefits that an inventor does get are few enough, as a rule.

\section{The Self-moving Mill.}

The last section has shown an example of the attempts of inventors to increase a man's 


\section{MECHANICAL PARADOXES.}

power without adding to it from any external source. Another favourite endeavour has been to produce power where there was none at all without bringing it from any external source. The two problems are essentially the same. To make two pounds of lead out of one is quite as hard as to make one pound of lead out of nothing at all. It is really a task of that nature that many inventors have set themselves.

The most common device for making power produce itself and maintain itself "with no visible means of subsistence" is a mill on one side of which gravity can act with greater leverage than on the other.

Fig. 26 is a diagram of such an arrangement, and represents the principle governing the design of several such devices for which patents have been taken out.

A wheel has a number of jointed spokes, the joints being capable of bending from the straight line only in one direction, so that the outer limb can hang straight down on the side on which the spokes are rising, as at A B, but cannot fall beyond the straight on the side on which the wheel is falling, as at D E. At the end of each outer limb is a weight, as at F G H. As the spokes rise on the left, the joints bend and allow the weights to hang down at a shorter distance from the centre, thus diminishing the leverage at which they act, and so reducing their turning power. When the arms have 


\section{SELF-MOVING MILL.}

descended a little below the position at $\mathrm{K} \mathrm{F}$, so that the folding half is a little beyond the perpendicular, they unfold to the full length of the straightened arm, as at $\mathrm{E} \mathrm{G}$ and $\mathrm{D} \mathrm{H}$. At this greater length of leverage, the weights have greater turning power; they overcome the weights acting with less leverage on the other side, and cause the wheel to revolve. The power beyond what is required to overcome

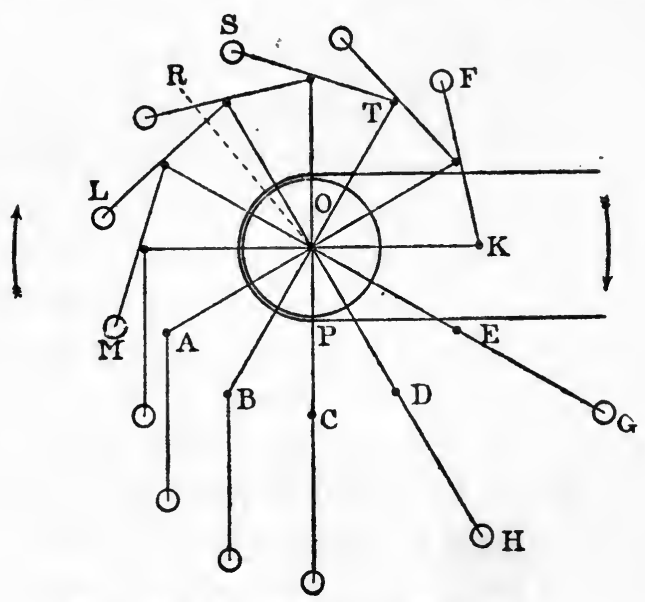

FIG. 26.-FALLACY OF THE AUTOMATIC MILL.

the friction of movement can be taken off by a drum and belt, and employed to do any useful work.

The exhibition of this scheme is enough to condemn it in the eyes of those who possess in any degree the mechanical sense.

Its logical condemnation on grounds of scientific possibility is equally emphatic. The 


\section{MECHANICAL PARADOXES.}

power of the machine is confessedly derived from the energy given up to it by each weight in the course of falling from the highest to the lowest point of its course. But in order that it may fall from the top to the bottom, it has had to be lifted previously from the bottom to the top. And in being lifted, it has received from the machine just as much energy as it gives up in falling the same distance. The weights, therefore, consume all the power which they produce, and there is none left over for doing other work by the drum and belt-none, even, for overcoming the slightest losses from friction. And so the machine cannot even turn itself round. It cannot move, and if turned by external force, will soon be stopped by friction.

But this is only a general proof that the invention must be a fallacy. It does not show just where the fallacy is. And while the inventor will not be satisfied with a condemnation on general grounds, thinking that their application by the critic is as likely to be mistaken as his own application of principles in detail, so also the amateur student of the matter has not learnt all that it is capable of teaching him until it has been shown in what particular points the inventor has misunderstood mechanical laws or has wrongly applied them.

First, then, an exaggerated view is taken of the leverage of the weights at the ends of the extended arms. The force of these weights, 


\section{SELF-MOVING MILL.}

being due to gravity, and therefore vertical, is not applied at right angles to the arms except when these are horizontal. Now the weights are never at the full length of the arms until after these have passed the horizontal position, for it is not till then that the weights overbalance and unbend the arms. But when the arms are oblique, as at R G, the weights, whose force is vertical, cannot devote it all to a tangential turning effect. It can be shown by the parallelogram of forces, as was done in the last section, that the part of their force which is devoted to tangential turning is to their whole weight in the proportion of $\mathrm{GC}$ to $\mathrm{GR}$; in other words, the leverage is not the full length of the arm, or the distance of the weight from the centre of turning, but its distance from the vertical line through this centre. And though this turning leverage $G C$, for weights at $G$, is still greater than $\mathrm{L} O$ or $\mathrm{M} P$, the turning leverage for weights at $L$ and $M$ on the other side, it is not so much so as appears to the eye when we look at the full length of the arm G R.

Secondly, it has been overlooked that the bending of the arms keeps a greater number of the weights on the ascending side, to compensate for their less leverage for turning. The weight $\mathrm{S}$, for instance, though its arm $\mathrm{O} T$ starts on the right-hand side, is itself to the left of the vertical line through $R$, and so its weight helps to prevent the left side rising. 


\section{MECHANICAL PARADOXES.}

There are, in fact, seven weights pressing downwards on the left, and only four on the right. Remembering these facts, it is easy to see that we have in the machine conditions which quite neutralise the extra leverage in the lower quarter on one side, and the inventor himself should be willing to admit that we are entitled to apply to the case the general principle that weights in descending on one side cannot produce more power than they consume in being raised the same height on the other. To expect more from the machine is as vain as to expect a bottle to yield more water than was put into it when it was filled. 


\section{PART II.}

\section{PARADOXES OF PHYSICAL STATE.}

I.

CURIOSITIES OF FREEZING AND MELTILIG.

I. Ice melting while growing colder.

SkAters know how quickly ice will melt away when the wind changes and a warm air comes blowing over it. Travellers in Arctic regions often have to obtain water for drinking by putting ice into a pan over a fire. These methods illustrate the melting of ice by applying heat to it; but it is possible to melt it without the application of heat-while, on the contrary, it is becoming colder. How is it possible to melt ice without heat? Well, the fact is that it is not melted without heat, though without the application of heat from external sources. Heat is necessary to melt it; but it is contrived that it shall be the ice itself which supplies the heat for its own melting

For ice can supply it. Although ice is cold, it is not on that account without heat. The statement that it is cold only means that it has less heat than our bodies, not that it has no heat at all. All things with which we are 


\section{PHYSICAL PARADOXES.}

acquainted have some heat, though those which we call cold have less than those which we call hot. To make ice colder, then, we must contrive to let it get rid of some of its heat.

Now, heat is a form of energy, transformable into many other forms of energy, such as light, electricity, magnetism, combination, decomposition, liquefaction, vaporisation, pressure, and movement. We see this in our steam engines and gas engines, which are merely machines for converting heat energy into movement energy. To deprive a thing of heat, therefore, is to withdraw energy from it, leaving it exhausted, or more exhausted than before, of energy. How, then, can we get things exhausted of energy?

The principle is the same for inanimate things as for men and other animals. Exertion brings exhaustion. If the doctor recommends us for our health to get quite tired once or twice a day, what we do is to work hard. It is true that some people get tired before they have done much hard work, but the principle remains true for the rest of us, and it applies equally to things.

Among other kinds of work, heat can do melting, whether of iron, lead, zinc, tallow, or wax. Let the heat of the ice then do some melting, and, for convenience, let it melt some of the ice itself.

It is not possible, however, for the heat of pure ice to melt ice, since that heat is not at a 


\section{FREEZING AND MELTING.}

higher temperature than freezing-point. To make it possible, either the temperature of the ice-heat must be raised or the melting-and freezing-point of ice must be lowered. Ice can have its melting point lowered by mixing it with salt. A mixture of water and salt requires thirty-two degrees of frost to freeze it; therefore a mixture of ice and salt can be melted by the heat of anything at a higher temperature than this. Such a thing is pure ice, which has been exposed for some time to the air: it remains at freezing-or meltingpoint, $32^{\circ} \mathrm{F}$., or zero on the Centigrade scale. At this temperature, then, it has heat enough to melt a part of its own substance when it has been made meltable at this and lower temperatures by being mixed with salt. It proceeds to melt a part of itself, devoting a part of its heat-energy to this work. Having so used up some of its heat, it has less heat left-it is colder.

How strongly ice is made to cool itself in this way is shown by the formation of a thick coat of hoar-frost on the outside of the vessel up to the level of the ice and salt inside. When a tumbler or other vessel contains ice or ice-water, dew can be seen collecting on the outside. This is the moisture of the surrounding air, condensed by the cold. But ice can never freeze this moisture into hoar-frost. Our mixture of ice and salt easily does so, for it loses so 


\section{PHYSICAL PARADOXES.}

much heat in melting itself that it reaches thirty-two degrees of frost.

When Fahrenheit first made this experiment (with sal-ammoniac) and discovered what intense cold it produced, he thought he had reached the lowest temperature obtainable. This is why that particular temperature was chosen as the zero of the Fahrenheit scale; and so, instead of freezing point being marked $\mathrm{O}^{\circ}$, as on the Centigrade scale, and boiling point $\mathrm{I} 80^{\circ}$, we have freezing $32^{\circ}$, and boiling $212^{\circ}$. We know now how great a mistake this was, since in liquid air we have 344 degrees of frost, while liquid and solid hydrogen are colder still.

Still, thirty-two degrees of frost constitute very severe cold. It is for this reason that throwing salt upon the snow is an unsatisfactory way of getting rid of it from the streets. It makes the snow meltable, no doubt, at a very low temperature, so that it disappears more quickly by melting itself. But in doing so it uses up so much of its own heat that it becomes excessively cold for the feet of passengers and horses. For we thus get its melting associated not with heating but with growing colder.

\section{Ice melted without Heat or Cold.}

There is yet a third way of melting ice : simply by squeezing it. If we were strong enough, we could take a lump of ice in the 


\section{FREEZING AND MELTING.}

hands and squeeze it into water. Not being strong enough, we must resort to mechanical pressure, and by this means it has been done.

A, Fig. 27, is a strong metal cylinder, screwed internally, and fitted with screwed plugs $\mathrm{BC}$ and $\mathrm{DE}$. $\mathrm{F}$ is a bullet, and the remainder of the space $C D$ is filled with water. The apparatus is placed in a vertical position, $B$ beneath and $E$ above, in such a freezing mixture as that described in the last section. The bullet, of course, lies at the bottom of the

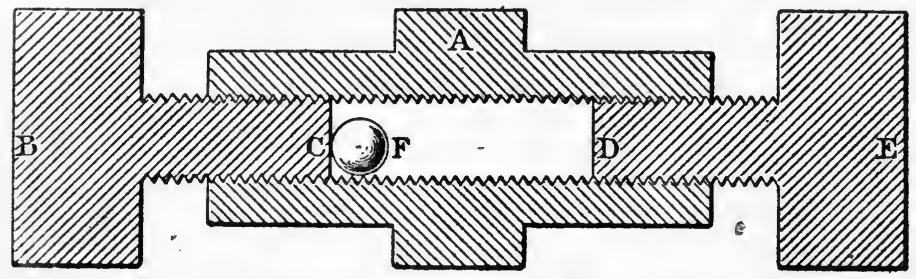

FIG. '27.-TO MELT ICE BY SQUEEZING.

water at the lower end, $\mathrm{C}$, of the space $\mathrm{F}$. When the water is frozen, the bullet is at the bottom of the ice, and will be found there if the cylinder (kept the same end up) be taken from the freezing mixture and the plug $\mathrm{B}$ be removed. Then replace the plug, and turn the cylinder the other end up, B above and $\mathrm{E}$ beneath.

Then by means of wrenches force in the plugs very hard, so as to create great pressure inside the cylinder, and keeping $B$ as the upper end, remove the plug $\mathrm{E}$. 


\section{PHYSICAL PARADOXES.}

The bullet will now be found at the end D of the ice chamber, having apparently travelled through the ice.

Replacing the whole for a time in the freezing mixture, to keep it cool, repeat these operations with $\mathrm{E}$ once more at the top, forcing in $E$, and then removing $B$. $F$ will be found to have travelled back to $C$, apparently through the ice.

The fact is that each time the ice is violently compressed, it is forced back into the state of liquid, the bullet falls through the water, and when the pressure is relaxed, the water is reconverted into ice.

That this is the case can be proved by listening carefully while the ice is under violent compression and the cylinder is turned end over end. The bullet can be heard and felt striking the bottom of the small chamber as it falls down each time the cylinder is turned over. While the pressure is on, there is, in fact, no ice ; it is compressed into water.

Ice, therefore, can be squeezed into water by the simple process of compression. This seems natural enough when we remember that water, in freezing, expands so as to occupy more space. If, then, we forcibly prevent water from occupying more space, it cannot freeze. Or if, after it has frozen, we force it back into smaller space, it must go back out of the state of ice, which requires more room, into that of water, which requires less. 


\section{CUTTING ICE.}

3. Cutting Ice without Severing the Parts.

This depends on the principle illustrated in the last section, and the experiment-a particularly pretty one-requires little and simple apparatus. First, we want a bar of ice, A B (Fig. 28), the most convenient way of obtaining which will be to make it ourselves. Get a large test-tube, about one inch in diameter; or, where that is not readily obtainable, a six-inch section of hollow brass curtainrod from which all internal roughness and burrs at the cut edges have been removed, and fitted with a cork at one end. Fill this vessel with water within an inch of the

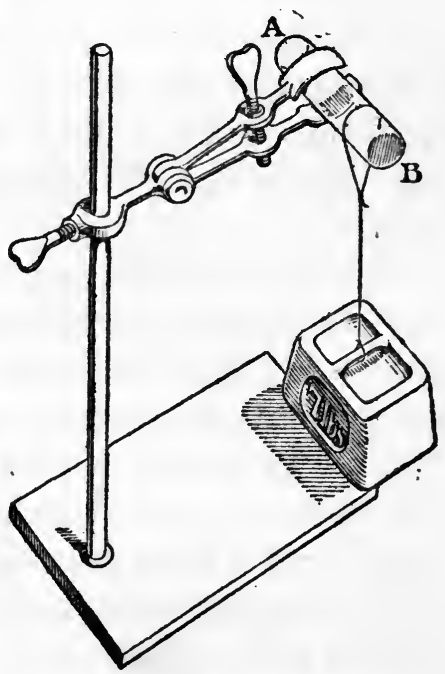

FIG. 28.-ICE RE-FROZEN ON: RELAXATION OF MELTING PRESSURE. upper end, and close with a cork. Bury it in a freezing mixture, such as that referred to in the last section but one-about eight pounds of ice, crushed up to the size of peas and beans (or of snow), mixed well with four pounds of crushed salt.

In less than half an hour the water will be 


\section{PHYSICAL PARADOXES.}

frozen solid. Take out the tube, dip it a few seconds in ordinary cold water, to melt the surface of the ice, which will be frozen fast to the tube and corks, then remove the corks, and push out the bar of ice. To get it out of the test-tube easily, a hole must be broken through the glass at the bottom, to allow air to enter as the bar of ice leaves. Fix the bar of ice horizontally by one end in a strong clamp on a retort stand. Or a round hole of the right size in an upright piece of wood will do very well.

Hang a weight of, say, seven pounds from the free end of the bar of ice by a fine wire, like that used by florists for wiring flowers, in such a way that the weight is two inches clear of the table. If the bar of ice be one inch thick, and the wire be one-hundredth of an inch, the weight of seven pounds rests upon a part of the ice whose area is the hundredth part of a square inch. That is a weight of 700 pounds, or nearly one-third of a ton, to the square incha very heavy pressure indeed.

Now we have seen that pressure alone can melt ice. Accordingly the pressure of the wire melts the ice immediately beneath it, so that it gradually cuts its way through as completely as a grocer cuts through a cheese by drawing a wire through it; but it takes a few minutes for the wire to cut through the ice.

But when the bar has been cut right through, 


\section{CUTTING ICE.}

and the weight drops on to the table, the piece of ice beyond the cutting-line is not severed, and does not fall, but remains attached, as before, to the main bar of ice-unless, that is, the experimenter is performing in public, and has imprudently announced the result to the audience beforehand. In that case the cut piece of ice is only too apt to drop down at the same time as the weight, when the lecturer and the audience are attentively watching to see it stick on.

At his next public experiment the lecturer does not explain the reason of the cut piece sticking on until it has stuck on, which under those conditions it will usually consent to do. It can then be explained as a thing that was expected with the utmost confidence.

The explanation depends on the principle of regelation, which is also seen at work in snowballs and glaciers. It has been explained that pressure melts ice. When a handful of snow is crushed together, some of the crystals are partly melted by the pressure. When the pressure is relaxed the melted ice re-freezes, and so the whole mass is to some extent bound together. Thus we get a snowball. It requires great pressure, however, to melt ice, and greater as the temperature is lower, every degree of cold requiring an enormous addition to the pressure, so that we are not strong enough to make snowballs of very cold snow, and the 


\section{PHYSICAL PARADOXES.}

time to do it is when a thaw wind has brought the snow back to zero $C$.

Similarly with the formation and flow of glaciers. The crystals beneath superincumbent masses of snow, getting warmed by contact with or proximity to the ground, are at last not too far below freezing-point for those under the heaviest strains to be partly melted by the pressure. As their yielding and taking up positions of less strain diminishes the pressure, the surrounding cold, at or slightly below zero, causes re-freezing or regelation.

So we get masses of ice beneath the surface, and movement and flow of these masses much as if they were a slow stream. This is visible in the glacier shown in Plate IV.

4. Ice unmelted in a Vessel of Boiling Water.

If a test-tube containing water be held in the flame of a spirit lamp or of a Bunsen burner, the water will in due course be heated to boiling-point, with the production of steam; but if it be so held that the flame is applied to the middle of the tube, as in Fig. 29, only the upper part of the water will be heated, the lower part remaining so cool that it is easily held by the hand while the boiling proceeds. The reason is that the heat of the flame causing the water to expand (the usual effect of heat) at the point where it is applied, makes it there- 


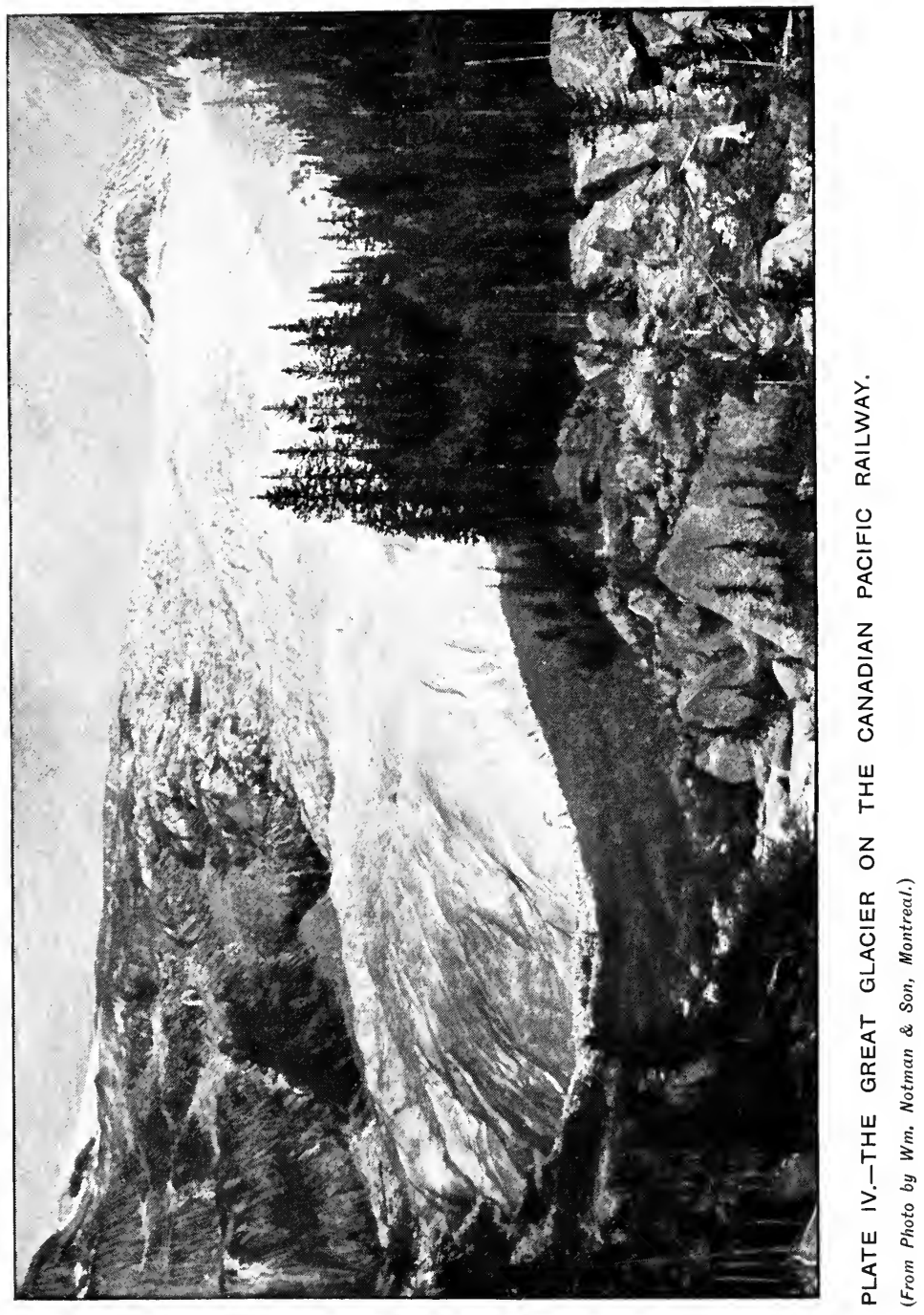





\section{CONVECTION CURRENTS.}

fore lighter. When a given quantity of water occupies, in its expanded state, more space, there is a smaller quantity of it in a given space - that is, it is lighter. The now lighter water is forced sideways and upwards by the weight of the heavier water from the top which presses

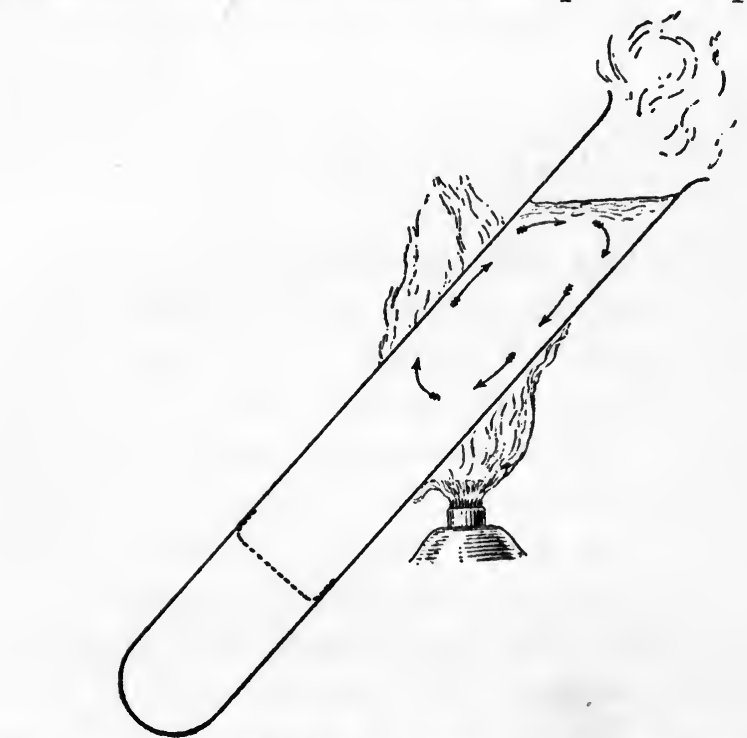

LFIG. 29.-ICE UNMELTED IN VESSEL OF BOILING WATER.

downwards under it, forcing it upwards. While the heat is applied these convection-currents are maintained, and the water keeps getting hotter until it boils.

The effect is made more striking if ice be placed in the bottom of the test-tube. Ice, however, being lighter than water, tends to float, just as the lighter water itself floats on 


\section{PHYSICAL PARADOXES.}

the top of the colder. To prevent the ice from rising, a perforated metal disc, or bundle of folded wire, or wire gauze, freely permeable to water, is placed over the ice before the water is poured in. This ice remains for the most part unmelted at the bottom while the water is briskly boiling above.

5. Expansion and its Opposite both produced by the Same Cause.

In the last section reference was made to the fact that water, like other things, expands under the influence of heat. It is only another way of saying this, to say that it contracts with cold. Water, however, expands in a very paradoxical manner, by which it is distinguished from most other substances except iron, which exhibits a similar paradox.

If a flask, filled with water, be closed by a perforated stopper, to which is fitted a long glass tube, the whole arrangement (see Fig. 30) can be made to act as a thermometer.

When the flask is heated, the heat makes the water expand and over-fill the flask. The spare quantity runs up the stem, and presently overflows at the top, clearly showing the influence of heat in causing expansion.

If now the flask be put into a vessel of ice broken small, and covered up to the neck with the ice, the temperature will rapidly begin to 


\section{PARADOXICAL CONTRACTION.}

fall again, and the water will re-contract. The colder the water gets the more it contracts, so that the water in the column, which was arranged to stand at the level $\mathrm{A}$ when we began cooling the flask, will keep sinking till it gets down to the level $\mathrm{B}$, when the water in the flask is at about $4^{\circ} \mathrm{C}$. or $39^{\circ} \mathrm{F}$. - a few degrees, that is, above freezing and melting point. Before we have cooled it to this point it would be very natural for us to think that as some cooling had caused some contraction, further cooling would cause further contraction indefinitely. This, however, would be a mistake. It would be pushing a principle too far, as did the man whose wife on Saturday night brought home a new kind of stove, which she had been assured would save half the coal. "Let's have another next week," he said, "and save it all."

As in everyday affairs, so in

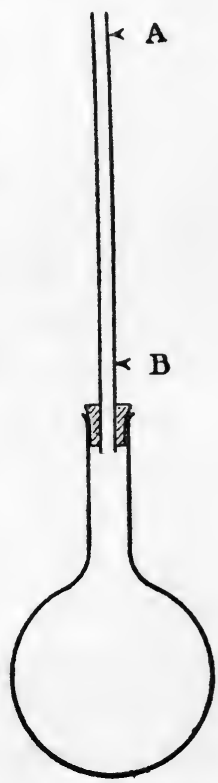

FIG. 30.-EXPANSION AND CONTRACTION OF WATER WITH HEAT AND COLD. scientific matters, it is possible to push a principle too far. It is often found that a law or principle which is almost exactly true in ordinary circumstances, requires much modification in extreme cases, and is suspended altogether when the case is so 


\section{PHYSICAL PARADOXES.}

extreme as to be practically one of a different kind. The solidification of water in the act of freezing is a case so extreme as to be a process of a different nature from the previous contraction of the water under a temperature which, though falling, was still higher than that at which it freezes. Freezing, in the case of water, appears to be the formation of crystals in which the molecules are arranged in rigid formations at a greater distance from one another than they occupy in the liquid. Thus the ice occupies ro per cent. more space than the water out of which it was formed.

It appears that, before the water is cold enough for actual freezing, there sets in, at about $4^{\circ} \mathrm{C}$., a preliminary process in which the molecules are already tending, with a force continually increasing as the temperature falls, to arrange themselves in the new formations which require more room. Consequently, the water expands progressively as it cools from $4^{\circ} \mathrm{C}$. to $0^{\circ} \mathrm{C}$., and then at the latter temperature undergoes a much greater expansion in freezing.

Thus we get the very curious and paradoxical result that; starting with the water at $4^{\circ} \mathrm{C}$., or $39^{\circ} \mathrm{F}$., and its level at B in the tube of our flask (Fig. 30), it will not matter whether we heat the water or cool it; in either case it will expand, and the column in the tube will rise towards A. 


\section{PARADOXICAL CONTRACTION.}

If we start from $4^{\circ} \mathrm{C}$. with the water-level at the top of the tube, at one time heating the flask up to boiling point, and at another time cooling it till the water within is all frozen, and in each case roughly measuring the amount of expansion by collecting the water which overflows from the top of the tube through a rubber connection, we shall find that by simply cooling it four degrees from $4^{\circ}$ to zero C., and then freezing it at the latter temperature without cooling it any further, we shall cause it to expand about twice as much as by heating it ninety-six degrees from $4^{\circ}$ to $100^{\circ} \mathrm{C}$.

The paradoxical manner in which water both contracts and expands with cold, is a matter of the greatest importance to human and animal life in temperate and arctic climates. It causes the cooling in winter of the water in lakes and ponds down to the temperature of $4^{\circ}$ C., saves them from getting colder, and limits the freezing to a comparatively thin layer at the top. The influence through which these results are obtained is the action of convection-currents similar to those described in the last section, but operating this time in an exactly converse manner. There we had them heating all the water above the level at which heat is applied-that of the flame; here we have them cooling the water below the level at which cold is applied-namely the surface of the pond. 


\section{PHYSICAL PARADOXES.}

Let Fig. $3 \mathrm{I}$ represent a section through a pond. The water on the surface A, exposed to cold east winds, or radiation into a clear sky, is cooled. Cooling makes it contract and become heavier than the rest, so that it sinks and forces the lighter warm water to the top. The cooled water becomes slightly warmed by contact with the ground at the bottom, $\mathrm{BCD}$, while the water now at the top be-

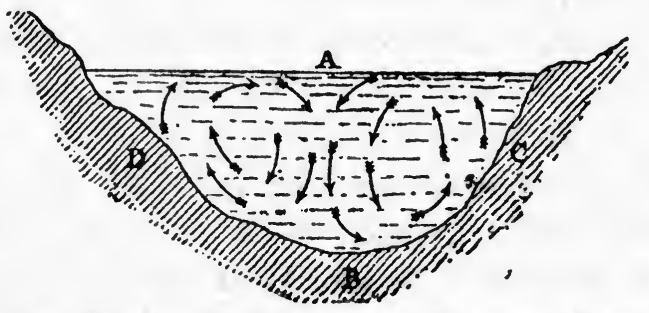

FIG. 31.-CONVECTION-CURRENTS IN WATER. :

comes as cold as that which was originally there, and in time colder. It is therefore now the heavier, and sinks in its turn, driving the other up again. Thus are maintained the convection-currents which keep quietly circulating until the water is all cooled down to $4^{\circ} \mathrm{C}$.

What happens then? The top layer, which gets cooled below $4^{\circ}$, ceases, as we have seen, to contract, and begins to expand again, as it gets colder. But expansion makes it lighter. The same quantity occupies more space. The same space, therefore, contains a smaller quantity or weight. Thus the water cooled below 


\section{PARADOXICAL CONTRACTION.}

$4^{\circ}$, instead of having any tendency to sink, floats because it is lighter than the rest. It therefore remains at the top, getting colder and lighter still. The convection-currents cease when once all the water has been cooled to $4^{\circ}$.

The top layer of water thus being unchanged, and so being unceasingly acted on by the cold wind and sky, is more rapidly cooled down the few remaining degrees to freezing point, and then begins to freeze, while the bulk of the water beneath it is not cooled below $4^{\circ}$. The water having in the act of freezing expanded much more than in cooling down to freezing point, the ice so formed is lighter in a still greater degree, and floats very strongly. So we get from the paradoxical way in which water and ice expand with cold the limitation of ice to the upper layers, and the freedom from severe cold of the water beneath it.

Now, what would happen if water, like other things, went on contracting indefinitely with increase of cold? In the first place, the convection-currents would not be checked, and would promote the cooling of the water till it was cooled down to freezing point right through to the bottom. Secondly, the formation of ice being accompanied by still greater contraction, the ice would be heavier than the water, and therefore as fast as it was formed it would sink to the bottom. The ice formed later would sink in its turn and accumulate above that 


\section{PHYSICAL PARADOXES.}

which preceded it until the whole of the water in the pond became one great block of ice.

It is easy to see that this would result in the total destruction of the fish, which are at present able to live in the water beneath the ice. Moreover, it would be impossible for men and their cattle to inhabit countries liable to severe winters, because of the lack of water. All the water would be frozen solid, whereas the paradoxical expansion to which it is liable limits the freezing, as we have seen, to the surface, and keeps the water in a fluid state beneath, where it can be got by breaking holes through the ice.

To the welfare of man and animals, therefore, this curious irregularity in the expansion of water is a matter of the greatest moment.

6. Strong Vessel burst by cooling Water in it.

It has been mentioned already that in the act of freezing water expands to such an extent as to occupy as ice ro per cent. more space than it occupied as a liquid. This expansion takes place in a very forcible manner, so that even strong iron vessels can be burst by this means. A method of testing this point experimentally, which admits of being worked on a small scale, and easily and repeatedly, is shown in Fig. 32. A strong little steel cylinder, with a central chamber $\mathrm{A}$ and $\mathrm{a}$ hexagon head $\mathrm{B}$, 


\section{FREEZING AND FORCE.}

is filled quite full with water. A small disc of thin copper sheet, $\mathrm{C}$, is dropped into a recess turned out of the upper end of the cylinder, and so held central. Over the disc is placed a strong ring-washer, D, of brass or gun-metal, to transmit pressure from the hexagon nut, E, which screws on to the cylinder. The hexagon nut has a hole drilled through it corresponding to that in the ring-washer, so that the middle of the outer surface of the copper disc is visible through ring-washer and nut.

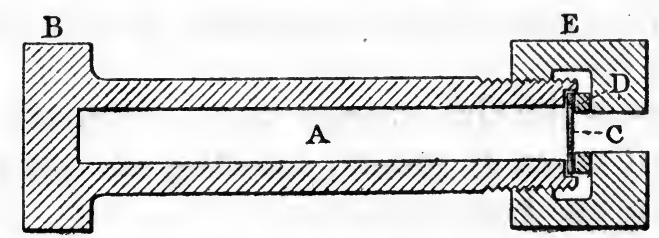

FIG. 32.-BURSTING FORCE OF WATER FROZEN IN CONFINED SPACE.

By screwing up the nut, the disc can be squeezed very hard between the cylinder and ring-washer, so that the chamber in the cylinder is hermetically sealed.

When the chamber is thus closed, full of water, without a bubble of air, the whole is placed in a freezing mixture such as that already described (two parts of pounded ice or snow to one of salt), which nearly covers it, leaving just the open end of the nut visible.

The cylinder, with the water inside, is soon cooled down to freezing-point, and below it. 


\section{PHYSICAL PARADOXES.}

The water tends to freeze; but as this involves the arrangement of its molecules in positions corresponding to its rigid, crystalline, or solid state, in which their distances from one another are increased, the whole mass would have to occupy more room, to permit of freezing. As more room is not available, freezing cannot occur. But with the increasing cold the molecules, in their tendency to take up the new arrangement, keep pressing against one another and against the walls of their prison with continually increasing force, until at last they burst the enclosure at its weakest part.

This is the thin copper disc. A smart report is heard when it yields, showing the force with which it has been ruptured.

The chamber having now been forced open, the molecules have room to re-arrange themselves in a crystalline form, and the water is suddenly converted into ice, with which the whole chamber is filled, while the excess quantity (its volume being greater than that of the original water) is forced out through the hole in the copper disc in the form of a long slender column of ice, which projects through the hexagon nut.

The same results can thus be produced by opposite causes. If we heat water hot enough in a strong iron vessel, we burst the boiler through the formation of steam. If we 


\section{FREEZING AND FORCE.}

cool it sufficiently, again we burst the vessel through the formation of ice.

The expansive force of freezing water plays an active part in the destruction of mountains. Water from rain or melted snow lodges in the crevices, and then on exposure to severe cold freezes with an expansive force which splits the rock as thousands of wedges might.

On a smaller scale the bursting of our water pipes is an instance of the same force. When a column of water is securely held between two taps, if the pipes are strong enough to prevent it from expanding, it cannot freeze. But if the expanding force be the stronger, the pipes will either stretch or burst. Water does not leak until a thaw comes, so it is not till then that the bursting is discovered, though it occurred during the frost. 
CURIOSITIES OF STEAM AND VAPORISATION.

I. Strong Vessel burst by heating Water in it.

OUR last experiment was the bursting of a strong vessel by cooling water inside it till freezing took place. The paradox here is that the opposite condition, the heating of the water, will produce the same effect.

The fact is only too familiar, as illustrated by the bursting of steam boilers, but it may be illustrated in a more convenient way than that-we need not imitate the ingenuity of Charles Lamb's Chinaman, Ho-ti, who invented the art of burning down a cottage to procure roast pig. Further, it is desirable to consider by what agency, in detail, an opposite cause can produce a similar effect.

First, then, for the experiment. If it be desired to show in the laboratory the bursting power of heated water, it will, of course, be necessary to take care that the burst can do no harm. For this purpose it will be best to have one part of the vessel made much weaker than the rest in order that it may certainly be the part to burst, and may be directed so that the explosion can hurt no one. For this purpose the strong iron cylinder closed by a thin 


\section{STEAM AND VAPORISATION.}

copper diaphragm, as arranged for the last experiment, will do very well. When the water is heated its expansion will burst the copper covering, just as that of the forming ice did, and the rapid formation of steam will be harmless if the opening is properly directed.

If, however, the chamber be only threequarters filled with water, the diaphragm will then be burst, not by the expanding water, but by the expansive force of steam, and both forms of explosion can be shown by the same apparatus. In the latter case, to ensure a good explosion if the heat be weak or if the quantity of water in the chamber be by accident very small, a diaphragm of thin indiarubber sheet may be used instead of copper. It will also save the confidence of a nervous experimenter, while making hardly less noise.

How, then, does heat, applied to water, produce explosive force?

Heat is mechanical energy developed in extremely small portions of matter, and closely associated with the other forms of minute mechanical energy which we know as electricity and light. The smallest particles into which we can divide substances without altering their chemical nature are called molecules, and heat may be briefly described as molecular vibrations. That some of the heat vibrations are internal to the molecules, and are to be classed as atomic vibrations, is shown both by 


\section{PHYSICAL PARADOXES.}

the convertibility of heat into and out of the chemical activity of atoms, and by the possibility of heat becoming latent; but manifest heat must be classed for the present as some undetermined form of vibrations of molecules.

These vibrations are enormously energetic, more energetic in a hotter body, and less so in one which is colder. In a body which is at a white heat the molecules are vibrating at the rate of more than six hundred millions of millions of times in a second.

In a solid we may suppose that the molecules are so closely packed, and have, comparatively, so little vibrating energy, that their mutual attractions hold them fairly rigidly in fairly fixed positions. This is only generally true, for it has been found that molecules of even very dense solids have some power of migrating. Still, we must accept it as generally true.

Now when the solid is made hotter, that means that its molecules, probably by the impact of more vigorously vibrating molecules of some other substance, such as a burning gas, are made to vibrate more energetically. They therefore strike one another harder blows, and so drive one another further apart. Thus we get the familiar phenomenon of the expansion of substances under the influence of heat.

Suppose the substance be a lump of wax, and let it be made hotter still. That means 


\section{STEAM AND VAPORISATION.}

that its molecules vibrate still more energetically, hit one another harder blows, and drive one another still further apart. The time comes when their vibrations are so energetic and their distances from one another so much increased that they are able to take that definite step in overcoming their mutual attraction which places them in a position of comparatively independent movement. They can move over and past one another with easy friction, almost with no friction. Their comparative rigidity in fixed positions is entirely gone. The substance is a liquid; the solid has melted under the influence of heat.

Next take a liquid, and make it hotter. Suppose it to be water in a closed boiler or cylinder such as we are taking for our experiment. The increasing heat means increasingly vigorous vibration of the molecules, until the blows they deal one another are so violent that some of those on the surface of the liquid are thrown off into the space above, through which they bound and rebound with great speed and energy, striking against the inside walls of the cylinder and frequently against one another. This is the state of a vapour, which very much resembles that of a gas. If a locomotive boiler were magnified to be of the size of the world, and all the molecules of steam within it in the same proportion, they would seem like india-rubber balls flying freely in all directions, 


\section{PHYSICAL PARADOXES.}

frequently clashing against one another and bounding against the inside of the walls of the world-wide boiler which contained them.

We are now able to understand how such a light and apparently unsubstantial thing as steam can exercise so heavy a pressure. It is the effect of the incessant bombardment by the swiftly-flying molecules.

If a boy throws a stone against a barn-door which is standing loosely open, he produces no effect beyond damaging the paint. But if a thousand boys each throw one stone per second, and every stone hits the door on the outside, this shower of stones, at the rate of a thousand per second, will exercise a steady pressure on the door which will easily close it.

This is how the molecules of water in the form of steam make a strong pressure upon the inside of the boiler. They are individually small, but they deal many million blows per second upon every square inch of the boiler's surface : thus the total pressure is great; and, as we know, the greater the heat-that is, the more violent the vibrations-the swifter the flight, and the harder the blows of the molecules, the greater the pressure of the steam.

\section{Explosion or Collapse?}

A lecturer is demonstrating with a glass flask steaming over a flame. Presently he pours 


\section{STEAM AND VAPORISATION.}

some cold water over it, and before long there is a loud bang and a cloud of steam, the flask is shattered, and hot water and broken glass fly for yards in all directions. An audience would unhesitatingly pronounce it " another good explosion."

The experiment in question is really no explosion at all, though it so well simulates one.

A little water is boiled in a glass flask, until the steam has been briskly issuing for a few moments. We saw in the last section how the rapid movement of the molecules of steam constitutes a source of powerful energy. The steam is able to drive out all the air from the flask, overcoming the atmospheric pressure of fifteen pounds to the square inch.

When the air has been all expelled, close the flask with a rubber or good cork stopper. But do not make the mistake of doing this while still holding the flask over the flame, otherwise steam will continue to be generated, and soon there may be a very real explosion, and at a very inconvenient moment. The time to close the mouth of the flask is just after removing it from the flame, while the heat of the glass is still causing the formation of steam. Then the closing should be done quickly, before condensation of steam allows any air to re-enter. The glass will safely stand the moderate pressure of any steam generated after removal from the flame. 


\section{PHYSICAL PARADOXES.}

When the flask is closed, place it in any convenient holder, as in Fig. 33, and wait a few moments. The surrounding air, which, in comparison with boiling water, is cool, soon condenses some of the steam inside, and cools the

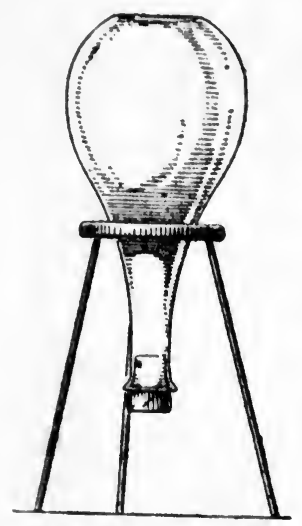

FIG. 33.-COLLAPSE OF FLASK UNDER ATMOSPHERIC PRESSURE. rest. This means that the molecules are darting about with less vigour, striking less forcibly the inside of the glass, and so exercising less pressure upon it. But the pressure on the outside remains the same as ever-nearly fifteen pounds to the square inch, many hundreds of pounds altogether over the whole outer surface. This is now unbalanced by the diminished steam pressure on the inside, and the flask may collapse, with the results already described.

The reason of the loud noise is that the air outside the flask, powerfully pressing inwards, rushes, when the flask collapses, towards the centre, where it meets together from all sides with a violent shock. The reason why glass flies for some distance is that some pieces, driven in forcibly towards the centre, happen to meet none coming in the opposite direction, and so fly far past the centre outwards on the opposite side.

If the flask be of thin glass, and the bottom 


\section{STEAM AND VAPORISATION.}

fairly broad and flat, it will collapse with a moderate reduction of pressure on the inside. But a round shape is stronger, and if the flask be well rounded at the bottom, or of thick strong glass, it may be necessary to secure a good difference of pressure by getting a considerable vacuum through a more complete condensation of steam. To effect this the flask can be placed in any convenient holder and a quantity of cold water poured over it.

Many a flask is, of course, strong enough to stand a complete vacuum inside, and then it becomes necessary to break it by a smart blow with a hammer or other hard instrument.

We still have the loud noise and flying glass and water, while the fact that the steam has been condensed with cold water shows that the result cannot be an explosion.

3. Water boiled by Cold instead of by Fire or Flame.

The simple apparatus for the last experiment will serve to illustrate another striking paradox. But this time we want neither collapse nor explosion, so the flask should be one that is rounded all over except at the neck, and of rather stronger make, and the water should half fill it, instead of being only about half an inch deep.

Boil the water, and, as before, close the 


\section{PHYSICAL PARADOXES.}

flask while steam is briskly issuing, so that when the steam is condensed there will be no air in the flask.

By the time that the flask is placed in the holder, the water will have left off boiling briskly. Pour water freely over the steam space, and brisk boiling will re-commence. The boiling will cease or re-commence as we cease or resume the pouring of cold water over the flask; and this will go on for some time, till the water is too cold to boil at all.

This paradoxical effect is due to the fact that the temperature at which liquids will boil depends upon their pressure. When first the flask is closed the pressure inside it is more than equal to that of the atmosphere, since the steam has been able to drive the air out and keep it out. Against this atmospheric pressure the molecules on the surface of the water cannot jump off into the space above, taking the form of steam, without constantly receiving energy of vibration from the hot flame; and so, when the open flask is removed from the flame, boiling ceases. But when the flask is closed and the steam is condensed by pouring cold water over the flask, the pressure inside is much reduced, and against this reduced pressure the vibration energy of the molecules is still great enough to enable them to jump off without the assistance of external energy. In other words, the water can boil without a flame. 


\section{STEAM AND VAPORISATION.}

We must apply cold to the steam instead of heat to the water.

By this arrangement.it is the heat-energy of the water itself instead of that of the flame that is doing the boiling. But if the heatenergy of the water is used up in converting many of its own molecules from the comparatively quiet state of liquid to the extremely energetic condition of vapour, there must be much less heat left in the water when the operation is over. And this is, in fact, bound to be the case. When the process has been carried on till boiling has very nearly ceased, the water is cool enough to be handled without the least discomfort.

This result, however, is open to the remark that, since cold water has been liberally poured over the outside of the flask, running down over and under it, no wonder the water in it is cold! That this criticism is unmerited can be made clear by arranging the experiment in a new way, which has other advantages also.

Fig. 34 shows an arrangement of two similar flasks which can be closed by one double-ended stopper pierced by a communicating tube. This tube can have its long end kept above the surface of the water in either of two positions by being bent in the manner shown in the diagram, and kept bent, if it be an indiarubber tube fitting over the projecting end of a glass or metal tube 


\section{PHYSICAL PARADOXES.}

which pierces the stopper, by passing a piece of bent wire along it.

If the water be boiled with the flasks in the position shown at $\mathrm{A}$, the steam will clear out the air from both
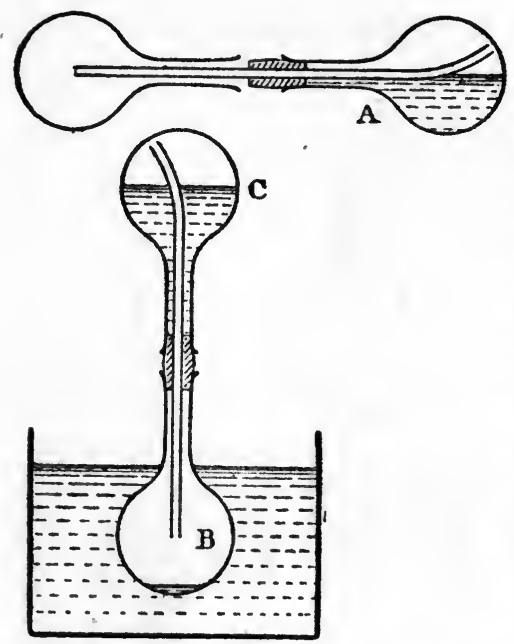

FIG. 34.-WATER BOILED BELOW BOILING HEAT UNDER REDUCED PRESSURE. flasks, which can then be connected and placed in the position $\mathrm{B} \mathrm{C}$.

$B$ forms a better condenser than the usual upper half of the hot-water flask, giving more area and a steadier application of cold, and thus producing brisker boiling. $\mathrm{C}$ gives a clearer view of the boiling, as there is no water pouring over it. And the condensing water lies under no suspicion of having helped by contact to produce the remarkable cooling of the water in $\mathrm{C}$.

\section{More Cooling with less Cold Water.}

If the man in the street (without whose assistance no speech or book would now be complete) were asked which would be the 


\section{STEAM AND VAPORISATION.}

colder-a substance kept quite under water, or one out of the water but kept wet with it, he would probably decide for the former. $\mathrm{He}$ would be wrong, as he has often been before.

The point is illustrated in Fig. 35, which represents the lower part of two thermometers, one of which has its bulb in the water, while the bulb of the other is just above the water, but is kept moist by some cotton wool or wick, which is tied round, above and below the bulb, and allowed to dip into the water beneath.

The thermometer A always indicates the lower temperature of the two in steady weather.

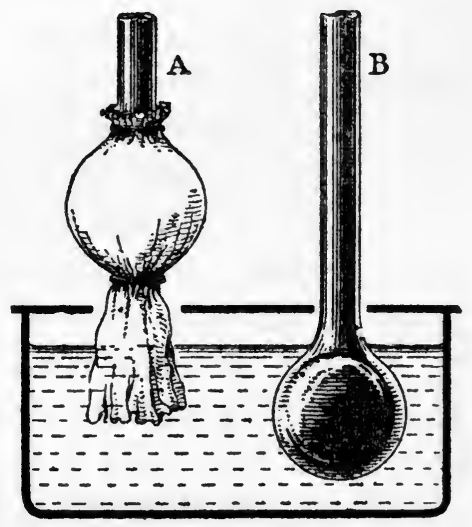

FIG. 35.-VAPORISATION DEPENDING ON DRYNESS OF AIR: THE HYGROMETER.

This effect depends upon the principle which we noted in the last section, that it requires heat-energy to convert water into vapour, and consequently the water which is supplying the heat necessary to vaporise a part of itself is thereby cooled.

In steady weather the water in the cistern of our illustration is practically at the same temperature as the air, and that is the temperature 


\section{PHYSICAL PARADOXES.}

indicated by the thermometer $\mathrm{B}$, of which the bulb is covered by the water.

But the bulb of the thermometer $A$ is covered by absorbent material which capillary attraction keeps moistened from the cistern. With so large a surface exposed to the air, it affords great opportunity for vaporisation, and in dry weather a good deal of water vaporises from the moist covering of the bulb. The performance of this vaporisation requires heat, which is supplied by the water itself in the act of vaporising, just as it was in the last experiment by the water boiling without a flame. Consequently the film of water in the porous covering all over the bulb is considerably cooled by having its heat used up in this way; and so this thermometer indicates a lower temperature than the other.

When the air is already well saturated with water vapour, or, as we commonly say, quite damp, drying from the bulb takes place more slowly, less heat is used up in the process, and so the water in the bulb-covering is less cooled, and thermometer A does not show a much lower temperature than $\mathrm{B}$.

Thus the difference between the temperatures of the two thermometers indicates the dryness of the air : when the difference is greater the air is drier, when the difference is less the air is damper.

Such an arrangement of two thermometers 


\section{STEAM AND VAPORISATION.}

for the purpose of measuring the dryness of the air is called a hygrometer, and is frequently placed in parks for public observation. The hygrometer, however, has its bulb B exposed to the air instead of being covered by water; and thus it more quickly takes the temperature of the air for comparison with the other thermometer.

We have placed the bulb in water in order to illustrate the paradox that a thing which is sunk in cold water may be less cooled than one which is in the air and only wetted by the water at a distance. 


\section{III.}

\section{CURIOSITIES OF HEAT CONDUCTION.}

\section{A Vessel too Hot to boil Water.}

IF a saucepan in which water is boiling on the fire be emptied, and a few fresh drops of cold water put into it, the heat of the pan quickly dries up the water-that is, converts it into steam or vapour. If, then, the pan be kept on the fire till it is much hotter than when it had the boiling water in it-till it is, in fact, red hot-and when it is in that condition a few drops of cold water are put into it, we might expect that they would flash into steam instantaneously.

At this point, however, it is well to remem ber that an objection will be lodged by the kitchen authorities to a proceeding which involves making a saucepan red-hot, an objection which is likely to be sustained, on appeal, by the higher court. We had better begin, then, from the beginning, with a professedly scientific piece of apparatus.

The vessel for the experiment may be a small dished plate, of section such as is shown in Fig. 36 at A. It should be of good conducting metal, silver or copper (it is less liable to get lost when left lying about if of copper), and 


\section{HEAT CONDUCTION.}

we are less likely to have to explain to beholders why the water did the opposite of what we had prophesied if we keep the upper surface smooth and bright.

Let the copper dish, supported on a convenient frame, be heated red-hot, and then let a few drops of cold water be carefully poured upon it. Instead of flashing instantaneously into steam, the water will rest on the dish in the form of a flattened globule or
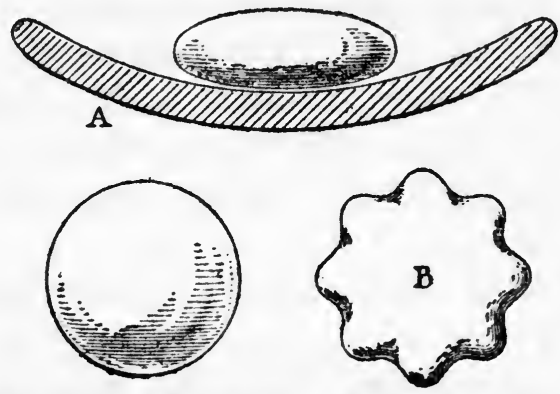

FIG. 36.-WATER IN SPHEROIDAL STATE ON RED-HOT METAL. spheroid, from which this state of matter has been called the spheroidal state.

Sometimes the globule is horizontally quite round, sometimes of the indented formation shown at B, sometimes its form varies, and sometimes it spins slowly round.

Why does the water, so close to the excessively hot dish, and surrounded by the rising flame from a large Bunsen, not flash into steam at once, but rest in its place for many minutes before it has slowly dried away? 


\section{PHYSICAL PARADOXES.}

The fact is, quite literally, that the dish is too hot to boil the water. It is so hot that before the water can quite touch it, its heat vaporises some of the water off the nearest surface and keeps it in the condition of vapour next the water and of gas next the dish. Thus there is a thin layer of gas and vapour between the water and the dish. The two never come into actual contact, because of the intermediate cushion on which the water rests.

Now, gases and vapours are very poor conductors of heat. Consequently the heat of the dish, great though it be, cannot get through this non-conducting cushion quite fast enough to boil the water, and only slowly vaporises it.

The water, being unable to get within molecular distance of the copper, cannot suffer capillary attraction from it, as from things which it wets; and so its shape is left to be determined by its surface tension and weight, as with quicksilver on things which it does not wet.

Hence very small drops assume an approximately spherical shape, while larger masses are flattened by their own weight into the spheroidal form which, as we have seen, gives its name to this condition of matter.

A very simple and very efficient apparatus for demonstrating the spheroidal state is a penny beaten smooth and slightly concave by 


\section{HEAT CONDUCTION.}

a round-faced hammer, and placed upon a redhot piece of iron which will maintain its supply of heat.

\section{Dipping the Hand into Molten Lead.}

It has been credibly stated that our present king, on one of his visits a long time ago to our seats of industry, had the courage to dip his hand into a vessel of molten lead. Whether this be true or not, the experiment is one which can be, and has not rarely been, performed without injury.

Water boils at $2 \mathrm{I} 2^{\circ} \mathrm{F}$, and if the hand were dipped for the briefest moment into boiling water, the result would be terrible pain and the most serious injury. The temperature at which lead melts is 400 degrees higher than that of boiling water. How is it that contact with it can be less dangerous?

The explanation is very much like that given in the last section, of the spheroidal state of water.

The heat of the lead vaporises the moisture in the skin, turning it into a kind of glove of steam-gas, which is a very bad conductor of heat, so that the heat of the lead is not very rapidly conducted to the skin. The skin itself has an outer insensitive portion which can, without pain, sustain excessive heat for a very short time, before its conduction through to 


\section{PHYSICAL PARADOXES.}

the sensitive nerves beneath. If, then, the hand be removed before the heat has had time to get through the layer of steam-gas and the outer layer of the skin, no unpleasant results will follow.

Observe that for this experiment the hands must be moist. They must therefore be carefully cleansed from all greasy matter, so that water afterwards may wet them well and adhere to them all over.

It is, perhaps, not necessary to add a further caution against keeping the hand in the molten lead too long. It will require, after all, a very short time for the heat to get through the vapour protection and produce destructive effects.

\section{Walking over Red-hot Stones.}

Plate VI. illustrates a ceremony which has its analogues in various parts of the world, but has been especially developed in the islands of the South Pacific. A personage with a semisacred reputation, half medicine man, half priest, seeks to maintain or add to his renown as a possessor of supernatural powers by showing what he can do.

A shallow pit is dug, stones and wood are collected, and the wood is kindled some hours before the performance (see Plate V.) Some of the stones become red-hot. They are poked 


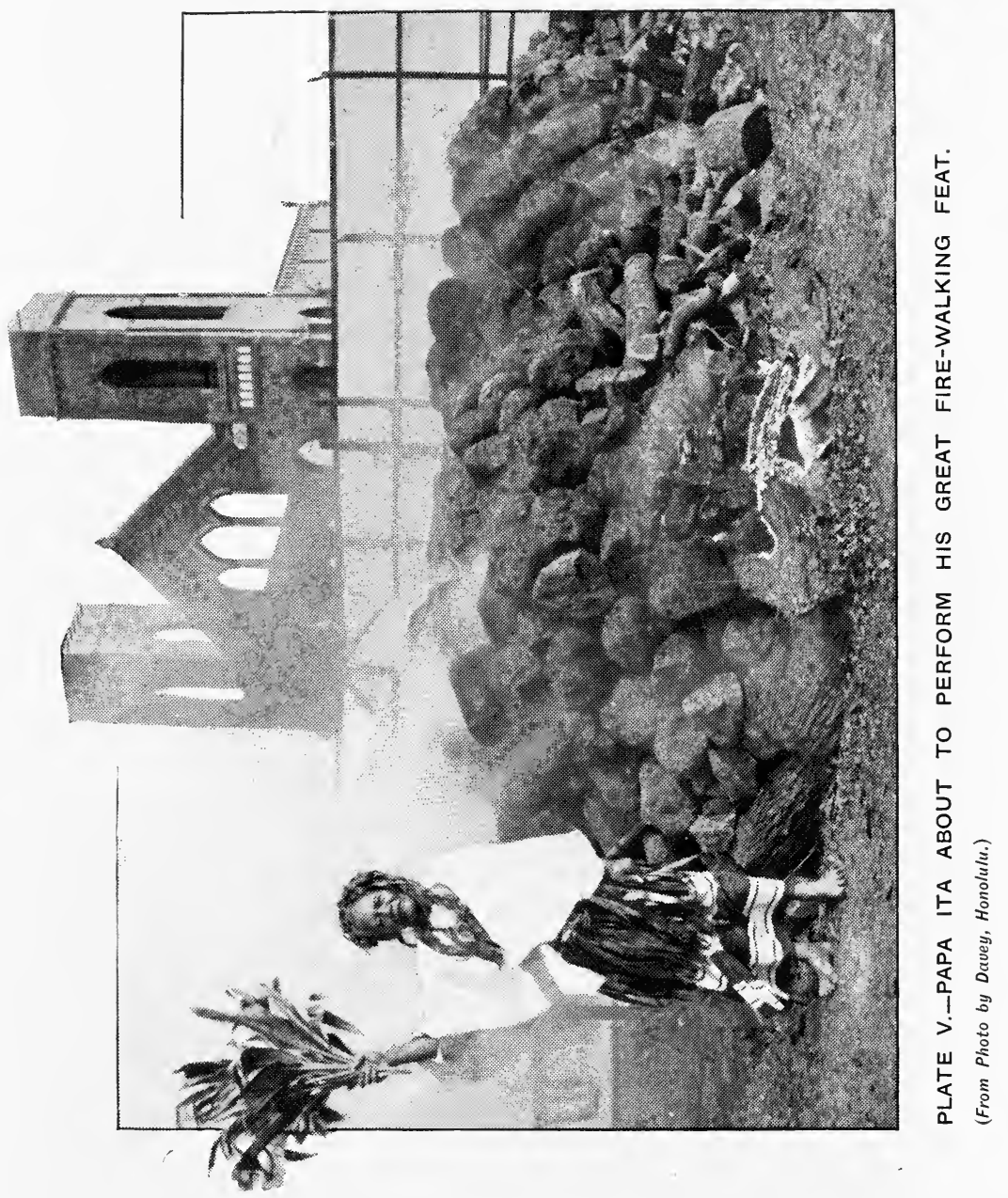





\section{HEAT CONDUCTION.}

about and turned over with green branches of trees, which, in being charred, make a great smoke. After a considerable time the performer advances barefooted at the head of a procession in single file, which contains a number of his disciples, who, under the protection of his magic, hope to be enabled to follow his example. On reaching the stones he proceeds to walk over them, picking his way, the first time, in a gingerly manner, with evident caution. His disciples follow, with more haste. The return journey is made with more confidence and deliberation. Lastly, a good many of the onlookers who are not professional performers or in training to become such, skip on and off the stones in an irregular way-not, however, trusting themselves, as a rule, too far out of reach of the ordinary earth.

The performance, as seen for the first time by strangers, is sufficiently astonishing. They feel that at any rate they have witnessed something which is worthy of investigation.

But from the observations of those who have gone to see the proceedings, not simply for the sake of getting a thrill-a state of mind which often leads to experiencing one without good cause-but with a definite intention of learning the truth, the following facts transpire.

The whole ceremony is well stage-managed, with a view to creating astonishment. The size of the fire and the length of time that it 


\section{PHYSICAL PARADOXES.}

burns create a great impression of its fierce heat. This is emphasized by the turning over of the hot stones, the view of the red-hot ones underneath, and the smoke from the singeing of the ends of the branches which are poked through the interstices to the hotter stones at the bottom.

During these proceedings much time is allowed for the upper stones to cool. The performers walk over the red-hot stones-not on them, but on those above them which are not red-hot. There is no unnecessary delay, no lingering in their movements; they do not dwell upon the situation. Civilised spectators, passing over some of the same stones immediately afterwards, find that the leather of their boots is not scorched. Natives, who are not performers, poke the same stones about with their naked feet.

We know further that, as we saw in the last section, a moist skin can endure very severe heat for a very short time without injury. While one foot is on a hot stone, the other is in the air undergoing cooling by evaporation of its moisture. The heat which may, nevertheless, be penetrating deeper into the skin, may just be short of being unbearable by the time the crossing is complete. The foot may occasionally get on to a stone which is really too hot; it will be quickly taken off again, and that stone will be avoided on the return journey, and meantime the suffering of pain may be 


\section{HEAT CONDUCTION.}

concealed. The performances of dervishes and other fanatics show that in the cause of imposture, as well as in that of faith, much pain can be stoically endured.

Putting these considerations together, and dwelling especially on the fact that the heat of the stones actually trodden on is not immediately destructive to leather, we may come to the same conclusion as careful observers of the ceremony, that though it embodies a striking combination, it includes nothing which is outside the laws of nature. 
IV.

CURIOSITIES OF VAPOUR JETS.

I. Passing the Hand through a Live-Steam Jet.

THE fingers of the hand may be passed rapidly, but without rude haste, in succession through a small jet of live steam close to the orifice from which it is issuing.

This steam is as hot as boiling water, as hot as the scalding steam from a kettle-spout. Why does it not scald?

In the first place, it is true steam-a vapour so hot as to be approaching the nature of a gas, not a partially condensed vapour, like the visible steam from the kettle, which consists of little droplets of liquid water, that can cling to and collect on the hand, wet it, and so impart to it by conduction the great specific heat which it possesses as water.

Some steam boilers have a hole cut in the side and fitted with a glass window to permit an observer to view the inside, which is illuminated for the purpose. Above the water is a clear space, with nothing visible. The steam is true steam, not partially condensed.

This true steam has, like gases, very little specific heat, even when at a high temperature; so that the thin film of steam in the jet which 
is in contact with the finger cannot give up much heat to the skin.

Secondly, this true steam has also, like gases, very little power of conducting heat, so that the film next the skin cannot carry to it the heat from the adjoining layers of steam.

When to these considerations we add the fact that the outer layer of skin, which is not sensitive, has to be heated by the small amount of heat imparted, before the deeper and sensitive layers can receive much heat, we see how it is possible to expose the skin to steamheat for a short time.

But it must be for a short time only. If the experimenter displays too much coolness and deliberation, heat enough will be conveyed before long to burn, though not to scald, the skin.

\section{The Stronger Overcome by the Weaker.}

At the time of its invention the steam injector was one of the most surprising of engineering contrivances. Few people, not engineers, know what an injector is or does; but it is well worth considering.

From a steam boiler comes a steam pipe, supplying the engine with steam. From the steam pipe comes a branch which takes steam to the injector. In the injector the current of steam meets a current of water brought by 


\section{PHYSICAL PARADOXES.}

another pipe, and forces it through a third pipe into the boiler. Briefly, steam from the boiler, and getting its pressure from the boiler, overcomes the pressure of the steam still in the boiler, and re-enters the boiler, carrying fresh water in with it.

This sounds a paradox indeed. Yet the wonder is still greater, for exhaust steam will do this. Steam which has passed through the engine, done its work there, and so been reduced to atmospheric pressure, will overcome a boilerpressure of, say, four atmospheres, and carry in water with it, raising or pumping this water, moreover, from a lower level.

This contradictory state of things depends upon the sudden condensation of the steam, concentrating all its energy within a very small volume.

When a jet of steam issues into a space where the pressure is about half of that in the steam chamber, it moves at a speed of fourteen or fifteen hundred feet per second, which becomes higher still after the steam has expanded. Moving at this velocity, particles have a great deal of moving energy, though they be small and light, like the particles of steam.

Now, steam occupies at atmospheric pressure more than seventeen hundred times the volume that it occupied as water.

If, therefore, it is condensed or turned into water again, it goes back into less than the 


\section{VAPOUR JETS}

seventeen-hundredth part of the volume that it occupies as steam. This means that a jet of steam suddenly condensed will have its diameter reduced to less than one-fortieth of what it was before. All its moving energy is, therefore, concentrated into this small jet of water from the condensed steam. That means that over this small area the jet has seventeen hundred times as much energy as before condensation, supposing the change of conditions to be realised with theoretical completeness. Allowing a large margin for imperfection in practice, the increase of energy is sufficient to enable the smaller jet of what is now condensed

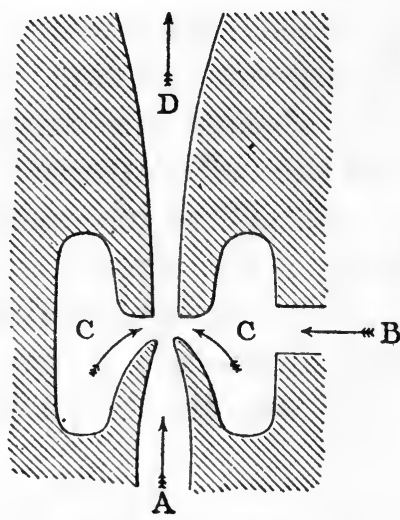

FIG. 37.-PRINCIPLE OF THE STEAM INJECTOR. steam or water easily to overcome the boilerpressure, and re-enter the boiler, carrying with it the water which condensed it.

The diagram in Fig. 37, in order to make the general nature of the operation clearer, has some of the details which are necessary in practice omitted altogether, and others exaggerated in their proportions, for the assistance of those who have no acquaintance with the injector at all. 


\section{PHYSICAL PARADOXES}

A communicates with the steam boiler or exhaust, which supplies it with steam. From its upper end a small jet of steam issues rapidly upwards. B communicates with the cold water supply and leads into an annular chamber $\mathrm{CC}$, which delivers an annular jet of cold water surrounding the steam-jet. In contact with this cold water the steam-jet is instantly condensed into water, forming the fine stream of rapidly moving water already described. This stream has energy enough to carry itself and the cold water which mixes with it into the passage $\mathrm{D}$, which communicates with the steam boiler; the stream, as it enters the wider part of this passage, gradually diminishing in speed and increasing in pressure until it is able to overcome the boiler-pressure. 
V.

CURIOSITIES OF VOLATILE LIQUIDS.

I. Freezing produced by Boiling.

IN a previous section we saw that the quantity of heat required for vaporisation is so great that hot water kept boiling at low pressure, without fire or flame to help it, used up so much heat of its own in boiling, that it was rapidly cooled to a moderate temperature. We have only to continue the process, keeping the pressure over the water low enough, and it will boil itself into ice. This has been frequently done; but to keep the pressure low enough for the formation of ice requires strong sulphuric acid and a good vacuum pump.

It is easier to get the freezing of water by the boiling of another liquid more volatile than itself, such as carbon bisulphide or ether. Carbon bisulphide is another thing whose presence in the house will be objected to by the powers that be, its odour being such that the exhaust from a motor-car seems in comparison to resemble the spicy breezes which blow soft o'er Ceylon's isle. We will therefore choose ether, though the smell of ether, too, will be anything but welcome in the house, and, 


\section{PHYSICAL PARADOXES.}

on the whole, it will be best to select for this experiment an afternoon when the powers are having a day's shopping.

It may be arranged as shown in Fig. 38. A piece of wood has a small hole or pit made in it, and this pit is filled with a few drops of water. In the water in the pit is placed a thimble, which is nearly filled with ether. (A pennyworth of methylated ether will suffice for

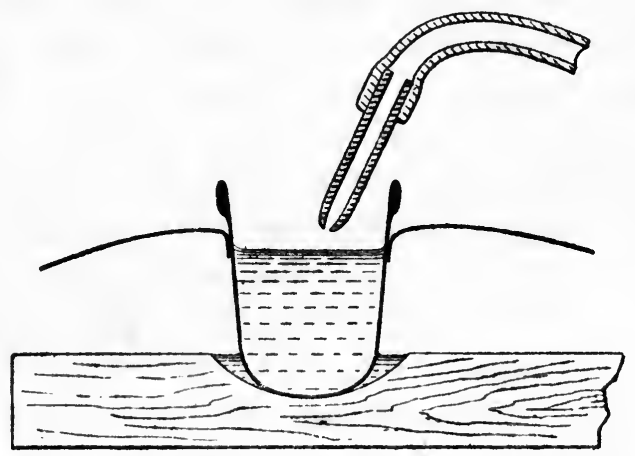

FIG. 38.-COOLING DUE TO RAPID VAPORISATION OF ETHER.

several repetitions of the experiment.) The bellows part of a spray-bottle arrangement is taken, and a piece of glass or other tube with a fine orifice is inserted in the end of the tube. (If the experimenter be young and breath plentiful, the bellows can be dispensed with.) As the ether is to be blown upon, a perforated shield of thin rubber sheet or other material fitted round the top of the thimble will prevent it from splashing over freely into the water. 


\section{VOLATILE LIQUIDS.}

Or care and patience in the blowing may be used instead. The vapour is highly inflammable.

The rush of fresh air and disturbance of the surface of the ether caused by blowing on to and into it give it abundant opportunities of vaporising, and it rapidly does so. The principle involved is that applied by a washerwoman in hanging out her clothes on a windy day. What she wants is to give the liquid water in the wet clothes an opportunity of disintegrating into its constituent molecules, and to give these an opportunity of exchanging their vibratory movements in the liquid mass for energetic movements of translation among the similarly moving molecules of the surrounding atmosphere. (This is what she wants, but she does not express it in this kind of language.) The object is attained by getting the clothes out in a brisk drying breeze. It is possible for the vapour from a liquid to pass into the surrounding space until that space is saturated with it. Under given conditions of temperature and pressure a space can only receive a definite number of molecules of a liquid. When this saturation point has been reached, further vaporisation can only take place by gradual diffusion of the saturating vapour into spaces further afield, so that by its thinning out room is made for a further number of molecules to come from the liquid and keep the space round it saturated. It is a much more rapid process 


\section{PHYSICAL PARADOXES.}

to sweep away bodily the whole mass of air surrounding the liquid, and the saturating vapour with it, so that the liquid is enclosed in a fresh quantity of air with abundance of empty spaces into which its molecules can move with as much greater facility as we can into a 'bus or a train when it is not already full.

In this way the artificial blast blown into the ether so facilitates and hastens its volatilisation that the process may be considered equivalent to boiling, and the heat used up in it and derived from the ether itself is so great that before the thimble is empty it has become cold enough to freeze the water beneath it, so that the ice cements the thimble to the board.

It has been mentioned that the difficulty in getting water to boil itself into ice is the necessity of using a vacuum pump and apparatus for keeping strong sulphuric acid stirred in a vacuum. But the system introduced by a well-known firm of supplying siphons and capsules for aërating liquids at home, provides a very convenient apparatus for showing this effect with another liquid.

If there is no such siphon in the house, and it is not desired to have one, the head alone (fitted with pricker and rubber washer for piercing, but without the glass tube and its connections) can be had from many chemists for less than a shilling, and a box 


\section{VOLATILE LIQUIDS.}

containing a dozen of the aerrating bulbs for Is. 4 d.

These bulbs, which are sold under the name of sparklets, are strong little steel capsules, containing liquid carbonic acid. This is, in the form of gas, the material which gives their fizzing and vaporising character to soda-water,

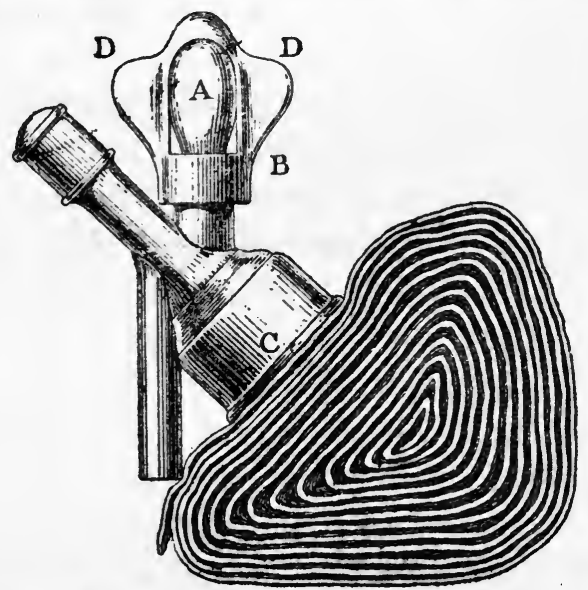

FIG. 39.-LIQUID CARBONIC ACID FROZEN BY RAPID VAPORISATION THROUGH SPARKLET SIPHON-HEAD.

lemonade, sparkling wines, and frothy beer. It is so volatile that it tends, when compressed into the liquid state, to re-volatilise with an energy which produces a pressure equal to forty or fifty atmospheres, according to the temperature. If the surface area of one of these sparklets be over two square inches, the total pressure inside it tending outwards in all directions is well over half a ton. 


\section{PHYSICAL PARADOXES.}

They are, therefore, not things to be played with. If highly heated, or opened in an improper manner, they explode with great violence. They should not be experimented with in any irregular manner by those who do not well understand such matters. If, however, they are kept at ordinary temperatures and opened in the proper way, they are as safe as they are convenient.

We will, therefore, use the proper apparatus for opening them, the ordinary Aërators' siphonhead, as shown reduced to about half-size in Fig. 39, simply removed from the siphon and without the glass tube and connections.

Put the sparklet bulb A into the opensided holder B, and screw it loosely into position, with its small end just entering the rubber washer. Press the base $\mathrm{C}$ against a roll of flannel or other porous cloth, in such a position (for the best possible effect) that the sparklet bulb A shall be vertical. Now screw down the holder by its ear-pieces $D D$, so as to force the small end of the bulb against the point of a pricker, which pierces it. Screw it down well to make a good hole.

The liquid carbonic acid rushes violently out of the hole, through a slot in the pricker, and into the chamber $\mathrm{C}$, in which it expands and vaporises. The sudden expansion and conversion into vapour require much heat, which is supplied largely by the liquid itself. 


\section{VOLATILE LIQUIDS.}

The liquid consequently becomes very cold - so cold that about one-third of it is frozen into a powdery solid, like snow, and is collected in a thin circular layer on the cloth, the clear gas having filtered through.

Theliquid has boiled itself into a frozen solid!

This solid carbonic acid is extremely cold. It has I43 degrees of frost on the Fahrenheit scale. Its extreme cold can readily be felt by pressing the finger upon it. More of it can be collected by piercing two or three capsules on the same surface. If a quantity of the size of a pea be forcibly compressed between the finger and thumb the excessive cold will cause mortification of the skin.

It is very volatile, and in a few minutes will all disappear by volatilisation, without melting. Any appearance of moisture is from moisture in the air, condensed by the cold surface left behind.

\section{Ice as a Heating Agent.}

Different liquids boil at different temperatures. Sulphuric acid or mercury must be made much hotter than boiling water before they will boil. Alcohol, ether, and chloroform, on the other hand, will boil at a much lower temperature than water; and water itself, as we have seen, will boil at a lower temperature when there is less pressure upon it. This can be 


\section{PHYSICAL PARADOXES.}

arranged by going up a high mountain, where there is so much less air overhead that its pressure is much lower, and water boils so easily at a low temperature that it cannot be made hot enough to cook potatoes.

Sulphur dioxide is a liquid which actually boils at a temperature below that at which water freezes. It boils at eighteen degrees of frost. Liquid ammonia (not the cloudy household ammonia, which is water with some ammonia dissolved in it, but pure liquid ammonia) and liquid nitrous oxide boil at lower temperatures still.

Lower than most others is the temperature at which liquid air boils. This substance, when boiling, has 344 degrees of frost.

Now, heat is always a condition of boiling. Even at this low temperature, then, there can be heat. It must not be supposed that there is no heat at or below the temperature at which water turns solid. We might as well say that there is no heat below the temperature at which melted wax or molten iron solidifies. Heat is entirely relative. It means the vibration of molecules, and this vibration may be more active or less active. When it is less active, we say that the substance is colder, which does not mean that it has no heat at all. Every substance known to us has its molecules vibrating, more or less energetically-that is, it has some heat, more or less. 


\section{VOLATILE LIQUIDS.}

When, therefore, we say that ice is cold we merely mean that it has less heat than our bodies or most surrounding objects, not that it has no heat. In comparison with some things it has a great deal of heat. In comparison with liquid air ice has as much heat as red-hot iron has in comparison with water. Consequently, ice can put liquid air into the same spheroidal condition as we saw that water is put into by red-hot metal. Until it has lost a good deal of its heat and got nearer the temperature of the liquid air itself, ice is too hot to make it boil !

At first the excessive heat of the ice (excessive in comparison with the extremely cold liquid air) keeps creating a cushion of vaporised air-gas between itself and the liquid, so that heat cannot pass directly by conduction, but only slowly by radiation.

But when the ice has been slowly giving up heat in this way, it gets at last cooled down to a temperature so much nearer that of the liquid that the two can come into contact. Then heat can pass more freely from the ice to the liquid, and instead of merely rapid vaporisation we get true and actual boiling. The ice has at length got cold enough to make the liquid air boil!

After the boiling has gone on for some time, and the ice has parted with more and more of its heat, it becomes finally as cold as the liquid air itself. Then, of course, no heat can 


\section{PHYSICAL PARADOXES.}

pass from one to the other, and boiling ceases.

The actual experiment is easily performed in either of two ways.

A piece of ice may be dropped into a quantity of liquid air. For the first few moments the spheroidal state prevails. The ice is too hot to touch the liquid, and there is only very brisk vaporisation. But being a bad conductor, the ice soon has its surface cooled sufficiently for active boiling, which is maintained by the heat slowly conducted from the centre of the lump.

Or a hollow may be cut in the top of a block of ice, and the liquid air poured into it, when the same series of events follows. The latter method offers an opportunity for a pretty and striking effect. As the nitrogen is boiled away first, the oxygen left behind supports brilliant combustion of a piece of wood, and the bright light showing through the ice looks very fine in a darkened room. 
PERPETUAL MOTION FALLACIES.

\section{Liquid Air and Perpetual Motion.}

Perpetual motion is a convenient phrase to represent the idea of getting power out of nothing, or getting more power out of a machine than is in any form put into it. It has always been a favourite object of those who have meddled with scientific or mechanical matters without having enough cultivated knowledge or practical experience and instinctive feeling to grasp the principles which govern their subject.

Some years ago, when the first public sensation in connection with the marvels of liquid air were beginning to pall, an American experimenter, who had installed a large air-liquefier on the system invented by the present author, made an announcement which produced a new thrill.

He had been able to use three gallons of liquid air in a motor much like a steam-engine, so as to work a compressor and liquefier which produced ten gallons more. Of the ten gallons he affirmed that seven might be used in another power engine to do useful external work, while the three remaining could be used to produce 


\section{PHYSICAL PARADOXES.}

other ten, and so on indefinitely. Having three gallons at the beginning of the day, he could keep renewing the original three, and as frequently supplying seven for working a factory.

It is obvious that what applies to three gallons and seven applies to thirty and seventy, or to 3,000 and 7,000 . It is also plain that if the seven gallons were not used in factory work, they could be employed to make twentythree gallons more, these to make seventysix, and so on indefinitely. There was literally no limit to the liquid air and the power which, without an additional ounce of coal or other fuel supplied, would grow, like the great herb out of the small mustard-seed, from the three gallons with which the development began.

Such a wonderful agent was to revolutionise manufactures and travel. Engines driven by coal, oil, or gas would be superseded in the factories and on the railways of five continents. Ships would cross the Atlantic in three days, driven by liquid air, without having to carry a ton of fuel. Air-ships would at last successfully cleave the sky, and submarines would plough the depths of ocean with the help of a beneficent agent which would not only provide them with power but would constantly renew a pure atmosphere for the under-water navigators to breathe. 


\section{PERPETUAL MOTION.}

To prove the absurdity of all this would at this hour be like attesting the death of Queen Anne. A man who formulates or accepts such a theory cannot have grasped the general truth that, though little may be added to little until we have much, one little can never make much. Mony a mickle maks a muckle, true ; but by no conjuring can one mickle be made into a muckle.

There was never a full investigation into the circumstances of this experimenter's professed success, but the only conclusion which could be drawn from the accounts vouchsafed to us is that in making the ten gallons at a moderate pressure he failed to note that he was working with a machine which had already been well cooled by the power spent in making the previous three; he was reaping the cold grown during the earlier operation, taking it out of the metal into the liquefaction; and in so doing he was re-warming the machine, which would then be incapable of repeating the performance.

Reversing the conditions for an instance easier of general comprehension: When a steam boiler has been boiled dry and made very hot, putting a few pounds of water into it will cause a pressure from steam generated by the heat of the metal, but that very process will cool it and incapacitate it for a repetition of the action. 


\section{PHYSICAL PARADOXES.}

\section{The Inexhaustible Source of Heat.}

When a jug of hot water is placed on the table, we know that before long it grows cool, and in time cold. A foot-warmer keeps constantly losing heat until it needs changing. Universally, according to our experience, a body which is hotter than its surroundings gives up heat to them until it is of the average temperature.

The ice in our experiment of the last section but one, after boiling the liquid air for some time, sinks at last to the temperature of the liquid itself, to which it has given up all its excess of heat, and thereafter it can do no more boiling.

But there has been discovered lately what appears to be an exception to this general rule of the dissipation and equalisation of heatenergy.

If radium is put into liquid air, as it was by the late Professor Curie, it behaves at first like the ice, causing brisk vaporisation, and boiling, which presently dies down. But with radium it never ceases altogether. A little boiling of the liquid goes on constantly. If the liquid air be put away for twenty-four hours, with the radium in it, the latter will still be slowly boiling it. If the level of the liquid air be maintained by fresh supplies, it will be found at the end of a month, of a year, apparently of 


\section{PERPETUAL MOTION.}

a lifetime, that the same rate of boiling is still being maintained by the original small saltspoonful of radium. It never gets cooled down to the temperature of the liquid air. It is only another way of putting this to say that the radium appears to be an inexhaustible source of heat.

The matter would have been easier to understand if some loss of substance could be detected, showing that there has been combustion or some other chemical or physical change going on of which the constant output of heat could have been a product. But after the longest period during which radium has been observed at work producing heat and other manifestations, it has been impossible subsequently by the aid of the finest balance to detect the slightest loss of weight or any other chemical change. It looked like a miracle, a suspension of the great law of the conservation of energy. It looked as if perpetual motion had at last materialised.

It was not long, however, after the phenomena of radio-activity had first astonished the world, before Professors Rutherford and Soddy, of the McGill University, Montreal, discovered an explanation which is now generally accepted, and which brings the behaviour of radium within the law of the conservation of energy.

The explanation will be referred to again in 


\section{PHYSICAL PARADOXES.}

a later section, and a brief account of it must suffice here.

It is agreed that atoms, the smallest portions of matter known till quite recently, consist of still smaller particles or corpuscles, which vibrate with enormous energy within the atoms. A small proportion of the atoms of all substances are continually disintegrating or breaking up. Radium only differs from other substances in that this proportion is in its case much higher than in theirs. The component parts, corpuscles, and groups of corpuscles fly out from the disintegrating atoms with a speed proportionate to the enormous energy with which they were vibrating within it, speeds of from I5,000 to 150,000 miles per second. Striking one another and adjoining particles of radium at this velocity, they develop an amount of heat which in proportion to the amount of matter involved is enormous.

Thus the heat constantly given out by radium is the natural result of a definite process constantly going on, and as this process involves degradation of energy and disappearance of substance there is no contradiction of the great law of conservation.

The loss of substance is so slow that it is imperceptible for the time during which radium has been under our observation; but in spite of this the results of the action are appreciable because the power is relatively enormous which 


\section{PERPETUAL MOTION.}

is embodied in the corpuscular vibrations of comparatively few atoms, and liberated by their disintegration.

\section{A Clock which is Never Wound and Never} Stops.

The radium clock, as it is somewhat fantastically called, an invention of the Hon. R. J. Strutt, is another instance of what appears to deserve the name of perpetual motion.

A half-size sketch of it is shown in Fig. 40.

It consists of an electroscope suspended from the lower end of a small glass tube containing a little radium of about the size of a wall-flower seed. This is fastened to the top of a larger glass vessel, which is a vacuum

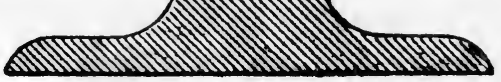

FIQ. 40.-THE RADIUM CLOCK: PERPETUAL MOTION.

tube-that is, has had all the air pumped out of it before it was sealed up. The action is as follows :

Among the things which come from the atoms of radium on their disintegration are the alpha rays. These are, for small things, somewhat large groups of corpuscles, and, for swift things, somewhat slow missiles, flying out 


\section{PHYSICAL PARADOXES.}

in all directions at a speed of less than 20,000 miles per second. They are therefore unable to get through the first glass wall.

Other things which fly out from the disintegrating atoms of radium are the beta rays, tiny bodies about the two-thousandth size of the alpha rays and ten times as swift, which means that they have a striking energy a hundred times as great in proportion to their weight. These are swift and small enough to pierce their way through the glass walls, and get clear away from the radium chamber.

The small beta rays have a charge of negative electricity, which they carry away with them. The larger alpha rays have a positive charge, which remains with them, so that there arises an accumulation of positive electricity in the radium chamber, which by induction causes an accumulation of positive electricity in the leaves of the electroscope.

Both leaves being charged with the same kind of electricity, they begin to repel each other, as similar poles of magnets do. As the charge accumulates, the repulsion increases until the leaves touch the foil placed at the sides of the tube, which, having a metallic connection to earth through the glass, discharge the leaves and allow them to fall together again.

But the radium is constantly at work, a fresh charge of positive electricity is soon accumulated, and the separation of the leaves 


\section{PERPETUAL MOTION.}

is repeated and followed once more by their falling together.

This process is apparently able to go on indefinitely-not merely for months, but for years and for generations.

And there is no fresh motive power supplied to keep up the movement. No fuel is burnt, no dynamo driven, no friction made, no mechanical motion given to the apparatus.

Here, then, it looks as if we had another form of perpetual motion.

The apparatus is called a clock because of the regular intervals at which the movement of the leaves takes place, as with the pendulum beats of a clock; and with enough radium to work the machine on a large scale, no doubt it could be made to record the time on a dial.

As for the motion being perpetual, it is not so. The accepted theory is, as stated, that some of the atoms are constantly undergoing disintegration, and, as radium, disappearing; and by the amount of that loss the quantity left behind is diminished. True, the loss is so small (surprisingly small, in view of the effects produced), that it cannot be measured by balances or other tests.

It is calculated, however, that it is fast enough for half of the radium to have disappeared in about a thousand years; so that a clock of this kind started in the year A.D. I would now be going at about quarter speed. 
VII.

MAGNETISM.

ELECTRICITY and magnetism hardly lend themselves at all to the uses of such a book as the present one. Paradoxes are views contrary to general and natural expectation. The views may be correct or false, but for a paradox to be interesting it should, as a rule, be justifiable. To be of general interest to others than persons of special knowledge, paradoxes should be concerned with matters of a familiar nature, and their justification and explanation should be capable of being readily understood by intelligent laymen, as based not too indirectly upon facts and principles of common experience.

Now, to the natural man the only electrical and magnetic phenomena of ordinary experience are thunder and lightning, sparks from stroked hair, and attraction by the loadstone. These are astonishing enough, but the most accomplished science cannot explain them in the sense of showing how they arise as special manifestations of well-known and easily intelligible principles of universal acceptance and application, such as the law of conservation of 


\section{MAGNETISM.}

energy, the law of inertia, or the law of action and reaction. On the other hand, so far as they can be shown to be of identical nature with phenomena producible in the laboratory under certain conditions and in definite relations to other phenomena, they are material for scientific study, not for a book of paradoxes.

In electrical study there cannot be paradoxes in our sense. There is in these matters no general body of opinion, expectation, or prejudice, the result of untutored experience, to be apparently contradicted by special cases. If we leave out the modern version of the view that thunderbolts were a kind of javelin hurled by Jupiter, there are no natural views at all, because there is no natural knowledge, on this subject.

The whole matter, facts and experience, as well as views, expectations, and beliefs, has been scientific from the beginning. Every student of electricity begins and continues the study prepared to believe anything of which he has evidence; and laymen are by this time well enough acquainted with their own ignorance in such matters to accept without question things accepted by those who know. No civilised man can now witness any electrical experiment with the feelings with which, for the first time (if he has been fortunate enough to grow up without seeing or hearing of it before), he sees a gyroscope supported loosely 


\section{PHYSICAL PARADOXES.}

on one end of its axis and yet not falling to the ground.

Electricity, then, though it offers plenty of wonders, will not provide us with any popular paradoxes at all. But magnetism, in its one popular manifestation, offers a paradox which, if the phenomenon were not so familiar, would rival the gyroscope in its astonishing nature, and surpass it in the difficulty of solving the puzzle.

\section{Pulling without any Cord.}

In " the simple life," that of animals and savages, action at a distance is always of the nature of repulsion. If a stick or stone be thrown, if an arrow or bullet be fired, its first effect upon the object struck is to repel it. The effect is that of an indirect push. We push the stone, and the stone at the end of its flight pushes something else. Indirect pushing, or pushing at a distance, the simplest of us can understand. It is understood by some of the animals. Monkeys have learnt the art of throwing.

But pulling at a distance is outside the experience of any creatures except cultivated man. To pull fruit down we use a hooked stick. To pull the landing we use a boat-hook. To pull the boat we use a rope. To pull up the coal we use a wire; and to pull up the bucket from the well we use a chain. In all these cases 


\section{MAGNETIC ATTRACTION.}

of pulling there is no action at a distance; the distance is bridged by some material connection.

The child's astonishment, therefore, when first it sees the toy-swan pulled by the magnet without contact is a perfectly philosophic state of mind. It is noting an experience of a new kind.

Later in life we get more habituated to the idea of pulling at a distance, and often call it suction, as when we say that the pump-bucket sucks or draws water which is many feet below in the cistern. In still higher development we seem to possess means of drawing a boat when by Hertzian waves we steer it towards the shore without having any apparent material connection with it. And a form of pulling at a distance which extends through all the known universe, though its nature and extension were long unrecognised, is the universal gravitation discovered by Newton.

The most familiar of these instances, that of the pump, is now well known not to be a case of suction at all, as the word is commonly understood. The bucket at A (Fig. 4I) has no mysterious power of drawing the water at $B$, and, in fact, does not draw it, though it is usually spoken of as doing so.

What the bucket $\mathrm{A}$ does is to lift and push up the air at A, which would otherwise press downwards upon the water at B with a force 


\section{PHYSICAL PARADOXES.}

of fifteen pounds to the square inch. On the rest of the water, at $\mathrm{CC}$, the air continues to exercise that pressure, and the water, being a fluid, transmits it equally in all directions, including the upward direction at B. The water

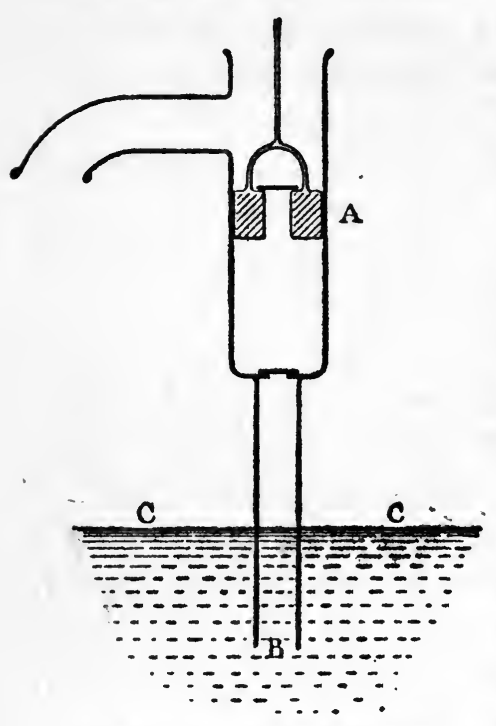

FIG. 41.-SUCTION BY A PUMP REALLY REPULSION BY AIR.

at $B$ is therefore pushed upwards by this pressure, as the counterbalancing pressure downwards has been removed by the bucket. Thus the water rises at $B$ by repulsion from below, not by pulling from above.

Here is a case, then, where the action which appears to us to be pulling, drawing, suction, or attraction, and which we so name, is in reality an indirect or circuitous process of pushing or repulsion. The water is pushed up the pipe of the suction-pump by atmospheric pressure just as truly as it is pushed up the pipe of a force-pump by muscular pressure.

All other so-called suctions-that by a boy's wet leather and string, that by a fly's foot-cushions, the drawing of smoke through a pipe-stem, the drawing of cider-cup through 


\section{MAGNETIC ATTRACTION.}

a straw : these, and all similar cases, are found on examination to be cases really of circuitous pushing or repulsion, which is allowed to act by the removal of a counterbalancing push in the opposite direction.

Let us proceed to cases much more difficult-such cases as that which arouses the keen interest and astonishment of the childphilosopher: the attraction of a toy-swan by a magnet. Is this, in truth, an action of a new kind ? Is it pulling at a distance, or is it, like the pump-suction, really repulsion by a circuitous course ?

To answer this definitely, as a proved matter, is impossible. Nobody knows, in the case of magnetic attraction, as we do in the case of pump-suction, the exact nature in detail of the mechanical actions at work in the bodies which are the seat of this particular phenomenon. We must resort to considerations of probability from the nature of the case and from analogy.

We know that in an electro-magnet the magnetic energy is derived from the electric energy in a wire coiled round the magnet-that is, from some special form of vibration in the small particles of the wire. And since the wires do not touch the magnet, are at a distance from it, however small, these vibrations are communicated by means of some intermediate vibrations set up in the intervening ether. The change, therefore, in the soft iron, which 


\section{PHYSICAL PARADOXES.}

converts it into a magnet, is probably in its turn the production of a special form of vibration in its small particles.

Now, how can the vibrations in the soft iron, which constitute it a magnet, act upon something at a distance so as to make it tend to come nearer ? Is it by a pulling force which, acting between them, and between them only, draws them together, or is it by means of pushing forces which, indirectly excited to act in their rear, push them together from behind ?

There are no proofs on this head, but there are three lines of indication as to the probabilities, and they all point in one way.

Firstly, there are the cases which are analogous in their gross or general character, such as have already been referred to: the cases of mechanical suction, of which we clearly understand the action in detail. These cases of apparent pulling at a distance all prove, on careful examination, to be cases of indirect or circuitous pushing.

Secondly, the other vibrations, whose nature in exact detail may be unknown to us, but whose manner of action we understand, appear to convey the same suggestion. It is generally accepted that the mechanism by which heat influence is transmitted is the delivery of a series of blows-that is, repulsion strokes-by the vibrating molecules of the hot substance upon those of an adjacent substance or upon 


\section{MAGNETIC ATTRACTION.}

the adjacent particles of ether. Light influence is transmitted in undulatory vibrations, exercising a repulsion-push whose force has recently been measured with exactness by Lebedew and others. Sound is transmitted from a vibrating body by means of the repulsionblows which it delivers upon other bodies in contact with it or upon the surrounding air. Analogy would lead us to expect that the minute details of electric and magnetic action are of a similar nature, and that though the gross effects in some cases may be of the kind that we call pulling, these are only the results of disguised, indirect, or circuitous influences of repulsion.

Lastly, it is possible to conceive the existence of pushing mechanism by which magnetic vibrations can cause distant bodies to approach, while no mechanism for pulling influences is conceivable.

Now, a thing is not necessarily real because we can conceive of its existence, or unreal because we cannot imagine it. But when, of two opposite explanations of phenomena, one is in accordance with principles realisable by the mental faculties which have been developed in some degree of harmony with the outward experiences of ages, while the other contradicts those principles, the former explanation has a right to the preference as a working hypothesis until further knowledge is obtained.

It remains to show that it is possible to 


\section{PHYSICAL PARADOXES.}

conceive of a mechanical system based on pushing, direct or indirect, which should make it possible for special vibrations of the particles of a medium to cause the approximation of two bodies surrounded by it.

Let A and B (Fig. 42) be two particles of material substance, and let the remaining

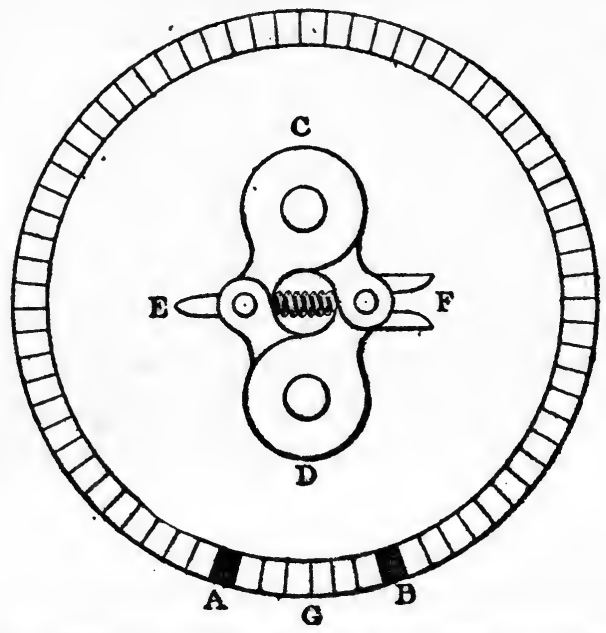

FIG. 42.-APPARENT ATTRACTION IN GENERAL: THEORY OF REPULSION.

segments of the ring be particles of the medium by which they are surrounded. A side view of the particles of the medium, on an enlarged scale, is shown in the centre of the ring. C and $\mathrm{D}$ are massive joints connected on the principle of the balls of a steam-engine governor, so that, as the particle revolves on a horizontal axis, these joints tend to fly apart by centrifugal 


\section{MAGNETIC ATTRACTION.}

action, compressing the spring in the middle. The tendencies to expansion of the governor balls and the central spring balance each other, in the position shown, for a certain speed of revolution. At $\mathrm{E}, \mathrm{F}$ are connections for universal joints, without holes or pins, which enable the revolutions of the particles to control and be controlled by one another, but do not enable the particles to pull one another, though they may push.

When the ring of particles is in equilibrium (imagine them kept in their places by a groove or tube, inside which they revolve without friction), let A undergo some special vibrations by means of which it can quicken the revolutions of the particles of the medium in front of it towards $\mathrm{B}$, while retarding the revolutions of those behind it all the way round the rest of the ring.

The quickened revolutions through $A$ G B increase the centrifugal force of the masses $\mathrm{C}, \mathrm{D}$, and cause the particles to flatten out vertically, while they contract horizontally, the spring being compressed, so that $\mathrm{E}$ and $\mathrm{F}$ are nearer together, and the particles do not push one another so hard.

As the particles in the rest of the ring are revolving more slowly, the $\mathrm{C}$ and $\mathrm{D}$ masses have less centrifugal force, and allow the springs to expand, causing the particles to press against one another more forcibly. 


\section{PHYSICAL PARADOXES.}

Thus the particles in the greater part of the ring press more forcibly against the rear of the particles $A$ and $B$, while those between them press less forcibly against their faces.

They therefore move nearer together.

And they have not been pulled, but pushed together. What looks like attraction is really repulsion. None of the particles of the medium is armed with a hook or loop of any kind with which those between the particles of substance could pull upon one another to bring the substances nearer together. Their coming together has been due to the pushing of the particles behind them.

Those who are least familiar with speculations of this kind must be warned that the foregoing is not in the smallest degree a suggestion of the actual nature of the connection between ordinary matter and ether, or the way in which electricity and magnetism act. The true state of the case is enormously more complex. Each atom of substance is a group of corpuscles with interdependent movements comparable with those of the solar system. The construction of the ether, if simpler, may still be far from simple; and what really takes place is more like a modification of the orbital movements of the component corpuscles than a change in the speed of our steam-engine governor. The chains of action, moreover, are 
not confined to a ring, or even a series of rings, but radiate in all directions.

The object of the example is to show that it is possible, without going far outside the ordinary conditions of mechanical action, to conceive of arrangements by which bodies which tend to move together are really pushed towards each other by repulsions from behind.

Is it equally possible to conceive of any mechanical means by which bodies at a distance, however small, can pull one another together ?

The answer to this must be, no.

The only means of pulling which we can imagine is some kind of hooked rod or wire, looped rope or chain.

But, in the first place, such means of pulling imply a windlass of some kind to wind up the slack, an arrangement for which it is inconceivable that there should be any equivalent among the atoms and corpuscles which are the seat of these actions.

And, in the second place, if we imagine a series of hooks or loops, as in a chain, we are only deferring the difficulty, for we have to explain how the former part of a hook can draw the latter, which is not to be explained by imagining still smaller hooks in the component parts of the longer hooks. That would be explaining a system by itself.

The apparent pulling at a distance which we see in magnetic attraction can, then, be 


\section{PHYSICAL PARADOXES.}

rationally interpreted as a circuitous pushing, but not as anything equivalent to the mechanical pulling known to us.

There still remain to be considered the facts of the universal attraction of gravitation.

We undoubtedly have got everything in the universe behaving as if it could pull at everything else, however distant; and where other influences do not interfere, things do come together in accordance with this general tendency.

Is this attraction of gravitation something sui generis, or is it another case of what looks like pulling being really indirect pushing ?

Of the theories on which it has been attempted to explain the action of gravitation, the only one fairly consistent with itself and with the facts, as well as in harmony with the rest of the structure of things so far as we know it, is the theory of Le Sage.

Briefly, this is that space is occupied, though not filled, by small particles rapidly flying, like the molecules of a gas, in all directions, frequently striking one another and striking other objects. They repel everything in every direction. But when two bodies are near together they shelter each other from many of the blows which but for their mutual proximity would have fallen upon each from the direction of the other; thus they are less powerfully repelled from each other than they 


\section{ATTRACTION OF GRAVITATION.}

would otherwise have been, whereas they are as strongly as ever repelled towards each other by the blows which fall upon their rear. The result is that they are driven towards each other, or, as we say, attracted. And it can easily be shown that the force which drives them together must vary inversely as the square of the distance, in correct agreement with the law of gravitation.

The theory has certain weak parts, and the present author, in his book, "Radium Explained," has suggested amendments to strengthen these portions and bring the theory into harmony with the most recent knowledge of the minute structure of matter.

All that can be said within our present limits is that Le Sage's theory is the only explanation of the attraction of gravitation which is intelligible and workable.

And, once more, it explains that attraction, so called, is not a special force, but only a special case of the indirect action of repulsion.

It is probable that the same principle holds regarding the attraction of cohesion which exists between extremely small particles in extremely close contact, which gives us the solidity of iron and the tenacity of silk.

In the days of the old view of atoms, that they were indivisible particles, though it was easy to realise that one atom striking another could communicate its motion or energy to the 


\section{PHYSICAL PARADOXES.}

one struck, it was impossible to imagine how one atom could attract or pull another, unless we imagined that they had hooked projections - a fantastic conception which would advance us no further, since we should still have to explain how the hooks could hold fast to the rest of the atoms unless by the force of attraction, which thus would be invoked to explain them instead of being explained by them.

But now that we believe atoms to consist of elaborate combinations of separately moving units, comparable to solar systems, it is impossible to imagine an atom in any way pulling or drawing its neighbour; and to explain how atoms exercise that tendency to mutual approximation which we call attraction, we are driven once more to suppose that they are in some way removing or diminishing repulsion between their faces, so as to allow greater influence to repulsions in their rear which tend to drive them together.

Thus there is every reason to believe that attractions of all kinds, from that universal influence of gravitation defined in Newton's great law, to the manifestations of cohesion, magnetism, and chemical combination, would prove, if we could learn the nature of their mechanism in detail, to be special cases of removed or limited repulsion, allowing greater effect to indirect or circuitous repulsions acting from the rear. 


\section{ATTRACTION OF GRAVITATION.}

This is undeniably true of the pump suction. All analogy and the limitations of thought, which itself is founded upon the possibilities of experience, force us to the conclusion that it is true of all kinds of suction and attraction whatever.

The attraction commonly believed in, as a special form of energy, does not exist; it is merely a special operation of the energy of repulsion, which is itself only a case of the great law of the conservation of energy or persistence of motion, slightly specialised by the transference of the energy or motion from one body to another. 


\section{PART III. \\ CHEMICAL PARADOXES.}

As providing subjects for popular paradox, chemistry suffers to some extent under the same disability as electricity and magnetism. It is almost too strictly scientific.

It has its puzzles of surprising interest, such as the true nature of chemical affinity and the arrangement of atoms within a molecule. It has also its paradoxes, such as the tantalisingly close approximation to exact correspondence in the proportions of the combining weights of the elements.

But those who can appreciate the interest, the importance, or the surprising character of most of the puzzles and paradoxes of chemistry are necessarily those who have some working experience, as students of chemistry, of the principles involved.

Impressions, prejudices, and preconceptions on chemical points do not come by nature, as they do in principles of mechanics, physics, and physiology, with the facts of which we must all necessarily deal every day of our lives. We live in a world of chemical products, it is true, but so few of us have a share in making them, or possess the knowledge necessary for 


\section{FIRE A SOURCE OF WATER.}

the work, that to most men one fact of chemical science is neither more nor less interesting than another, and a statement of the periodic law of Mendeléef and Newlands excites no more surprise than an announcement that one pound of hydrogen, in burning, always combines with eight pounds of oxygen.

There are, however, some paradoxical facts of chemical science which can be appreciated by any thoughtful layman, and a few of these will be presented here.

I.

\section{CURIOSITIES OF COMBINATION.}

I. Fire a Source of Water: Picking Moisture out of a Hot Flame.

We are accustomed to think of heat, and particularly of flame, in association with the idea of perfect dryness; but, as a matter of fact, a flame is constantly adding to the moisture in the room. An experiment will make this convincingly clear.

A B C (Fig. 43) is an inner tube or vessel of thin brass, packed with pieces of ice, and then filled with water, which runs in between the pieces. The outer tube $\mathrm{DE}$ is made of any convenient material, and leaves an annular passage between itself and the inner tube. If $\mathrm{DE}$ is also of brass its upper part may be slit downwards an inch or so, and the alternate 


\section{CHEMICAL PARADOXES.}

ends bent in to support the rim of the inner tube, leaving spaces for the free egress of combustion gases from the flame of a Bunsen burner

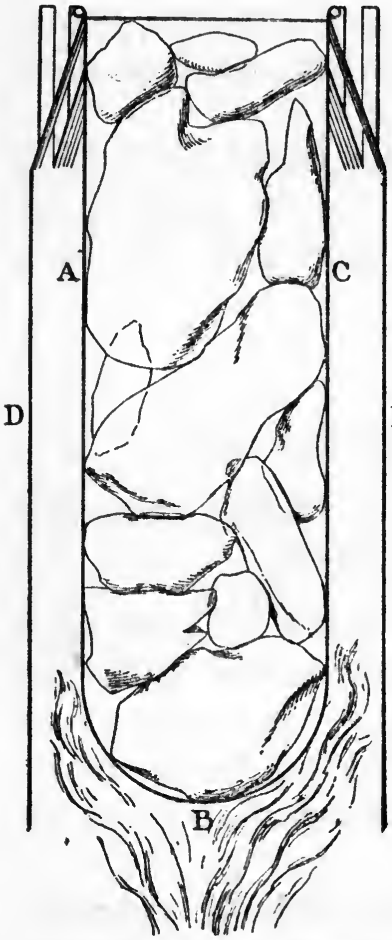

FIG. 43.-BARYTA MADE REDHOT BY POURING COLD WATER OVER IT. or spirit lamp applied at B. If the apparatus be held over such a flame, in a very short time moisture like dew will be deposited outside the inner tube. The droplets will quickly enlarge and grow together into larger E drops, which will run down the tube and fall off at $B$, either into the flame, which they will spoil, or into any receiver over which the tube may be shaken in order to collect the water.

This arrangement, or some other on similar principles, is only required to collect the drops of water quickly, certainly, and in considerable quantity; but other arrangements will illustrate the principle as certainly, if not quite so freely. The inner tube may be a piece of lead pipe beaten over at one end, or a large glass test-tube. 


\section{FIRE A SOURCE OF WATER.}

The outer tube, though it improves the experiment by confining the combustion gases and spreading them over the inner tube, is not indispensable. The facts can be shown even by holding a cold knife-blade or piece of glass in a flame for a second, when a deposit of moisture will appear on its surface. For this purpose it is better not to use an ordinary gas or candle flame, as the cold causes imperfect combustion and a deposit of soot, which obscures the effect.

There is no fact of more common observation than the deposit of moisture from the breath on the inner surface of window panes when the air is very cold outside. The same thing can be observed without anyone breathing in the room, if there are plenty of flames burning there, and discharging the gases of combustion into the room (not up the chimney).

It would appear, then, that moisture is actually produced by and in flames. So it is. Combustion is the rapid, heat-producing combination of substances, chiefly carbon and hydrogen, with the oxygen of the air. Nearly all combustibles are composed of carbon or hydrogen or both, often with other elements as well. When carbon combines with oxygen, the product is carbonic acid, with which we have at present nothing to do.

The product of the combination of hydrogen and oxygen is water, and as hydrogen is 


\section{CHEMICAL PARADOXES.}

nearly always present in combustibles our flames practically always produce water.

The reason why it is not more commonly observed is that hot air and gas can hold a greater quantity of water-vapour in solution than cold gases can; so that the excess of water-vapour, though present in the flame, is not often easily seen.

\section{Water a Source of Fire.}

That water, which is commonly used for putting out fires, should be capable of causing and maintaining them, sounds sufficiently paradoxical. It is, nevertheless, perfectly and literally true.

Water consists of two parts of hydrogen gas combined with one part of oxygen. Oxygen is an element which has a very strong tendency to combine with sodium and potassium, so strong that if either of these metals is thrown upon water, in combining energetically with the oxygen it tears it away violently from part of the hydrogen with which it is already combined in the water, setting this portion of hydrogen free.

We all know how two bodies coming violently together develop heat as.the result of the impact. Without further reference to the moral (or immoral) heat developed when two persons collide, owing, as each thinks, to the stupidity of the other, there is much physical heat 


\section{WATER A SOURCE OF FIRE.}

developed by transformation of the moving energy with which two masses of matter clash together, so that a small piece of iron between the hammer and anvil can be made red-hot by blows of the former.

In a somewhat similar manner heat is developed of much greater intensity when the molecules or atoms of elements which are said to have a strong affinity for each other rush violently together in the act of re-combination.

In the present instance the oxygen rushes into combination with the sodium or potassium so energetically and with the development of so much heat as to set fire to the hydrogen which is being set free at the same time. The result is a hydrogen flame maintained, instead of being put out, by the application of water to the metal.

Alcohol, which is a source of so much heat in other ways, is anything but cooled by throwing cold water upon it. The two substances, on being mixed, unite with so much energy that the addition of pure alcohol to an equal quantity of water, neither hotter nor colder than itself, results in a distinct rise of temperature.

The same thing occurs still more powerfully on the union of water with sulphuric acid, or with caustic potash or soda. The resulting heat is indeed so great in these cases that there is danger_of a ${ }_{-}$glass vessel being cracked, 


\section{CHEMICAL PARADOXES.}

and as the liquid produced is a powerful corrosive, care should be taken to make the experiment in a suitable place. In the case of strong sulphuric acid, if a drop or small quantity of water be poured upon it, the water is so suddenly and violently heated as to be rapidly

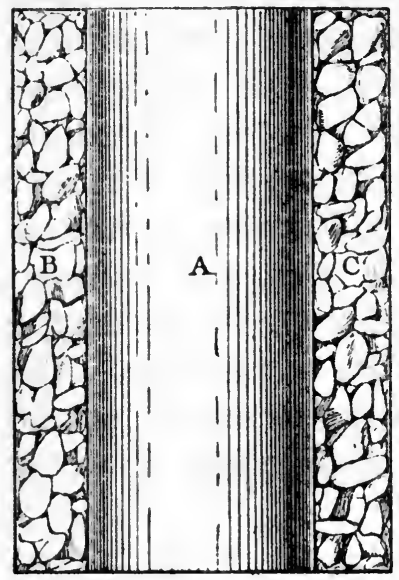

FIG. 44.-TRAVELLER'S FOODTIN HEATED BY LIME AND WATER. vaporised in an explosion which may scatter some of the corrosive acid. It is, therefore, advisable to begin making this mixture by pouring the sulphuric acid gently into the water, not vice versâ. More commonly seen is the heat produced by letting quicklime unite with water. This operation is often so carried out in building work as to produce actual boiling of the water, and the method has lately been made use of for the heating of food where no fuel or pans are available for the purpose. The prepared soup or other food is sealed as usual in the inner tin vessel, A, of Fig. 44. This is surrounded by another compartment, B C, which contains quicklime, also hermetically sealed.

When hot food is wanted, the outer vessel is unsealed, and water poured upon the lime. 


\section{ALLOTROPISM AND ISOMERISM.}

The two substances by their union become hot enough to heat the contents of the inner vessel.

More remarkable still is the effect of pouring water upon baryta or barium monoxide, a substance of very similar constitution to that of quicklime. If a glass vessel, not liable to crack, say a beaker of about four inches diameter, be filled with lumps of baryta which have been kept quite free from moisture, and water be poured into the intervening spaces, the heat developed by the union will soon make it boil; and presently through the water and glass some of the pieces can be seen to be at a bright red heat; so intense is the fire produced by the application of cold water.

Similar heat has been seen developed in enthusiasts when cold water is thrown on their favourite schemes.

3. Paradoxes of Substance and Form.

The very few people who nowadays have learned no chemistry are much astonished on learning what widely different forms the same element can take.

It is strange enough at first, though we soon get used to it, to find how completely an element can have its nature changed by combination with other elements. The oxygen which we breathe as a gas in the air forms, in combina- 


\section{CHEMICAL PARADOXES.}

tion with another gas, hydrogen, the liquid which we drink as water; and, combined with silicon, it makes the solid quartz, flint, or sand beneath our feet.

An element, however, can sometimes alter its appearance and behaviour without combining with other elements. Thus oxygen, by simply having its atoms grouped in little masses or molecules of three each instead of two each, appears as a different gas, ozone. So sulphur can appear as yellow crystals, as a yellow amorphous solid, or as a soft tenacious mass. Phosphorus may appear as a soft yellow material so combustible as to burn spontaneously, or with a dark colour and not inflammable except at a high temperature.

The most remarkable instance of allotropic forms is given by carbon, which appears as charcoal, graphite, or diamond. In each of these forms it is exactly the same element as in the others; and on burning with oxygen the same weight of each of them produces exactly the same weight of carbonic acid gas. So that coals are quite literally and strictly entitled to their name of black diamonds.

What we have seen to be true of elements is equally true of compounds, a fact designated by the term isomerism. Thus the gas acetylene and the liquid benzene are composed of exactly the same elements in the same proportions. Their different properties depend on the fact 


\section{SUBSTANCE AND FORM.}

that the groups of their atoms (the molecules) are of different sizes and perhaps of different arrangements.

There are three kinds of tartaric acid, all containing the same proportions of carbon, hydrogen, and oxygen. Yet they all act differently upon light. A solution of one turns the plane of polarisation to the right, another turns it to the left ; while the third lets it pass through straight.

Dextrose is a kind of sugar which owes its name to the fact that it turns the plane of polarisation to the right. It is found in sweet fruit, with an equivalent quantity of another sugar, which is called levulose, because it turns the plane of polarisation to the left. Yet both of these sugars consist of molecules each containing six atoms of carbon, six of oxygen, and twelve of hydrogen.

So oil of turpentine, oil of lemons, and oil of lavender all have as chief constituent a substance whose molecules contain ten atoms of carbon and sixteen of hydrogen; but in each of them their substance differs from the similarly composed substances in the others.

It is important, therefore, to remember that nature's cookery can produce very different dishes out of the same ingredients taken in the same proportions and so little altered that they can be recovered in the same state in which they were before the cooking began. 
II.

\section{DISINTEGRATION.}

r. The Philosopher's Stone.

IN the Middle or Dark Ages diligent search was made for the philosopher's stone, the magical material which at a touch should be able to transmute all things into gold. To put it less crudely, the alchemists were hard at work, with the best chemical knowledge of their day, trying to find the means of changing one substance into another, and especially of changing the baser metals into gold.

They had enormous faith in the resources of their art, if they could only learn to command its secrets; and had very little idea of its limitations.

Their faith in the unlimited possibilities of change in the qualities and appearances of substances, was no doubt the growth of the really wonderful changes in these respects which soon became familiar to the merest smatterer in practical chemistry. Those who had seen human knowledge and control of matter manifested to the extent of getting the 


\section{THE PHILOSOPHER'S STONE.}

solid metals, gold and silver, dissolved in clear fluids, and subsequently recovered from them, might well be excused for thinking that no limits were set to human powers in this direction.

The great lesson taught by modern chemical science was that things are what they are, and cannot be made into anything else; that silver may be dissolved and re-precipitated, combined with other substances and separated from them again, appearing sometimes in a solid and opaque form, sometimes liquid and transparent, sometimes as crystals, and sometimes metallic; but that through all the changes there is always present, in whatever forms, exactly the same amount of silver as at first, and that by proper means exactly this quantity of silver can be recovered. Out of a hundredweight of silver not a grain can be changed into any other metal, nor a grain of any other metal changed into it.

The structure of the things in the world was enormously simplified by finding that all the complicated compounds which form our environment could be analysed into (at that time) sixty or seventy simple substances called elements, which, by their combination in different groups and proportions, formed the varied assortment of substances among which we live.

And the more nearly this task of simplification became completed, the stronger grew the 


\section{CHEMICAL PARADOXES.}

conviction that each element was everlastingly individual and unique ; that, whatever changes might be effected by composition and decomposition in the appearances and qualities of the substances made out of the elements, no one element could ever by any means be changed into any other.

Closely associated with this was the other great doctrine of modern chemistry, that the smallest portion of existing things is the atom; and since all existing things are made out of the elements, the smallest portions of the elements are atoms, the atoms themselves being indivisible, unbreakable, and imperishable.

It will be seen that this doctrine of the unalterable nature of the atoms of which ele ments consist necessarily involved the former doctrine that no element could by any means be changed into anything else.

Both of these great doctrines have recently had to be given up.

The researches inspired by the remarkable properties of radium have led to the conclusion that the atoms of which elements are made up, so far from being imperishable, are constantly in certain proportions disintegrating into their still smaller component parts, the corpuscles, and that the phenomena which so strikingly differentiate radium from other things depend upon the fact that its atoms are disintegrating in larger proportion. 


\section{THE PHILOSOPHER'S STONE.}

The questions arise, What becomes of the parts which fly out from the disintegrating atom? And what becomes of the part which remains behind?

A partial solution of the first of these questions was obtained, about three years ago, by Sir William Ramsay, at University College, London. He had the satisfaction of witnessing in his experiment the most interesting event, theoretically, that has occurred in the whole history of science. Having placed in a tiny tube a small quantity of the emanation from radium, he discovered, in a week, the spectrum of helium, a gas which he had himself previously been the first to discover in the world, though astronomers had long since learned by spectroscopic observations of its presence in the sun.

Radium, then, had changed during a week into helium.

Now, radium and helium are, so far as chemical and physical tests can decide the matter, different elements.

Here, then, we have the transmutation of one element into another-in principle, the discovery of the philosopher's stone and the realisation of the dream of the alchemists.

How far it will lead no one can say, or whether we shall ever be able to deal so freely with the transmutation of elements as we can now with the analysis and synthesis of compounds. 


\section{CHEMICAL PARADOXES.}

\section{Disintegration in General.}

The process of disintegration is not a simple one; not only do some of the groups of corpuscles thrown off by the disintegrating atom of radium develop into atoms of helium, but the part left behind undergoes further development through various stages, producing various substances of which lead appears to be the most stable. Earlier still in its own history radium appears to be a product of the disintegration of uranium. Here we have not only four separate elements connected by transmutation changes, but a remarkable instance of the prevalence of the process of disintegration.

Further examination has shown that, besides the other recognised radio-active substances, uranium, thorium, polonium, and actinium, which are undergoing changes of the same nature as radium, and besides the others of a similar character which are being or are to be discovered, many well-known substances show, on very careful examination, that they are capable, though in a much less degree, of the same manifestations as radium, and therefore are undergoing similar degradation changes. Mercury and copper show decided evidence of this character, and as the delicacy of observation has increased it appears to have been practically proved that, though they vary in the degree of their radio-activity, none of the 


\section{DISINTEGRATION.}

elements is altogether free from those degradation changes which cause its excessively slow wasting away. The hardness of diamonds, the strength of iron, the massive solidity of granite, -none of these procures exemption from this universal decay. The process is a remarkable instance of the mills of God grinding slowly and grinding exceeding small. In a very literal sense we have here no abiding city. Grant millions enough of centuries, and every atom of our world will have been scattered into its component dust. 


\section{PART IV. \\ PHYSIOLOGICAL PARADOXES.}

I.

THE EYES, AND PECULIARITIES OF VISION.

I. A Blind Spot in a Sound Eye.

Close the left eye-by putting the left hand over it if necessary-and then holding Fig. 45 level, look with the right eye at the letter $\mathrm{R}$. Although you are looking at $\mathrm{R}$ directly, you can quite easily see $\mathrm{L}$ at the side, without changing the direction of your glance. We can see many things " out of the tail of our eye" while directing the gaze at something else. If the sheet with the letters on it is about ten inches off, bring it slowly nearer, still keeping the two letters level. At about six inches distance from the eye the letter $\mathrm{L}$ disappears from view. A moment before you were not looking at it, but you saw it at the side. Now you are not looking at it, and you do not see it, unless you take your gaze off $R$. But keep your gaze on $\mathrm{R}$ as before, and bring the paper still nearer, keeping it level. L comes into view again. 


\section{THE BLIND SPOT}

Reverse these processes, beginning with the paper as near to the eyes as allows you to see comfortably, and looking at $\mathrm{R}$ with the right eye. $\mathrm{L}$ is seen, though not looked at. Remove the paper to about six inches. $L$ is not visible. Remove it still further, and $\mathrm{L}$ is seen again. The same phenomenon can be seen with the left eye, closing the right eye with the right hand, holding the paper in the left hand, and looking at $\mathrm{L}$.

It thus appears that each eye has a blind spot. The explanation will be assisted by Fig. 46 , which gives a plan corresponding to what
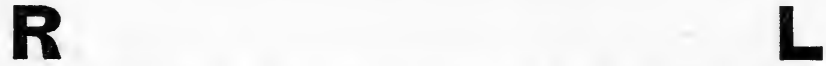

FIG. 45.-DEVICE TO SHOW EXISTENCE OF BLIND SPOT IN EVERY EYE.

would be seen if a section were taken horizontally through the middle of the eyes and looked at from above. $\mathrm{R} \mathrm{E}$ and $\mathrm{L} \mathrm{E}$ are the sections through the right eye and left eye of a person facing towards $\mathrm{A}$, but looking towards B. C represents an obstacle blocking the view of the left eye. Automatically, however, the two eyes converge in the direction of vision-that is, upon $R$. When the right eye is gazing at $R$, that means it is so directed that the light from $\mathrm{R}$, passing through the pupil and lens, strikes the retina at the back of the eye just at the point marked by the end of the line from M L. This point, the macula lutea, or yellow spot, 


\section{PHYSIOLOGICAL PARADOXES.}

especially at its centre, where there is a small central hollow (the fovea centralis), is the part of the retina which is most sensitive to light, and so we turn it directly opposite the incident rays from the object at which we desire to look directly.

But othcr parts of the retina also are sen-

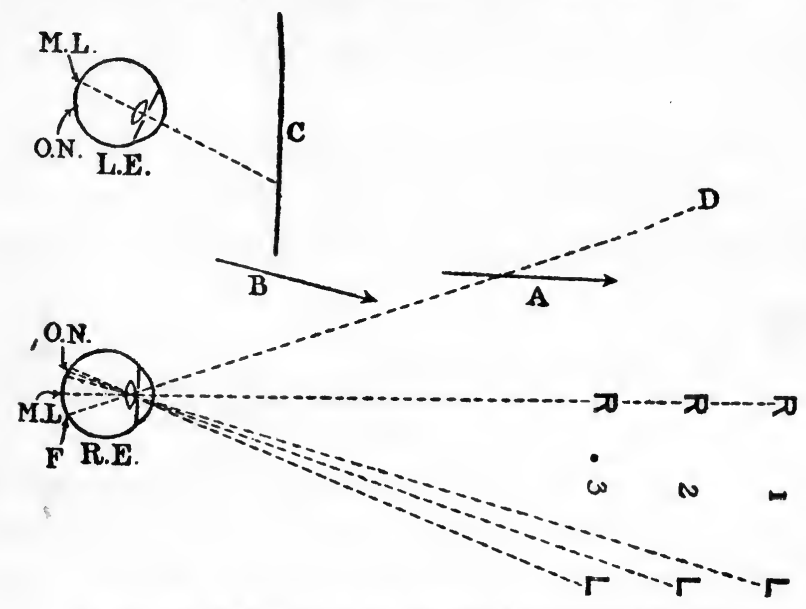

FIG. 46.-EXPLANATION OF BLIND-SPOT EXPERIMENT.

sitive, though less keenly so. Consequently the light from objects at the side, as D and L, produces images, though less distinct ones, at the points marked by the ends of the lines from $\mathrm{F}$ and $\mathrm{O} \mathrm{N}$; and this is how we are enabled to see things which are out of the line of direct vision. Now, it can be seen from the dotted lines that the light from the three L's strikes the retina in three different places if the retina be kept unmoved by keeping the macula lutea 


\section{THE BLIND SPOT.}

always opposite $\mathrm{R}$ - that is, by keeping the gaze on $\mathrm{R}$.

Consequently Lr, L2, and L3 ought to be seen by three different parts of the retina as the sheet carrying the two letters is brought nearer.

But the middle one of these points of the retina, opposite $\mathrm{L} 2$, and marked by $\mathrm{ON}$, is the point at which the optic nerve enters the eye, before it is divided into branches terminating in the sensitive ends all over the rest of the retina which receive the impressions of light.

The nerve itself, where it enters the eye under the name of the optic disc, has none of these sensitive nerve-endings in or over it.

Now, the places to hear telephonic messages are not at the entrance of the wires into the exchange room, but at the instrumental termination provided for the purpose. In the same way there is no perception of light over the optic disc. It is a blind spot.

And the arrangement for approximating and removing $\mathrm{R}$ and $\mathrm{L}$ on a sheet of paper is contrived for the purpose of ensuring an attempt to see with this blind spot in such a way that the failure to do so shall be observable.

\section{The Sane and Sober scemg Double.}

Sit where you can comfortably see a doorknob, clock face, or some other well-defined 


\section{PHYSIOLOGICAL PARADOXES.}

object of moderate size at the opposite side of the room. (Out of doors some equally welldefined object at a distance, such as a flagstaff, factory chimney, or church steeple, may be taken.) While looking at the door-knob, hold up in front of it the first finger of one hand, pointing upwards, the rest of the hand being closed. The door-knob is seen distinctly. Less distinctly, but still quite plainly, are seen two fingers, one on each side of the doorknob.

Now look directly at the finger, which is only six or ten inches from the face. One finger is seen distinctly. Less distinctly, but quite plainly, one on each side of it, two doorknobs are seen.

Now for the explanation.

We saw in the last section that the fovea centralis in the macula lutea in the middle of the retina at the back of the eye is the spot of keenest vision. Consequently, the straight line through this spot and the centre of the lens is the line of direct vision, and that part of the external world which is in this line is the part most clearly seen. So that when we wish to see any object clearly, each eye sets itself so that its own line of direct vision points to the object. Therefore the lines of vision of the two eyes meet in the object. If the object is at all near, these two lines enclose a definite angle, and the two eyes are far from 


\section{SEEING DOUBLE.}

parallel. Yet as each one sees the object in its line of direct vision, the brain receives the sensation of one object only. The images make two impressions, one on each retina, but only one image is consciously perceived.

This state of things is shown in Fig. 47, where $\mathrm{R}$ represents the right eye, and $\mathrm{L}$ the left in a plan view seen from above. Both are directed to the primary object $\mathrm{P}$, and though they each receive a separate impression of it,

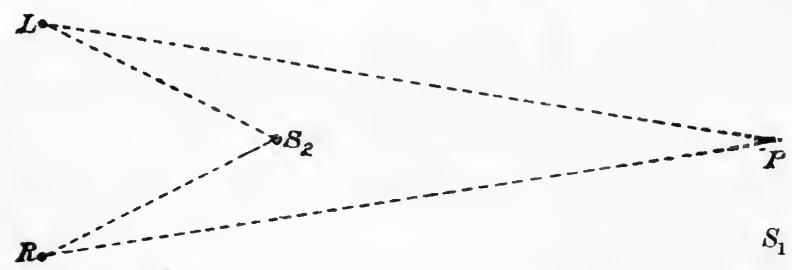

FIQ. 47.-THE BRAIN'S INTERPRETATION OF THE EYES' VISION.

as each receives it in the central line of vision the mechanism of sight-sensation is such that the brain only sees one object.

A secondary object, $S_{1}$, at the same distance from the face, is on the same side of the central vision line for each eye, and in the same part of the field of vision of each eye ; so this also, making two similar impressions on the two eyes which are looking at $\mathrm{P}$, is seen by the brain as one object.

But if there be another secondary object nearer to the face, in the position $S_{2}$, this appears on the right-hand side of the vision 


\section{PHYSIOLOGICAL PARADOXES.}

line of the left eye, and on the left-hand side of the vision line of the right eye. In the two eyes looking at $\mathrm{P}$, it appears in opposite parts of the field of vision. And as the brain recognises only one field of vision at a time, that is for one position of the eyes, images in opposite parts of the field must necessarily look like different objects. Hence it is that when the eyes are looking at the door-knob $\mathrm{P}$, the finger $S_{2}$ is seen as two fingers, one visible to each eye.

Similarly, if the eyes are directed to the nearer object $S_{2}$, their lines of vision run from $L$ to $S_{2}$, and from $R$ to $S_{2}$. Then the more distant object $\mathrm{P}$ appears to the right eye on the right-hand side of the central vision line, and on its left-hand side to the left eye. Each eye perceives it in a different part of its own. field of vision. Consequently, the brain once more, when the eyes are looking at the finger $\mathrm{S}_{2}$, sees the door-knob $\mathrm{P}$ as two door-knobs.

Readers will remember how the poet of Caledonia, after an evening which put him in a position to say

"I was na fou', but just had plenty"

on his belated return to his humble home, diverted his mind from the thought of the reception awaiting him there by turning his attention, poet-like, to the study of Nature. He studied the moon, and speedily found him- 


\section{SEEING DOUBLE.}

self confronted with a problem which he modestly admits his inability to solve :

"To count her horns wi' a' my power

I set mysel' :

But whether she had three or four

I couldna tell."

Let us see whether science can explain the poet's difficulty.

The diagram in Fig. 48, which represents

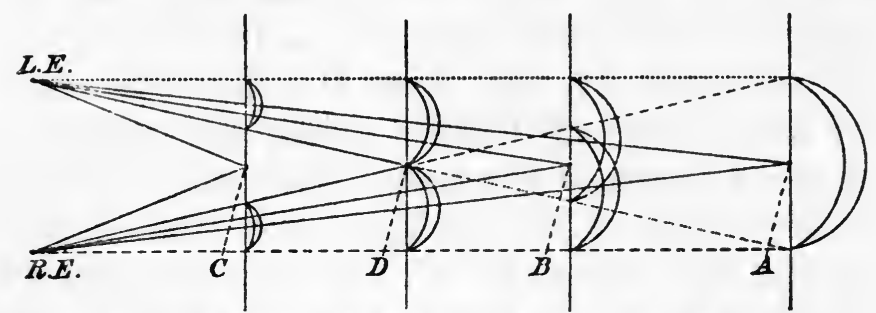

FIG. 48.- THE MOON AS SEEN BY A MAN WHO IS "FOU'."

the facts in exaggerated proportions, will help the explanation.

An ordinary observer of the moon, adjusting his eyes so that their central lines of vision meet in $\mathrm{A}$ at the distance of the object, and at its centre, would receive in his right eye, $\mathrm{RE}$, an image filling the angle outlined by the dash lines, and in his left eye, L E, an image with its boundaries marked by the dotted lines. As these images are identically related to the point $\mathrm{A}$, which is the centre of the field of vision for both eyes, both eyes receive the same image in the same part of the field 


\section{PHYSIOLOGICAL PARADOXES.}

of vision, and the brain is conscious of seeing one moon only.

But the influence of the barley bree, on those who have had so much that they are willing to admit they have "just had plenty," is to interfere with the co-ordination of the muscles. It does not paralyse the muscles, but prevents their contractions from being adjusted with exactness or certainty. Thus the observer in this state will sometimes set his eyes so that their lines of vision converge at the distance $\mathrm{B}$, the point $\mathrm{B}$ being the centre of both fields of vision. Then the right eye sees its image of the moon with one horn far to the right of the field and the other a little to the left, while the left eye sees one horn far to the left of the centre and the other a little to the right. For eyes so converging there are four separate horns visible, belonging to two moons which cross over each other.

But " the poet's eye, in a fine frenzy rolling," as described in anticipation by another poet, Shakespeare, sometimes effected the convergence of its line of vision with that of the other eye at a much nearer point, $C$. In this plane the image for the right eye appears well to the right side of the field of vision, while that for the left eye appears equally far to the left. As the two eyes see them in different parts of their two fields, which to the brain appear to be one field, the conscious vision 
LOOKING THROUGH THE HAND.

is of two separate moons, each complete, though small, which exhibit between them four horns.

When the eyes happen to converge to the point $\mathrm{D}$, the images for the two eyes reach outwards from the centres of the two fields of vision. The brain sees these two centres as one point in space, so that the two moons appear to touch, possessing in the middle one horn-point in common, and a separate one at each end, so as to make three horns altogether.

Thus is justified the poet's hesitation to decide, not between two and four, but between three and four, as the number of the moon's horns.

\section{Looking through the Hand.}

Hold a roll of paper in the left hand, and putting it up in front of the left eye, look through it at some bright object at a distance, such as a picture on the opposite wall. Hold up the palm of the right hand in front of the right eye, so that the edge of the palm is against the side of the roll and about 6 or 8 inches in front of the eye.

The palm of the right hand might be expected to block the view of the right eye, but instead of that the observer feels that he is looking right through a hole in the right hand, somewhere in the position of the dotted 


\section{PHYSIOLOGICAL PARADOXES.}

circle (Fig. 49), and that he is seeing the picture through this hole in the hand.

This appearance, which is well marked and very striking, depends upon the ocular habit of attending to the chief thing, and disregarding others-a habit which, though we may contrive special experiments in which its

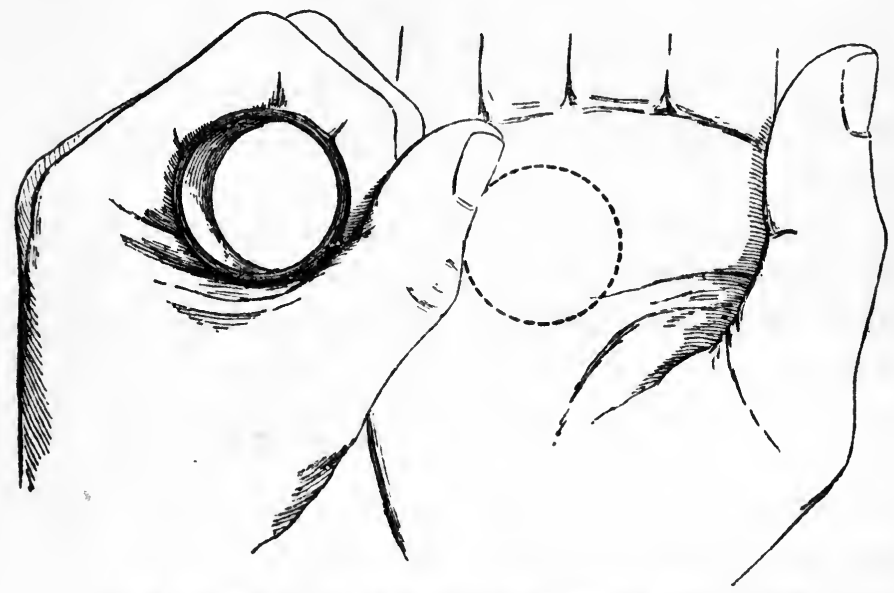

FIG. 49.- HOW TO SEE A HOLE THROUGH THE HAND.

guidance fails us-is for ordinary circumstances very advantageous.

There are three respects in which we can let our eyes disregard unimportant matters, which are, nevertheless, quite visible if we care to attend to them. Firstly, when we want to observe an object, we direct our eyes straight towards it, so that each eye has it in the centre of its field of vision, and then we neglect 


\section{LOOKING THROUGH THE HAND.}

objects which are visible outside the central line of sight. If we look steadily at a picture on the other side of the room, and two yards from the picture is a person at whom we are not looking, although we can see quite well whether that person is reading, writing, or playing cards, as a rule we neglect to note such points because our interest in the picture is keeping upon it the attention of our eyes.

Secondly, we can neglect things that are at the wrong distance for clear vision. We can focus objects at which we wish to look, as truly as a camera or a telescope can. We do it by using certain muscles of the eye to alter the shape of the lens. And when the lens is set for a certain object, others before and behind it are out of focus and consequently illdefined. This helps us to neglect them, and so to escape living in a world of doubles. For, as we saw in the last section, the convergence of the eyes upon the object looked at causes nearer and farther objects to appear duplicated.

Lastly, when one eye only can see the object we wish to look at, we neglect the things seen at the same time by the other. A rifleman can perfectly well learn to sight the target with his right eye without for a moment closing the left. He can neglect its vision for the time being.

Similarly, in the foregoing experiment, the left eye, looking through the tube at the 


\section{PHYSIOLOGICAL PARADOXES.}

definitely illuminated wall, sees there such distinct objects that it unconsciously focuses the wall by modifying its lens. But in this matter the two eyes cannot act separately, so the right eye is automatically set at a long focus, too. Consequently, anything quite near, such as the palm of the right hand, is very hazily and indistinctly seen, and the image of it is easily neglected in comparison with the brilliant scene offered to the other eye by the portion of wall which is in view. Outside this limited view the vision of the left eye is limited by the circle of the paper roll. Not so with the right eye. It is free to see the palm of the hand-indistinctly, because it is out of focus, but quite perceptibly.

Thus we get the following combination :The left eye sees distinctly the portion of wall enclosed within the ring of the paper roll, in comparison with which the right eye neglects the corresponding part of its own field of vision, including part of the palm, which is out of focus and indistinct. Outside this part of the field of vision, the right eye sees the rest of the palm-indistinctly, because out of focus, yet positively. In comparison with this, the left eye neglects the corresponding part of its field, the interior of the paper roll, which is equally out of focus, much darker, and in strong contrast with the well illuminated and well focused image coming through it. 


\section{LOOKING THROUGH THE HAND.}

Shortly, the left eye sees part of the wall, and the right eye sees part of the palm. The brain combines them as one image- a round piece of wall seen through a round hole in the hand-the rest of the images being neglected.

That these things are only neglected, not unseen, can easily be shewn by helping some of them to attract attention in a way very similar to that once adopted by ladies in the beauty patch. Let a small piece of stamppaper be stuck in the palm just where the hole is to appear. This will come into view, and by careful observation it will be possible, while still focussing the wall, to see the part of the palm where the hole is, and even to detect some of the palmistry lines in this area.

Similarly, if a tiny hole be made in the side of the tube, this will let light through, and so make it possible to attend to the image of the inside of the roll, on which writing, printing, or parallel lines may be observed.

\section{Blue and Yellow not producing Green.}

Those who in their childhood played with a box of colours-and how many have not done so ?-soon learned that when the green tablet was lost, a fair substitute could be got by mixing blue and yellow, just as a mixture of 


\section{PHYSIOLOGICAL PARADOXES.}

blue and rose would produce purple, or red and yellow would produce orange.

Asked, then, what colour they would expect to see if they covered the light of a darkroom lamp first with a yellow sheet of glass and then with a blue one over the yellow, most people would be inclined, if the suspicion of a catch did not hinder them, to say that the light would look green. This, however, it would not do.

Yellow glass looks yellow for two reasons : because it lets yellow light come through, and because it absorbs and stops all other rays. The second reason is quite as important as the first. Similarly, blue glass is blue, not only because it lets blue rays pass, but because it stops all others. Through the yellow glass, therefore, the blue one receives no blue rays, nor any others except the yellow. Receiving no blue rays it can pass none. The yellow rays which it does receive it cannot pass, because it is in virtue of its inability to pass any rays except blue ones that it is blue. And it receives no others. It has, therefore, no rays that it can pass at all.

In other words, a light behind both blue and yellow glass should be made black or dark if the two colours are pure and deep and there is no refraction from the surfaces of the glass. And the result is sufficiently near blackness to surprise those who look for green. 


\section{SEEING COLOURS.}

5. Looking at One Colour, and seeing Another.

We have all seen in the monthly magazines the soap advertisements which depend upon staring at some strongly coloured letters; but many have not examined them with the attention which they deserve as paradoxical phenomena of genuine scientific interest.

Take from the shelves a book which is bound in some strong, bright colour, such as a vivid red. If there are letters printed or stamped on it, mark some small point where two lines cross ; if it is plain, make a very small mark upon its surface. Keeping the head steady and the book still, stare hard at this mark for a minute or half a minute. During this time do not let the gaze wander from the small mark to any other part of the surface. This fixity of gaze on one spot is contrary to natural tendencies, and will require great determination. After about half a minute close the eyes and cover them with the hand. An image of the object looked at will be seen, but not in its natural colour.

The colour seen will be the one complementary to the natural one-that is, the one which, if compounded with the natural colour, would give white. So, if the book be a bright red, the after-picture will be green, and vice versâ. Yellow gives rise to blue, and blue to yellow. 


\section{PHYSIOLOGICAL PARADOXES.}

The nerve endings, which are sensitive to light, are liable, on excessive stimulation, not only to fatigue, but to reaction in the form of automatic negative stimulation. For a very rough analogy to the result, which does not pretend, however, to explain the mechanism, we may consider a steel spring. If we disturb this from its neutral position by bending it to one side, the further we do this the more difficult it becomes to do it further still, and the more strongly the spring tends to bend back past the neutral point in the opposite direction.

If our visual nerves are stimulated by all the rays of light which go to make orange, they undergo fatigue for that colour stimulus-orange is less able to produce a vivid sensation.

Not only so, but when that stimulus is withdrawn, the result of the first stimulation is a reacting or negative stimulation, producing a sensation of what may be called the opposite kind of light - that is, the light which would result from all the rays of white which were not present in the original stimulus.

It seems a pity that the negative or reacting effect, producing an opposite sensation, is not found in more of our nerves. When the nerve of a tooth has, by contact with food, been stimulated to agony, the immediate removal of the stimulus is by no means followed by the opposite sensation of pleasure. On the contrary, the agony often grows keener with time. 


\section{II.}

THE EYES AS FALSE WITNESSES.

I. Opposite Movements looking Identical.

A SURPRISINGLY large part of what we believe that we see is not directly seen with the eyes, but inferred, however swiftly and instinctively, by the judgment, from previous knowledge and experience. This explains the well-known frequency with which honest witnesses of the same events see in them things which are different, and even contradictory.

If a windmill is seen at a distance on a dark and cloudy night, with no light behind the spectator, and only a dull sky behind the mill, no details are visible. Only large masses can be seen, and these without any gradation of shades to help in defining relative distances or obliquity of surfaces. The mill, as seen under these circumstances, may be represented diagrammatically by $\mathrm{A}$ in Fig. 50. Of the movement of the sails all that can be seen is that they rise on the left and fall on the right, like the hands of a clock, and that their ends describe an ellipse, not a circle. This shows that their plane of revolution is oblique to the spectator; but whether they 


\section{PHYSIOLOGICAL PARADOXES.}

are nearer to him when on the right hand side or on the left, he has no means of knowing. The actual facts seen by him in A would correspond equally well both to the arrangement shown at $B$ and to that shown at $C$.

But the mind, in drawing its conclusions, does not limit itself to the information supplied on each occasion by the senses. It relies also on the help of unconscious reasoning and on the instinctive judgment which has grown out of past experience.
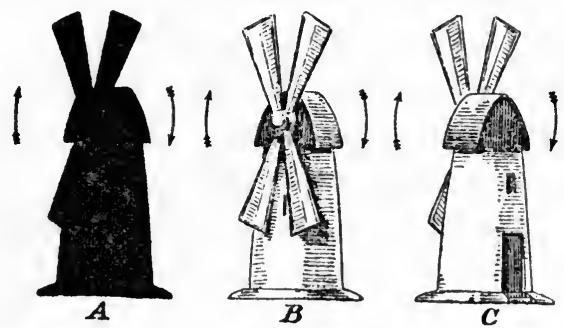

FIG. 50.-LIMITATIONS OF SIGHT: MENTAL INTERPRETATIONS.

It may be, for instance, that there is some general practice in building the sails of windmills, to construct them all to turn in the same direction. The rule may be to construct them so that a spectator with his back to the wind would always see them going round clockwise. In that case, a miller from a distance, seeing the view suggested in $A$, and feeling the wind to be somewhere from his left towards his right, would be sure that he was looking towards the front of the sails, and 
FALSE INTERPRETATION.

that the actual arrangement was that shown in $\mathrm{B}$, since in that position alone could a wind from the left send the sails round clockwise, if they were set in the regulation way.

But the local miller, knowing that these particular sails were built against the rule, so as to go anti-clockwise as seen by a spectator with his back to the wind, would know from a glance at the scene suggested in $A$, that the only actual arrangement possible, with a wind somewhere from the left, was that shown at $\mathrm{C}$.

Thus two witnesses-each, as far as could be judged, a competent man-might honestly give opposite evidence as to a scene which they had witnessed at the same time from much the same point: one testifying that the sails were in front of the mill, the other that they were behind it.

With unskilled observers it would be a matter of what we call chance whether in the view $A$ they first saw the arrangement $B$ or $C$. But whichever arrangement was first realised, it would get such a hold on the imagination that for most persons it would be impossible afterwards to realise the other. First impressions would give the same conviction as technical knowledge, and from such persons also we could easily get honest yet absolutely conflicting evidence.

A somewhat similar case is that of a small 


\section{PHYSIOLOGICAL PARADOXES.}

boat seen on the distant horizon after sunset against the evening sky. The diagram A, Fig. 5I, suggests the distance and smallness of the object seen upon the edge of the dark sea. It is too far off and too ill lighted for the set of the sails or the pointing of the boat to be seen; but a few minutes' observation shows that it is travelling in the direction of the lower arrow-head. As the wind is blowing in the direction of the upper arrow-head, it is

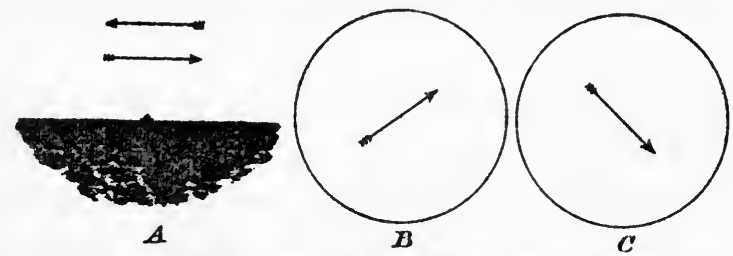

FIG. 51.-LIABILITY OF INTERPRETATIONS TO ERROR.

obvious that the boat is tacking, but on which tack it is cannot be seen. A bird's-eye or balloon view of that part of the sea might show that the boat is moving in the direction $\mathrm{B}$ or in the direction $\mathrm{C}$; which of the two the eye cannot distinguish.

Here comes in the influence of habitual knowledge and unconscious judgment.

A fisherman fifty miles away, who happened to observe this boat on the horizon, and could only see that she was moving to the right against the wind, but was well acquainted with the fishing customs of that part of the coast, might easily say to himself, without 


\section{FALSE INTERPRETATION.}

taking a moment for thought: "Here comes the first of the fleet back to port." He would instinctively feel that she was tacking in the direction marked $\mathrm{C}$, and would be prepared to testify that he saw a boat sailing to shore.

But a native of the port, knowing that on this occasion the fleet from that port was not expected back for several hours, and knowing that a boat had sailed to the west just sufficiently long ago to have reached the position of the observed vessel while sailing in the direction $B$, might be ready to testify confidently that at that hour he saw a craft sailing away from shore.

Thus two honest and apparently competent beholders of the same boat's movement at the same hour might afterwards bear confident witness, one that he saw it sailing into port, and the other that he saw it sailing out to sea.

In numerous cases, not so easily set forth as these, we are liable to mistake for things actually seen what are partly acts of judgment or imagination founded, and sometimes wrongly founded, on what we have seen.

\section{False Parallels.}

It is not only the politician, on the side opposed to ours, who is guilty of employing deceptive parallels. Nature herself practises the same trick. 


\section{PHYSIOLOGICAL PARADOXES.}

Very often, when the clouds lie in streamlines along the sky, it will be observed, on looking at those which are low down near the horizon, that there is a point on the horizonline from which all the cloud-lines in that half of the sky seem to radiate, some sideways and some upwards, much as suggested in Fig. 52. If there are cloud-lines all over the sky, the observer should turn round and mark the part of the horizon exactly opposite to this point of convergence. The second

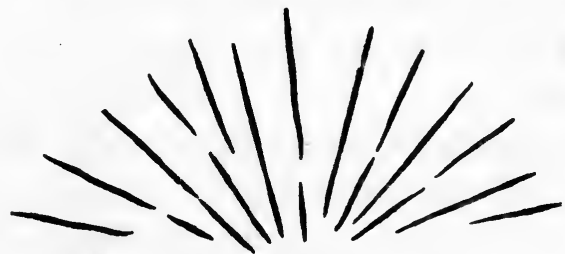

FIG. 52.-APPARENT CONVERGENCE OF CLOUD-LINES.

point will also appear to be one towards which all the cloud-lines in that half of the sky converge. There are two such, one opposite to the other. This phenomenon is not always very plain. Sometimes the cloud-masses are rounded, shapeless, indistinct, and not definitely arranged in lines or streams. Yet even the apparently irregular clouds will often be found, on close observation, to be arranged in rows or ranks; and if these be regarded as the cloud-lines, two opposite points of convergence will be found, as described above.

Where this arrangement of clouds is well 


\section{FALSE PARALLELS.}

marked it is almost impossible for the beholder to doubt that his eyes see cloud-lines which are actually nearer together at their extremities than they are in the middle of the sky.

This is one of Nature's deceptions. The cloud-lines are really parallel; they do not converge at all.

If we look along any long lines which are parallel to each other, they appear to converge
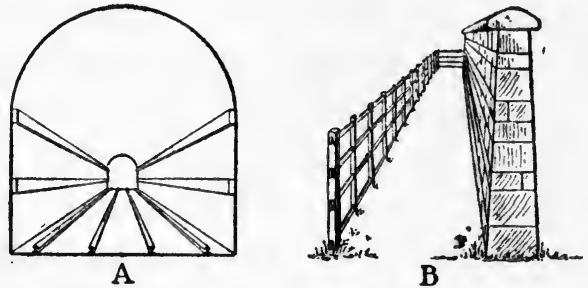

FIG. 53.-A LAW OF PERSPECTIVE.

together towards the end which is farthest from us. Thus if we look along the inside of a tunnel towards the entrance, as in Fig. 53, A, or the railway lines in Plate VI., we see the rails and the other lines of the tunnel, which we know to be really parallel, appearing almost to run into each other at a distance. Or, if we look along a straight piece of path, bounded by an iron fence and a wall, as in Fig. 53, B, we notice the same thing. This is a wellknown effect of the conditions of vision, which is called one of the laws of perspective. 


\section{PHYSIOLOGICAL PARADOXES.}

It would involve too long a digression to go fully into the explanation of this; and it must suffice for the present to say that the lines of vision for equal spaces enclose smaller angles at the eye when they are remote from it than when they are near to it; so that the distances between parallel lines look smaller when far off than when close to.

This law of perspective, illustrated in avenues of trees, long dock-sheds, pier-columns, embankments, and numerous other objects, are illustrated also by the clouds. The manner in which clouds are formed frequently results in their being ranged in lines. Even when these lines, owing to their being parts of a cyclonic or anticyclonic system, are in reality parts of the circumferences of concentric circles, or parts of diverging radii, the circles involved are of such enormous size, and the portions of cloud-lines under observation are relatively so small, that they are indistinguishable from lines which are truly straight and truly parallel. So it is possible for a person, in very thick, foggy weather, to follow the fence right round a circular racecourse, under the impression that he has been walking in a straight line; or for two persons to move away from the fence in lines at right angles to it and not far apart, under the impression that these lines were parallel, whereas they are really lines meeting in the centre. 


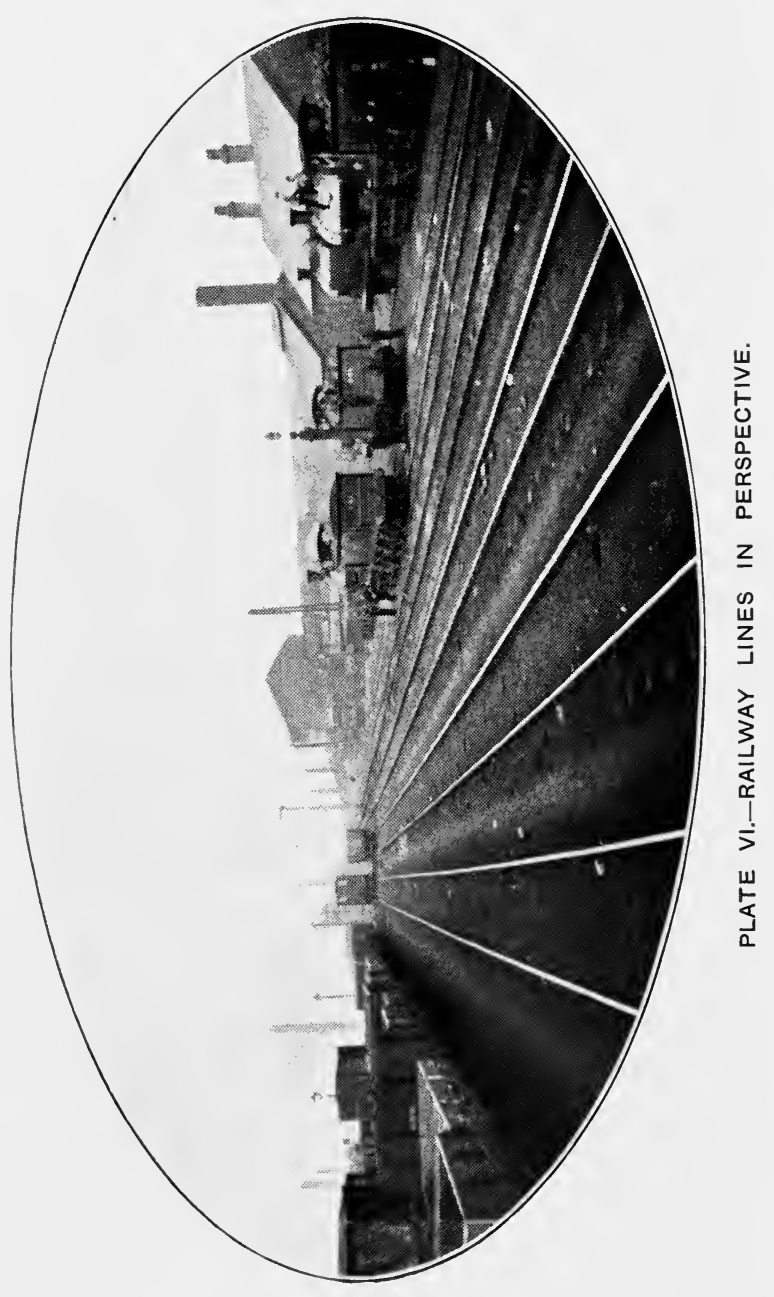





\section{FALSE PARALLELS.}

Well, the cloud lines being, within the limits of human observation, parallel, they come under the law of perspective which has been referred to, and so, to our eyes, they appear to approach one another as they recede from us. Now, they are nearest to us where they are directly overhead; and here they look fairly parallel. Forwards and backwards, as the distance increases, they seem to draw nearer together, till, as they approach the horizon, the

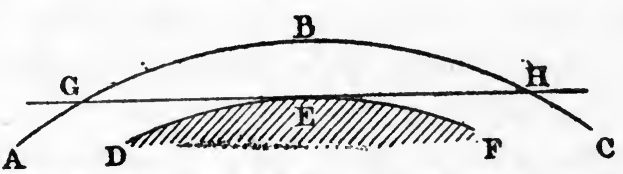

FIG. 54.-THE SPHERICAL SHAPE OF THE CLOUD FIRMAMENT

ends of the lines appear to converge towards a point not far beyond it.

Hence their apparent arrangement like the leaves of an opened fan.

In the case of the clouds this effect is intensified by the fact that the ends of the lines are actually lower than the middle. If the cloud firmament were a plane, perfectly flat and level, under the law of perspective, its edges, with the ends of the cloud lines, would appear nearer to the horizon than their middle part does to the earth's surface. But the cloud firmament, A B C, in Fig. 54, is not a plane, but a spherical outline, concentric with the spherical surface of the earth, DEF; and it actually does cut the horizon-line GE H. The 


\section{PHYSIOLOGICAL PARADOXES.}

effect of perspective is to bring apparently nearer to the spectator at $E$ the points $G$ and $H$, at which the clouds really do come down to horizon-level, and so to give a sharper slope to the appearance of spreading upwards and outwards. The appearance of spreading outwards, however, is appearance and nothing more.

\section{False Levels.}

The view of a scene often produces a wrong impression as to which parts of it are higher and which are lower.

Cyclists, who are very sensitive to fine differences of level, not seldom find that a road which presented the appearance of a fairly stiff rise in front of them is in reality level, or even slightly down-hill. More frequently, but less agreeably, it happens that what looked in front like a coming occasion for easy driving or possibly free-wheeling, is actually more or less of a rise.

Such errors are usually made by the judgment rather than by the eyes. We misinterpret the appearances caused by a level beyond a rise, or a dip beyond a level, a gradual widening or narrowing, a passage into or out of shade, an increase or decrease in the size of trees adjoining the road, a difference between the actual gradient of the road and its general direction up or down a valley or a mountain. 


\section{FALSE LEVELS.}

A few well-known instances will illustrate this.

We often find, on traversing it, that country which from high up a mountain had looked as flat as a billiard table is really undulating, or even hilly, with upland and hollow, highly perched castle and deep ravine, long sloping meadows, and streams between steep wooded banks. The effect of viewing this tract from a great height was to smooth away all the hills and produce an appearance of dead level.

Yet, strange to say, a view, from a similar great elevation, of a considerable hill not far off on the other side of a valley, will make it look steeper and higher than it looked from beneath. And in the same way a view of the sea from a high hill close to it presents it as a considerable hill rising upwards from the shore.

So that viewing scenery from a great height sometimes has the effect of diminishing hills till they disappear altogether, sometimes exaggerates their height, or even makes hills appear where there are none.

These contradictory effects are due, some of them to the nature of the impressions made by actual outward facts upon the eye, others to erroneous judgments caused by applying to unusual cases the instinctive habits acquired in and suited to ordinary circumstances.

When the point of view is low down, the 


\section{PHYSIOLOGICAL PARADOXES.}

existence of hills and hollows is made obvious by the fact that the prominences obstruct the view of the low ground beyond them. When the point of view is very high, this guide to the structure of the country is withdrawn, because the eye looks down upon the surface of hills and hollows alike; while the difference of distance between the higher and lower parts is so small in comparison with the distance of both from the observer as to be imperceptible, so that it forms no guide to height. In such cases we

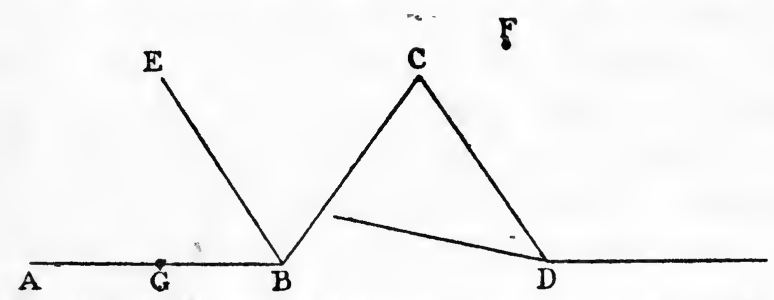

FIG. 55.-VARIATIONS IN APPARENT STEEPNESS OF HILLS.

actually see a view in which there is no representation of higher and lower levels.

Where we think that we see heights greater than those which exist it is the thought, rather than the sight, that is in error.

Suppose A B (Fig. 55) to represent a stretch of flat country, and B C D a hill. Familiar with the level ground, we judge of the steepness and height of the hill by the inclination of its face, B C, to the level ground-in other words, by the size of the angle A B C.

But if, instead of level ground at A B, there 


\section{FALSE LEVELS.}

be a hill, whose face is $B E$, and we look at the hill $B C D$ from a point $E$ well up the hill $A B E$, having now $E B$ instead of $A$ B for our base-line, the face of the opposite hill BC makes with this base-line an angle $\mathrm{EBC}$, which is much more acute than the angle A B C. Though we know that the base-line $\mathrm{EB}$ is not level, as A B is, our minds and eyes so constantly associate steepness and height with the smallness of the angle between the baseline and the hill, that we cannot help thinking the hill-face B C looks steeper and higher seen from a point $E$ on an opposite hill than from a point $\mathrm{A}$ on the level.

And in the case of the sea viewed from high up a steep hill close to it, this effect causes the appearance of elevation in the sea, which is level, so that it looks as if it were a hill of water.

The apparent height of a hill, as seen from an opposite hill, is exaggerated by two other causes.

Any height seems greater from above than from beneath. We so much more frequently s ee the height of a tree, a church-tower, or even a steep hill, from beneath than from the top, that the same height seen from the top is much more impressive, and consequently seems much greater. Thus a hill seems higher viewed from the top than from the valley; and an opposite hill, of obviously equal height, shares this increase of apparent height. 


\section{PHYSIOLOGICAL PARADOXES.}

Lastly, a view from an opposite height often brings into view higher portions of a hill which had been invisible from the lower ground. Recurring to Fig. 55, we see that if the hill B C D had a higher summit F, this would be invisible from $B$ or $G$ on the level ground, being concealed behind the lower shoulder $\mathrm{C}$, while it would be brought into view by climbing up the opposite hill to $\mathrm{E}$.

Thus there are several ways in which viewing a hill from an opposite hill makes it look higher, while it is undoubtedly the case that small hills looked down upon from a mountaintop lose their apparent height and often cease to be distinguishable from level ground.

\section{False Continuity.}

Our eyes see great differences in the surface and texture of objects. A sponge, a heap of grain, a heap of lump sugar, are all obviously porous and discontinuous masses. Sandstone, brick, and paper are less obviously of the same structure, yet a little close observation shows that these also consist of separate pieces with spaces between, though the pieces and spaces are both on a smaller scale.

Many other substances appear to be of an entirely different construction. The surface of the skin, the nail, a glass tumbler, or a copper tube, the inside material of a piece of wax, or 


\section{FALSE CONTINUITY.}

a lump of lead, all these seem to be absolutely continuous, to have no intermediate spaces, and not to consist of a multitude of little bits either loosely heaped or firmly cemented together.

Close observation shows that this obvious impression is erroneous. The wing of a butterfly or brightly coloured moth, the petal of a geranium or iris, smooth and polished as they

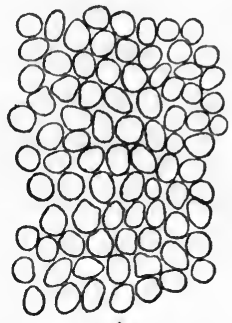

A.
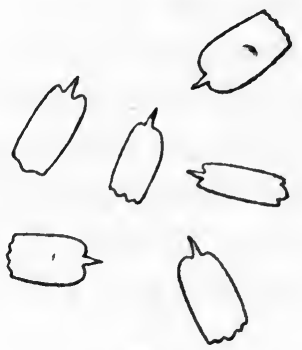

B

FIG. 56.-DISCONTINUITY: FLOWER PETALS AND SCALES OF MOTH'S WINGS.

seem to the eye, are really built up of separate pieces as a house is of bricks.

Seen through a microscope, the petal of a flower is found to be constructed as shown at A (Fig. 56), where the round, or rounded, masses are separate coloured cells, with uncoloured spaces between them. B shows the appearance, similarly magnified, of scales from a moth's wing, which in their natural position are arranged all in the same direction, neatly overlapping one another like slates on a houseroof. 


\section{PHYSIOLOGICAL PARADOXES.}

On a larger scale, precisely the same result can be observed without the aid of a microscope. The field which in May looks half a mile off like a huge piece of polished emerald, really consists of myriads of separate blades of grass. In July a stretch of the hill-side which presents, across the valley, the appearance of a huge patch of soldiers' scarlet, or of a slice cut out of the blue sky, is actually composed of innumerable separate flowers of poppy or of lavender. We must be always on our guard against thinking that a surface or a substance is continuous because it looks so. The fact is simply that there is a limit to the smallness of things observable by our eyes, and when the size of several contiguous objects is so small or the distance so great that the angle they subtend at the eye passes these limits of smallness, they can no longer make separate impressions, but they unite to produce a common effect, and thus cause an appearance of continuity which has nothing in reality corresponding to it. 


\section{III.}

THE EARS AS FALSE WITNESSES.

\section{Ventriloquism.}

THE ear is no judge of the direction of sound or of its distance. These things are inferred from the properties of which the ear can judgenamely, its intensity, its pitch, and its quality or timbre, which is, after all, only the special combination of sounds of different pitch.

The first point-as to direction-is illus-

$\times \mathbf{B}$

Dx

EX

\section{$X \mathbf{A}$}

F.X

FIG. 57.-EXPERIMENT ON LIMITATIONS OF HEARING.

trated by the following well-known experiment.

A person is seated on a chair, blindfolded. Two others stand beside him, one at each hand. One of them holds in his fingers two coins, which can be clicked together, or any other apparatus for making a small noise. The click is made 


\section{PHYSIOLOGICAL PARADOXES.}

irregularly, in various positions, such as A, B, C, D, E, F (Fig. 57), all in the fore and aft plane through the centre of the head, and the sitter is asked to guess each time from which direction the sound came. To neutralise indications given by the sound of moving limbs or sleeves, each performer moves his hands each time to some other positions in the central plane.

The sitter has surprisingly little powerin fact, no power, of judging whence the sound proceeds. He may guess rightly sometimes; but it is a mere guess, and owing to the greater number of possible wrong positions than of right positions, his wrong guesses are much the more numerous. He will frequently guess that the sound comes from $\mathrm{D}$ when it comes from $\mathrm{A}$, and will mistake a sound from $\mathrm{F}$ for one from $\mathrm{C}$.

It is true that something can be learned as to direction, but not by the ear alone. The facts presented by the ear are worked up by the reason, though so quickly sometimes that it seems instinct rather than reason that is at work. In the above experiment, if the click be made to one side of the middle line, the sound is heard more distinctly by the ear on that side, and the sitter at once gives a correct indication as to the side. So, when we want to judge on which side a cuckoo is calling, we find by trial that position of the head in which the sound is loudest for one ear, and if, on turn- 


\section{VENTRILOQUISM.}

ing completely round, we find that the sound is then loudest for the other ear, we judge that it comes from that side. This, however, is not being told the direction by the ear. The ear tells us only when the sound is most intense, being a good judge of intensity, and the reason then judges by our position of the direction of the sound.

Similarly the ear is no judge of distance. The following cases, both of which came within the author's personal experience, will illustrate this.

Two men were in a large bedroom, their beds being about three yards apart. In the stillness of the night one of them heard a slight sound, as of someone stepping stealthily on the gravel drive, which came close under the windows, then pausing a short time as if listening or looking into windows, and afterwards going stealthily on again. He asked his friend if he heard someone creeping over the gravel, and, receiving an affirmative reply, went to one of the windows and looked out and listened. He neither heard nor saw anything, and went back to bed. The same thing happened again, and with the same result. On hearing the sound a third time, he rushed to the window, threw it open quickly, and leaning out to look round, called out a challenge. Nothing could be seen or heard, and on closing the window once more he listened very carefully 


\section{PHYSIOLOGICAL PARADOXES.}

till the sound began again, and then detected its origin in the fluttering of a moth at the top of the window between the blind and the glass.

The small sound in the same room had so closely imitated a greater sound at a distance as thoroughly to deceive two people who were listening very carefully.

It was not their ears that had misled them and that eventually discovered the truth. The ears had merely given information as to the quality, intensity, and duration of the sound; and from these facts the mind had drawn inferences, at first incorrectly, as to the direction from which it came and as to its origin.

Somewhat similar in the relation between cause and effect was the circumstance which furnishes the next example.

Everyone who has spent much time in an arable district, in autumn and winter, is familiar with the loud droning noise made by the threshing-machine, and knows what a definite individual character it has. This sound was distinctly heard in the stillness of the night, about as loud as if it came from a farmstead half a mile away, sometimes stopping and starting again, sometimes louder or quieter, as if the wind were changing its direction and speed.

The difficulty was that the neighbourhood was a residential suburb, and the nearest farmstead was two miles away, with intervening 


\section{VENTRILOQUISM.}

hills. No threshing-machine could have been heard so far. Moreover, it was near midnight ; no threshing-machine would have been at work at such an hour.

A careful examination showed that the sound could be heard much more plainly in one part of the room than elsewhere. We were getting warmer. Following this trail, we soon found a spot where the noise was distinct and individualised by those small subsidiary noises which prove a sound near. It was finally identified as proceeding from a narrow crack between the window-frame and the wall, where a little plaster had fallen away. The wind blew through this crack and caused the vibration of a half-loose piece of wall-paper which projected over the crack and acted like the tongue of a reed instrument, producing a note which varied in strength with the force of the wind.

Here, again, we have the ears giving information as to the intensity, quality, and pitch of a note, and the mind, upon this information, trying to base conclusions, at first unsuccessfully, as to the distance and possible direction and origin of the sounds which are heard.

Although in the ordinary affairs of life the formation of a judgment by the mind follows with instinctive rapidity upon the perception of sounds by the ear, so that we commonly think we hear where a sound is as well as what 


\section{PHYSIOLOGICAL PARADOXES.}

it is, still the process in the mind is a separate and distinct one from the process in the sense of hearing, and according as the other conditions vary, it can lead to different conclusions from the premises which, so far as the ear has supplied them, are identical.

It is of this principle that the ventriloquist takes advantage in producing his illusions.

If there were a person outside on the top of a building, going along the roof-ridge, his voice would come to the floor, or the inside of the building, muffled and faint. As he went further along towards the end of the building his voice would get fainter and fainter. We, sitting inside the building, could only hear of the voice that it was muffled and faint, and getting fainter. Of its direction and distance our ears could tell us nothing themselves. But our minds would judge, from its muffled nature and increasing faintness, that its owner was outside the building and going further off; and if the voice itself told us that its owner was moving along the roof-ridge, that suggestion would readily take root in our minds. If someone were calling to him in that position and getting rational answers back, the suggestion would gain imperative force.

This is the state of affairs which the ventriloquist brings about. When it is the turn for the man on the roof, the ventriloquist produces muffled and faint sounds such as we should 


\section{VENTRILOQUISM.}

hear from a man in that position. When it is his own turn he speaks with a full, clear voice, which serves well to bring out by contrast the faintness of the other. The matter of his remarks and of his interlocutor's bears out the suggestion to the full. The one weak point in the deception might have been that the voice supposed to come from the man on the roof comes really from the man on the stage - that is, from the wrong direction; but, the ear being no judge of direction, and the mind being supplied with materials for judging the direction wrongly, this is not a weak point in practice.

Incidentally, it may be mentioned that the word "ventriloquism "-speaking from the belly -is not a good one. The ventriloquist has to conceal from the audience the fact that when it is his interlocutor's turn, he is himself really speaking. To this end he employs various artifices. By pointing and other gestures he directs the eyes of the audience from himself elsewhere. Bending down sideways and putting up his hand to his ear, ostensibly to listen carefully, he contrives to hide his lips to a great extent from view. When unable to hide his face he limits the movements of the lips to the very least that is necessary for speech, and it is surprising to see how little facial movement will suffice a skilled performer. It is a help in this matter that the circumstances of the case 


\section{PHYSIOLOGICAL PARADOXES.}

often require only indistinct and muffled utterance as in the instance above. By these and other devices the employment of the lips for speaking is so well concealed that some people used to believe the performer produced the voice lower down than the lips and throathence the name ventriloquist.

\section{False Continuity.}

The limitation of our sense-perceptions in the direction of smallness produces erroneous ideas in connection with hearing, as well as with sight.

Whenever we hear a beautifully produced smooth musical note, we inevitably think of it as something which is acting smoothly and continuously upon the ear.

This is not the case. The smoothest musical note consists of a succession of waves in the air produced by a succession of blows upon it. The blows are delivered either by successively escaping portions of compressed air, as in whistles and reeds, or by some rapidly moving object, as with strings and bells.

The blows vary in the rate at which they are struck. In the deepest musical note they succeed one another at the rate of about 40 per second, and in the highest at the rate of 4,000 per second. We can hear sounds which are beyond the musical range in both direc- 


\section{FALSE CONTINUITY.}

tions, having vibrations from as few as I6 to as many as 38,000 per second.

It might be thought that if sound be due to the air being struck a succession of blows, we should perceive it as a succession of separate impressions.

And so, indeed, we do, under certain circumstances. If a man with a very deep voice speak with his back leaning against the back of a form, his voice can be felt as vibrations by another person leaning against the same formback. Or the fact can be observed simply by placing the hand on the front or back of his chest while he is speaking, especially if he be requested to say " ninety-nine."

And if we try to use bass notes which are too deep, we begin, even with the ear, to perceive the separate vibrations of which the notes consist, which is the reason why the musical scale cannot reach to the bottom of the audible scale.

But, for the most part, musical notes are, in fact, heard, not as successions of separate strokes, which they really are, but as continuous states. How is this?

It depends upon the fact that impressions on the ear, like those on the eye, are not instantaneous, but last for a definite time. It is on this principle that the cinematograph works. The impression made on the eye by one picture remains till the next impression is 


\section{PHYSIOLOGICAL PARADOXES.}

made by a very similar picture in exactly the same position. So we get the effect of changes in one and the same continuous picture-or we should do so, if the instrument did not jump, and if cracks in the films did not produce frequent representations of lightning in weather and scenes in which it is inopportune.

So with sound and hearing. Each impression lasts for an appreciable time; and if, while it is still in force, another impression of exactly the same kind is made-if, that is to say, the sound is a musical one, not too deep in the bass-each impression keeps up the effect produced by those which preceded it. Thus an intermittent succession of separate sounds affects our perceptions as one continuous sound without a break.

Here we have another instance of the untrustworthiness of the senses as instruments of scientific research. They tell us, usually with great efficiency, until they have become dulled by what we call civilised life, the facts which it is important for us as animals to know correctly; but they are unreliable informants as to the causes, means, and processes to which the facts owe their existence. 
IV.

\section{THE TOUCH A FALSE WITNESS.}

I. The Hotter feeling the Colder.

Not only are heat and cold relative things, greater cold meaning simply a state in which there is less heat; but our perceptions of heat and cold are relative also. A thing is felt to be hot or cold in relation to the temperature of our body or part of our body; and not merely in relation to the natural heat of the blood, a little over $98^{\circ} \mathrm{F}$., but in relation to the previous temperature of the hand or other part, which may itself have been heated or cooled by contact, with air, water, or other substances. A well-known instance makes this principle very clear.

Take three large jugs of water, one as warm as it can be without discomfort to a hand which remains in it for some time, one cold, and the third obtained by mixing equal parts of the two preceding, so that its temperature will be intermediate. Fill the basin A (Fig. 58) from the jug of warm water, B from that of cold, and $C$ and $D$ with the water of intermediate temperature.

Let some person who has not seen these 


\section{PHYSIOLOGICAL PARADOXES.}

arrangements being made, and who is blindfolded to prevent him from seeing vapour from the warmer water, hold his hands for a minute one in the water in $\mathrm{A}$ and the other in that in $B$, and then say which is the warmer. He will, of course, say that A is decidedly warmer than B. Let him then take his hands out of $A$ and $B$, and put them immediately into $C$ and $D$, which are both of the same temperature, and say at once which is the warmer. He will be sure to say that $\mathrm{D}$ is, unless he knows the
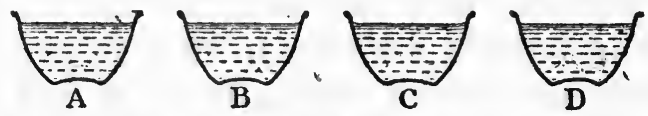

FIG. 58.-THE NERVES AND IMPERFECT SENSE OF TEMPERATURE.

trick from previous experience, and wishes to have the amusement of spoiling the trial.

The reason of his mistake is very plain. The hand which went into $\mathrm{C}$ had previously been in very warm water, so that $\mathrm{C}$ felt much colder. The hand in $\mathrm{D}$ had previously been in cold water, so that $\mathrm{D}$ felt much warmer. The sensation of relative temperature or change of temperature is much finer than that of actual temperature, so that while the right hand feels a clear sensation of being warmed, and the left of being cooled, the judgment inevitably decides that the agent which is producing the former effect is itself warmer than the other.

The paradox can be pushed a little further 260 


\section{TACTILE PERCEPTIONS.}

by putting into $\mathrm{C}$ somewhat more of the warm water than into $\mathrm{D}$, so that its contents are finally the warmer of the two. Nevertheless, the effect of contrast is so great that $\mathrm{C}$ will still be felt to be the colder, even when it is the warmer.

The effect of the surprise upon the person experimented on may be heightened by using one long dish or other vessel instead of the two basins $C$ and $D$, and letting the subject of the experiment have the cover taken from his eyes immediately his hands, removed from the two first basins $A$ and $B$, have been placed in the one long one. He then sees that the hands, which he had supposed to be in two different vessels containing water of different temperatures, are both in one and the same vessel of water.

2. Pain in the Foot when the Leg has been amputated.

To feel pain in a limb which one has no longer got seems absurdly impossible, yet it is a not uncommon experience.

It may happen in common experience that in a limb which is present we feel a pain which is not really present in the limb. This may easily occur in dreams, for instance, or in hysteria. Hysterical patients frequently suffer from the sensation of pain in parts of the body 


\section{PHYSIOLOGICAL PARADOXES.}

which are really free from pain; and it is not much more wonderful than this to suffer pain in a part of the body which is not actually present.

The fact is that pain is a feeling of the mind, and what happens in the limb is only part of the train of events which produce the feeling in the mind. The mind is in connection with the bundles of nerves which, running down the middle of the backbone, form the spinal cord. Groups of these bundles branch off from time to time to go to various limbs and other parts, much as a wire, or group of wires, branches off from the main collection by the roadside, to go to some town or village. Now, one of these wires can be cut at a point far from its destination, and through an instrument connected with its new termination messages can be sent to the head office in London which will seem as if they had been despatched from the old termination.

So with the severing of nerve-trunks in an amputation. Each fibre of the nerve ran to some definite part of the extremities of the body. When the nerve has been severed each one of its constituent fibres has been severed. In the process of healing or afterwards, when the contraction of the scar or some other cause of irritation stimulates some of the fibres of the nerve, it produces effects somewhat similar to those which would have 


\section{NERVES AS MESSAGE CARRIERS.}

been produced if the fibre were still continued to its original destination and were stimulated there, and they would arouse in the brain much the same sensation as before. So that if the fibres stimulated were those which formerly ran to the toes of the right foot, the patient may feel a pain or tingling in those members, even after the right leg has been amputated.

\section{Immediate Action Impossible.}

We have often been told to do such and such things immediately. To these orders obedience in the most strictly literal sense is impossible.

First of all, the command, when received, has to be conveyed by nerves from the ear or eye to the central administration office, the brain. The brain, after doing a certain amount of office work in recording the receipt of the message, and its relation to other events preceding or contemporaneous, sends out an order to the hand or foot which has to perform the evolution necessary to the accomplishment of the command, and this last order has to travel along the nerves to its destination. Now, the nerves, in carrying messages, behave in much the same way as the wires of the electric telegraph, to which they have been very frequently compared. 


\section{PHYSIOLOGICAL PARADOXES.}

But the nerves are very different from the wires in one respect, the speed at which they carry their messages. The electric current passes along wires at a speed which would enable it to make the circuit of the world a good many times in a second ; for small distances it is practically instantaneous. The speed of the message along the nerves is not nearly so great. It has been found on measurement to be between thirty-five and fifty yards per second.

There is, therefore, an appreciable time during which an order is being transmitted from the ear or eye to the brain, and another interval while the stimulus from the brain is passing along other nerves to the muscles which have to act.

Theoretically, then, it is impossible for the most willing servant to obey immediately, though practically it makes a great deal of difference whether the bell or signal be the one to begin work or to cease work.

\section{False Continuity in Sense of Touch.}

The sense of touch is limited, like the other senses, as to the possible fineness of our observations.

The skin of the back and of parts of the arms cannot distinguish between points which are two inches or more apart. If the point of a 


\section{SENSE OF TOUCH.}

pair of compasses be separated for that distance and placed simultaneously on these parts (not too forcibly if the points be sharp), the skin has the sensation of being touched by one point only. The back of the hand can distinguish points an inch apart, the palm of the hand points less than half an inch, and the end of the forefinger can distinguish points as near together as one-twelfth of an inch. The most sensitive part of the body in this respect is the tip of the tongue, which can appreciate the twenty-fourth part of an inch.

Substances like sandstone, which have very small prominences at a distance from one another of less than the twenty-fourth part of an inch, cannot have their projecting parts distinguished by the most sensitive skin; but that they have such parts can be felt by the appreciation of what we call roughness-that is, the capacity for producing a quantity of friction which is great in proportion to the surface and pressure.

But there are some substances, like glass, glazed pottery, and polished metal which, even to the most sensitive parts of our touch-organ - the skin-seem to have an absolutely smooth and continuous surface quite free from projections with intervening spaces.

The microscope once more shows that the apparent smoothness and continuity are only relative. Polished metal surfaces show the 


\section{PHYSIOLOGICAL. PARADOXES.}

grain of crystalline formation. Edges apparently clear and sharp show jagged and notched serrations when sufficiently magnified. It is with the sense of touch as with the other senses : to its imperfection only is due any evidence that we have, in things natural or artificial, of perfectly smooth continuity.

\section{Achilles and the Tortoise.}

We have had several occasions to consider cases of a deceptive appearance of continuity where things were not really continuous; and this will be a fitting place to consider the false continuity of motion, which may be suitably introduced by the classical puzzle of Achilles and the tortoise.

Achilles, having a world-wide reputation as a sprinter, was greatly surprised to receive from the champion of slowness, the tortoise, a challenge for a hundred yards' race on handicap terms-a start of 50 per cent. Being more amused than piqued, however, at what he considered the challenger's impudence, he readily consented to a meeting. He made no difficulty of granting the very long start of half the course, believing himself easily able to cover more than nine yards for the tortoise's one, and so to concede, if required, a start of 90 per cent. and win. To his astonishment, however, he found, when the race actually 


\section{ACHILLES AND THE TORTOISE.}

came off, that though he got upon terms with his antagonist as easily as he had expected, he could never quite get level-an experience with which he was so dumbfounded that in helpless surprise at his own incompetence he came to a full stop, and in stupefied astonishment stood so long stock-still that the tortoise had time to crawl slowly in a winner.

The difficulty which beat him is illustrated in Fig. 59. A is scratch, where Achilles starts. $\mathrm{T}$ is mid-distance, the starting point of the

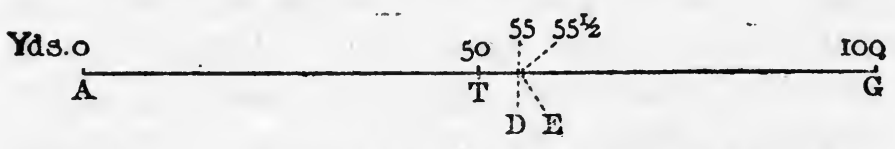

FIG. 59.-A HANDICAP RACE IN THE PURSUIT OF SCIENCE.

tortoise. $G$ is the goal, at the end of one hundred yards. Achilles travels ten times as fast as the tortoise; but the latter, slow as he is, does go five yards while Achilles covers the fifty which separated them at the crack of the pistol. Their positions, then, at the end of the first stage are at $\mathrm{T}$ and $\mathrm{D}$, the tortoise being still five yards to the good. While Achilles covers these five yards, the tortoise is able to go half a yard further, and their positions at the end of this second stage are at D and E. While Achilles covers the half-yard which now separates them, the tortoise gets another distance in advance, and so, at the end of the third stage, is still leading by the 


\section{PHYSIOLOGICAL PARADOXES.}

twentieth part of a yard-one inch and fourfifths. At the end of the fourth stage, his lead is reduced to a very little less than onefifth of an inch.

This goes on indefinitely. At the end of each stage the tortoise's lead, however much reduced, still exists; and during the next stage, while Achilles traverses the space which constitutes this lead, the tortoise is again getting one tenth of that distance in advance. As he is able to do this at the end of every stage, however great the number of the stages may be, it follows that he can always keep in front by some little distance, however infinitesimally small; in other words, Achilles can never quite catch him up, much less pass him by.

It was the unexpected appearance of this theoretical difficulty that so struck the champion of a heap. He was presumably stronger in the heels than in the head (though, indeed, one of his heels was the weakest part of his frame), so that the necessity of facing a mental difficulty of this magnitude overwhelmed him and left him so helpless that the tortoise had time to reach the goal. Otherwise, the most that the latter competitor could have effected would have been to make a draw; since an infinite number of stages, each one-tenth of that preceding it, could never have added up to the half of the course, which lay between his 


\section{ACHILLES AND THE TORTOISE.}

starting-point and the goal. He could never have got more than a fractionally small distance beyond $\mathrm{E}$ in the diagram.

Now, the question propounded is-what is the fallacy in the foregoing argument which professes to prove that Achilles, travelling ten times as fast as the tortoise, could never overtake it? What is the precise point in which it goes wrong?

Learned mathematicians, when asked this question, usually give a reply which, in one form or another, amounts to the following argument.

Let it be granted that Achilles can run the distance in $x$ seconds ( $x$ would be about ten if ancient times were something like as good as modern). Then, since Achilles is ten times as swift as the tortoise, the latter will require Io $x$ seconds for the course, and therefore $5 x$ seconds for half the course, which is the actual distance he has to go. But $5 x$ is greater than $x$, therefore he will arrive later than Achilles. That is, Achilles must win. Therefore the above argument to prove that he cannot pass the tortoise must be wrong.

Wonderful mathematician! Even the wayfaring man, with the well-known qualification, could not miss his way to that conclusion. It is plain to all of us that Achilles will win. We are none of us in danger of putting our money on the tortoise. We know that the 


\section{PHYSIOLOGICAL PARADOXES.}

argument must be wrong. The question issound as the argument seems in every detail, what is the detail in which it begins to go wrong, and how ?

The mathematician, driven, in spite of his learning, to recognise the real nature of the difficulty, resorts to an artifice in the form of a mathematical convention, which he attempts to palm off upon us as the real solution. Infinitely small things, he says, having no real size at all, are equal to one another, so that when the distance between Achilles and the tortoise has become infinitely small, it is equal to the distance between him and a point in front of the tortoise, and he can traverse the latter distance in the same time as the former.

But mathematical conventions can only be allowed to pass while we remember that they are conventions, brief statements summing up the facts with an error so small that for practical purposes it does not matter. When attempts are made to use them as strict statements of exact truth, and arguments are founded upon them, they lead us astray.

When we speak of infinitely small spaces, if we mean spaces which, though very small, are nevertheless real and actual, it is obviously not true to say that they are all equal. A real space can be divided into two, and by an inevitable axiom, it is greater than either of its parts. If, however, we mean spaces too small 


\section{ACHILLES AND THE TORTOISE.}

to have any objective existence for us, too small not only to be measured, but even to be expressed, mere figments of the imagination, then the imagination can follow them into their differences, and while recognising that they are so small that neither they nor their differences can have any importance in practical calculations, we can nevertheless conceive of their being divided into parts, and then we must necessarily conceive of the whole as being greater than any of its parts.

If, therefore, we admit as mathematical conventions that infinitely small things have no size and are equal to one another, these are only brief and convenient ways of saying that such things are too small for their sizes or their differences of size to be worth taking into account in any practical calculations. But to found an argument upon them as exact expressions of strict truth is inadmissible.

Moreover, if it were true that infinitely small things are all equal, this would tell against the mathematician's explanation even more decidedly than for it. For at each stage of the race, the infinitely small distance that the tortoise went ahead would be equal to the ten times greater distance covered simultaneously by his antagonist, and so he would still be the same distance in advance. Not only could Achilles never pass him, he could not even keep gaining on him as before. 


\section{PHYSIOLOGICAL PARADOXES.}

Since the swift, however, do sometimes pass the slow in a handicap, there must, as the mathematician has demonstrated, be some very definite fallacy, though he could not discover it, in the argument which would make out that this never could happen.

The difficulty in finding it is due to the fact that it is not a mere verbal or syllogistic fallacy which could be excluded by careful adherence to the rules of logic, but consists in the application of one of the most radical conceptions of the human mind, which, nevertheless, we may find it necessary to revise, that of the continuity of motion and space.

Our persuasion that there is continuity in sounds heard and in things seen or touched is equally deep-rooted, but we have already learned that this persuasion cannot stand against a close observation of the facts. It may prove to be equally unreal in the case of motion and space.

Now, the argument against Achilles winning depends upon the assumption of this continuity, or, to put it in another way, upon the assumption of the infinite divisibility of motion and space. We say, at a certain point in the argument, however small the distance between the competitors, while Achilles is traversing that distance the tortoise can be going a still smaller distance in advance. Perhaps this is not true. Perhaps there is a limit to the 


\section{ACHILLES AND THE TORTOISE.}

possible smallness of distances in actual fact, though not in our imagination; and it may be that when the distance between the runners has been reduced to a certain degree of smallness, it will be impossible for any smaller distance to exist, and so the scheme on which we have made the tortoise able to keep in front becomes impossible.

A diagram will make the matter clearer. Take the race at a point where Achilles has so nearly overtaken the tortoise that the distance between them is so excessively small as to be

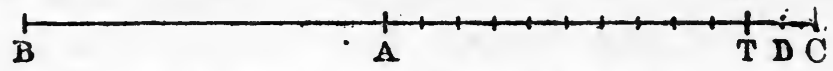

FIG. 60.-SPACE AND LIMITS OF DIVISIBILITY.

approaching the size which we call infinitely small. In order to examine the state of things, then, we shall have to view a part of the course enormously magnified, so that it may appear, as in the diagram, some millions of times its actual length. Let A (Fig. 60) be the position of Achilles, and $T$ that of his competitor. While the tortoise travelled his last stage from A to $\mathrm{T}$, Achilles had travelled ten such stages -namely, B A and nine equal stages preceding it. Then, says the argument, while Achilles travels the next equal stage A $T$, the tortoise goes on one-tenth of that distance from $\mathrm{T}$ to $\mathrm{D}$. Quite right. And then again, proceeds the argument, while Achilles travels from $T$ to $D$, 


\section{PHYSIOLOGICAL PARADOXES.}

the tortoise gets one-tenth of that distance in advance of $\mathrm{D}$.

But let us suppose that there are no smaller distances than TD. How this could come about we will consider afterwards. For the present we will reflect that though we can conceive of half or quarter of the distance $T D$, many things are conceivable which do not actually exist or happen. It is quite conceivable that a pound of lead might become a pound of gold. It is conceivable that a gold sovereign, shut up in the purse, might become two sovereigns ; or even that we might hear of a rich relative having died in Australia and left us heir to half a million sovereigns. But it does not follow, because a thing is conceivable, that it is true, or even possible. And so it may be that there is in nature a limit to the possible smallness of things, spaces, and movements.

If, then, $T D$ is the smallest possible or existing space, it follows that the tortoise cannot travel one-tenth, one-half, or any other fraction of $\mathrm{T} \mathrm{D}$. His next stage must be equal to $\mathrm{T} \mathrm{D}$, namely $\mathrm{DC}$. But while the tortoise travels from $D$ to $C$, Achilles goes ten times that distance-namely, T D, D C, and eight other spaces each equal to $\mathrm{D} \mathrm{C}$. He thus gets eight such stages in advance of the tortoise.

Thus with the postulate that space is not infinitely divisible, we can not only explain in detail exactly where the error is in the argu- 


\section{ACHILLES AND THE TORTOISE.}

ment that Achilles could not pass the tortoise, but we make it plain also how he necessarily will do so. As no other explanation can be given which is not an illegitimate and unilluminating juggle with words, and as we know from the facts of observation (corroborated by the reasoning of our friend the learned mathematician) that the swifter actually does pass the slower in a race, we have no choice but to accept the explanation as true, and to believe that there is a limit to the smallness of things, spaces, and motion.

This postulate, however, is so much at variance with our accustomed habits of thought, that it cannot be expected to pass without itself receiving careful consideration and an attempt at explanation. When we think of the flight of a bird or a bullet from place to place, the attribute we would most confidently assign to such flight is its continuity. Admitting that the speed of flight may have increased or decreased, either progressively or intermittently, we cannot, without special consideration, imagine that any portion of the space included in the flight could be too small to have been separately passed through after the preceding and before the succeeding spaces have been entered upon.

To understand that there may be spaces too small for separate movement-that is, that movement may not be continuous, we 


\section{PHYSIOLOGICAL PARADOXES.}

must begin by remembering that matter is not continuous. The hardest crystals, the most ductile metals, the clearest liquids, all consist of invisibly small molecules separated by numerous spaces. The molecules are built up of separate atoms which also have much freedom of movement within the molecules. The atoms themselves consist of minute corpuscles which have relative motions of the greatest activity and occupy individually much less space in the atom than one gnat does in a swarm of gnats. So far from continuous is the structure of even the densest and heaviest elements, such as uranium, radium, platinum, gold and lead. It is possible, and even probable, that the corpuscles themselves consist of still smaller particles or granules which have as free movement, relatively to each other, as have the corpuscles which form atoms.

Now, it is quite conceivable that there may be a limit to the smallness of particles or granules of matter. It is difficult, indeed, to conceive that there should not be such a limit. There was, it is true, a time, and that not very long ago, when it was more natural to believe that there was no such limit. We could crush a piece of sugar into small pieces, each of these into smaller, and with the assistance of smooth, hard surfaces and a microscope, we could effect and prove still further subdivision. So that it seemed fair to say that the only limit 


\section{ACHILLES AND THE TORTOISE.}

to a continuation of this process was the imperfection of our instruments of crushing and observation. That meant that there was no natural limit to the divisibility of substances.

For more than a hundred years now, however, since Dalton promulgated his great atomic theory, we have been accustomed to think we had scientific evidence that all things are constructed of similar small portions of definite size, called atoms, which are indivisible and indestructible, so that with their separation the process of subdivision must stop-not accidentally, because of the limitations of our instruments, but of necessity, because of the natural structure of things.

Of late years, it is true, this theory has had to be revised. There has been reason to think that the Crookes tube, which produced Röntgen rays, contained matter in a finer state of division than atoms, that atoms within it were broken up into corpuscles or radiant matter, as it was called. This view has been strongly confirmed by the study and explanations of the phenomena connected with radium and similar substances. And it may yet become necessary to accept the divisibility of corpuscles into still finer portions of matter.

But the habit of a hundred years being still strongly upon us, and being itself a natural mode of connected thought, having been very fully realised by Democritus and Lucretius 


\section{PHYSIOLOGICAL PARADOXES.}

more than two thousand years ago, we can hardly help believing there is a real and natural limit to the divisibility of matter-that is to say, substances are constructed of small particles or granules which are themselves indestructible and indivisible.

The conception of matter as not infinitely divisible makes it easier to think of motion in the same way. But for those who find a difficulty in believing that a thing may be true without having an idea of some way in which or some means by which it can be true, it will be helpful to consider, by way of illustration, the details of arrangements which would bring about the same state of things on a larger scale.

Suppose that ten acres of ground were divided into squares of one yard each in the manner shown in Fig. 6r. Let each square yard be covered by a board of the same size, which is swung on pivots so that by suitable electric connections and power contrivances it can be quickly turned over. Let all the boards be green on one side and red on the other.

If this piece of ground be viewed from a great height on a distant mountain, when all the boards have their green sides uppermost, it will look much like an ordinary green field of very uniform colour-say a field of young wheat. The distance will be too great for any of the boards or the divisions between them to be visible. 


\section{ACHILLES AND THE TORTOISE.}

Now let the electrician cause the three boards A B C to turn over suddenly all together, so as to show their red side. Similarly, let the three next, D E F, be turned over immediately afterwards, and in quick succession $\mathrm{G} \mathrm{H}$ I. A

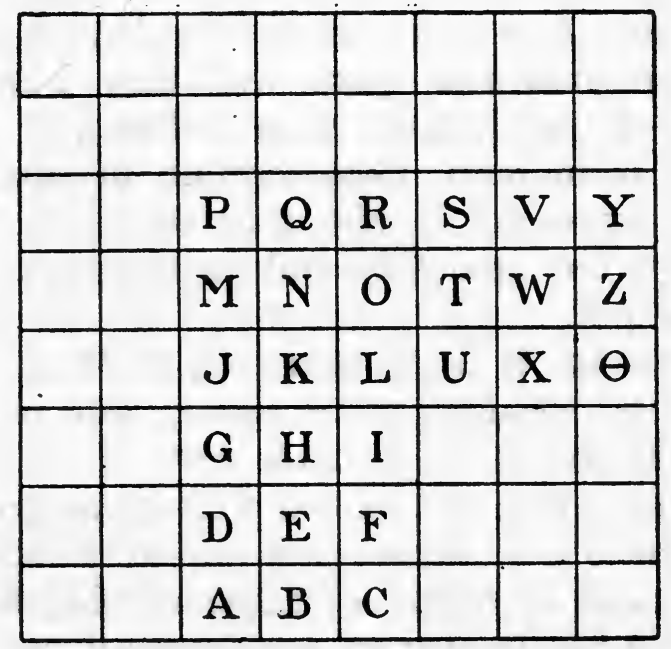

FIG. 61.-DISCONTINUITY OF MOTION.

spectator on the mountain would now see that a small red square has suddenly appeared near one edge of the field; or, being too far off to see the exact shape of the square, he might note simply that he saw a small red spot.

Immediately after $\mathrm{G} H$ I have turned their red sides up, let $\mathrm{J} \mathrm{K} \mathrm{L}$ do the same, and simultaneously let A B C be turned over again so as to show their green sides once more. Then let $\mathrm{M} \mathrm{NO}$ be turned to red and $\mathrm{DEF}$ 


\section{PHYSIOLOGICAL PARADOXES.}

to green, and immediately afterwards $P Q R$ to red and G H I to green.

There will now be no red at A I, where the red spot originally was. It will be at $J R$ having travelled by successive jumps through the positions $\mathrm{DL}$ and $\mathrm{GO}$. But these jumps have been to a spectator on the distant mountain so small and quick that they have not appeared as jumps. The individual movements have been imperceptible to him, and it has appeared to him that the spot moved quickly, but smoothly and continuously, from A I to $\mathrm{J} \mathrm{R}$.

Now let $\mathrm{S} T \mathrm{U}$ turn red, $\mathrm{P} M \mathrm{M}$ simultaneously turning green again, and so with $\mathrm{V} W \mathrm{X}$ and $\mathrm{Q} \mathrm{N}$ and with $\mathrm{Y} Z \Theta$ and $\mathrm{R} O \mathrm{~L}$. The spot of red will appear to have changed its direction and moved steadily to $\mathrm{UY}$; and it might continue moving in this direction for twenty or one hundred yards, or change its direction again and move towards any other point. Through all these movements the spectator on the distant mountain would appear to have seen the red spot change its position much as we think we see a fly crawl over the window-pane or a player run over the cricket ground, sometimes faster, sometimes more slowly, sometimes in one direction, sometimes in another, but always with continuity - that is to say, never passing from one position to another without having been at each 


\section{ACHILLES AND THE TORTOISE.}

of the intermediate positions during the intervening time.

Now we, who have seen in detail the working of the boards which cover the ground, know that his impressions are wrong in two respects.

In the first place, it is not true that any object has moved from A I, where he first saw the red spot, to U Y or any more distant position. All the boards which he first saw at A I, with their red sides up, are still there, with their green sides up. And when he sees the red object at $U Y$, there is not anything there, as he imagines, which has come from A I.

Secondly, the motion of colour which he has seen take place from A I to J R, and from $\mathrm{J} R$ to $\mathrm{UY}$, has not been, as he imagines, a continuous motion. When it advanced beyond G H I it never occupied half, or quarter, of $\mathrm{J} \mathrm{KL}$, for there are no half or quarter boards. Each board turns over as a whole.

Thus we see that the continuity and even the reality of the movement of objects may be entirely deceptive.

To the latter point we will return a little later. At present we will consider how this illustration helps to apply the principle on which we criticise the argument against Achilles beating the tortoise-the principle that space is not infinitely divisible.

In the field which we have described above let there be two red spots moved by two 


\section{PHYSIOLOGICAL PARADOXESิ.}

operators, one of whom can operate twice as fast as the other, so that his spot can advance two yards while the other advances one; and let them have a race across the field, the fast one beginning at the side and the slow one with a start of less than one quarter of the distance to be traversed. Since the latter moves only half as fast as the other, it cannot move threequarters of the distance while the fast one goes right across; and it is therefore certain to be beaten, though the fallacious argument against Achilles might be adopted as follows:

Suppose the slow one has a start of thirtytwo yards ; then, while the fast one covers this distance, the slow one gets another start of sixteen yards. While the fast one covers this sixteen yards, the slow one goes eight yards further in advance, and so on continually, always getting a further start equal to half the distance which separated them at the commencement of each stage.

No. When the distance between them is reduced to one yard, the slow one cannot afterwards get half a yard in advance, because there are no half-yard boards. What happens is that while the slow one goes another yard, the fast one goes two and gets level. For the next yard of the slow one the fast one goes two, and is well ahead.

Thus we see that, by accepting a limit to the divisibility of distance or space, we are 


\section{ACHILLES AND THE TORTOISE.}

able to understand how the swifter can overtake and pass the slower. Not, remember, to understand that it can do so. That is easy enough. But to understand in detail how it can, in spite of the argument against Achilles.

The illustration of the field shows us how this can come about by our being so far removed from the objects that things and movements which are really discontinuous appear to be continuous.

But this result could equally well be brought about by a sufficient smallness in objects which are near to. A small object near to can subtend as small an angle at the eye as a larger object at a distance. It is only necessary, then, to believe that objects consist of very small particles or granules, to understand that changes of state can pass over them which affect our eyes, touch, ears, even aided by the most delicate instruments, as continuous changes, while in reality they are fragmentary and interrupted. And this belief is one which science has already, on other grounds, adopted. It is generally accepted now that the particles or granules of which substances consist are excessively small; and, if not definitely laid down as a conclusion, it is, at any rate, a constant postulate of scientific thought, that they are not infinitely small.

In the preceding discussion one consideration has been postponed. Our field consisted 


\section{PHYSIOLOGICAL PARADOXES.}

of square boards, and when a red patch, consisting of nine of these boards, and looking at a distance like a small red spot, was seen to move from one part of the field to another, there was, in fact, no real object which did move across the field. Now, in real life we have not merely surfaces, but substances (with depth as well as length and breadth), to deal with. Is it conceivable that, when the substantial objects with which we are acquainted appear to move from place to place, this appearance is due not to the movement of any substantial object, but to the cessation in one place of arrangements which produced the phenomena of that object and the production of those arrangements in fresh positions, so as to give the appearance of movement of the object? This would be parallel, in our field of boards, to the cessation in one place of the arrangement of boards with red sides up and the production of this arrangement in other positions.

Such a scheme is not only conceivable. It is as much in accordance with the facts of observation as any other scheme of matter and motion, while better able, as we have seen, to explain such facts as the swifter passing the slower.

There is already good reason to believe that all matter would prove, on its ultimate analysis, to be material of one kind, and that 


\section{ACHILLES AND THE TORTOISE.}

the various phenomena of what we call the different elements and compounds are due to differences in the groupings, arrangements, and vibrations of the ultimate particles of which matter consists. Thus we know that colour is a question of texture. Chemical composition is largely a question of grouping and arrangement. Heat, light, electricity, and gas-pressure are questions of vibration. Magnetic attraction, frequently a manifestation of electric energy, is therefore a question of vibration. Possibly also the attraction of gravitation itself is another question of special forms of vibration; and it may be that, as changes in the condition of iron can vary the degree in which it is the seat of magnetic attraction, so changes, not at present under our control, in the vibrations of the ultimate particles may vary the degree in which they are the seat of the energy of gravitation-that is, may change the weight of objects.

We know also that matter can influence other matter in its neighbourhood. Heat, light, electricity, and magnetism are all cases which exhibit the energy of matter displaying this tendency, which often takes the form of a tendency of the special kind of energy to reproduce itself in surrounding matter; and these manifestations often show themselves in definite relation to local direction.

It is quite conceivable, therefore, that what 


\section{PHYSIOLOGICAL PARADOXES.}

we call moving a substance really corresponds to the appearance of moving the red spot in our field of boards. It may mean setting in motion some machinery not yet understood which controls the vibrations of the ultimate particles of matter as our wires and motors control the turning of the boards in our field.

In that case, when the phenomenon occurs which appears to us the movement of an object, what actually happens is that the special vibrations which have produced the appearance of the various qualities of the object cease in the particles which have been their seat, and are immediately communicated to the adjoining particles in one direction. These in their turn pass them on to the next, and they to the next, and so on while the energy which set up the transference lasts. Thus the appearances of the body move through spaces which are far less than microscopically small ones, depending upon the sizes of the ultimate particles or the distances between them. These movements are separate and distinct jumps, like the movement of the red spot from one row of boards to the next. But the jumps are so small that, though the succession of a sufficient number of them produces a visible movement, the separate advances are not detectable by our most delicate instruments, much less by our senses, and so the movement appears to have smoothness and continuity. 


\section{V. \\ BODILY STRUCTURE. Valves.}

I. Pumps without Pistons : Self-repairing

ONE of the most interesting applications in Nature of mechanical contrivances for the performance of mechanical work is seen in the case of the veins and the heart. The heart is a great pump for driving blood to all parts of the body. The veins contain a series of pumps for drawing it back to the heart. These pumps have two great advantages over the forms which we make of metal. They are selfrepairing, and, owing to their elastic and collapsible structure, they are able, like our bellows and spray and syringe-balls, to dispense with pistons. It is the latter condition that makes the former possible; for, if Nature had ever developed an apparatus like our piston and cylinder, with the complicated arrangements necessary for working the piston, it is difficult to see how it could have been contrived that such apparatus should have had the power of growth and self-repair.

The blood-pumps of the body, then, work 


\section{PHYSIOLOGICAL PARADOXES.}

in the same way as the ball of a sprayer, by alternate compression and relaxation, or systole and diastole, as the physiologists call these movements. The compression squeezes the blood away, forcing it along the pipes, and then the relaxation allows a fresh quantity to accumulate ready for the next compression.

Though the method of action is different, the result is the same as in our metallic pumps; and in each case there is the same necessity for valves to prevent the fluid flowing back while the fresh charge is accumulating. In the physiological as well as in the metallic pump the valves are fittings of great importance. If they do not close tightly, some of the fluid already once driven out leaks back into the space which ought to be accumulating an entirely fresh supply, much of the energy of the pump is wasted, and it has a difficulty in maintaining the proper pressure.

Now the inside of the veins and heart cannot be got at for constantly recurring operations, such as the paring of the nails, the rubbing of the eyes, or the blowing of the nose; and so it is essential that the valves should be of a nature which admits of their coming into existence by ordinary processes of bodily growth and keeping themselves repaired and in good working order by similar means. Instead of being separate pieces, like the valve of a metallic pump, they must be an outgrowth or modifi- 


\section{VEINS AND HEART.}

cation of the surrounding tissues, just as, for the same reason, the forcing has to be done by compression of the whole apparatus, instead of by movement of a separate part, such as a piston.

We will take, first, the pumping machinery of the veins as the simplest modification of the pipes or tubes which convey the fluid.

The veins contain blood, which has to be urged towards the heart. Their walls are very soft and flexible, so that they can easily be flattened by squeezing. Squeezing them flat drives out the blood to some other part of the veins; but it must be driven towards the heart, not away from it. And that which has been driven on must not be allowed to return and take up the room of the further quantities which ought to follow. These two objects are secured by an arrangement of valves at intervals along the course of the veins. The valves are so arranged as to allow a current to flow easily towards the heart, but not away from it, so that blood which has once moved past a certain point cannot return.

The valves consist of pockets, arranged in pairs, one on each side of the vein. Fig. 62, X, shows the view obtained by slicing a vein down into two parts, so as to leave on each half one complete pocket, A B D F C F. A B D is the loose upper edge. The flap is attached round AFCFD. At $\mathrm{Y}$ is seen the view 


\section{PHYSIOLOGICAL PARADOXES.}

obtained by cutting down across the middle of the pockets instead of between them, and here the vein itself is shown distended by the pressure of the blood which is filling the pockets and pressing together the loose edges of the flaps so as to close the opening against its own return. This position of affairs is also shown in cross-section at $Z$, which gives the view obtained by cutting across the vein just above
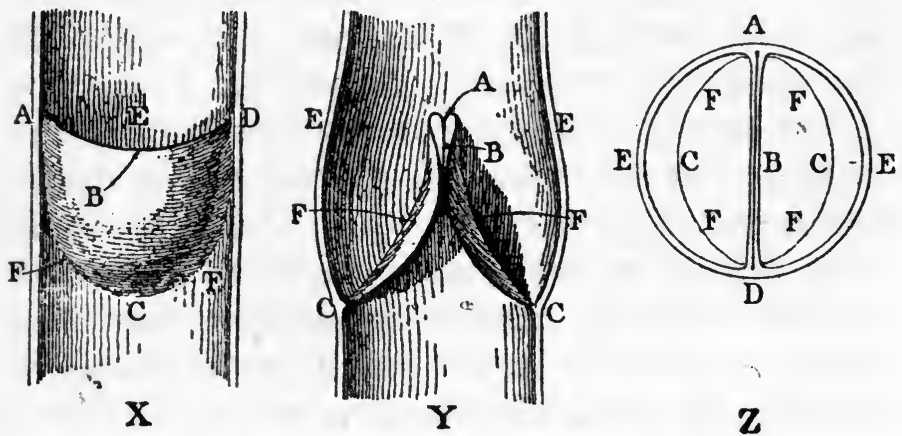

FIG. 62.-THE VALVES IN THE VEINS.

the valve, and looking down into the pocket at each side between the vein wall and the flap-edge, which is pressed hard against the flap-edge of the other pocket.

A study of these three views will readily show what an excellent as well as simple arrangement we have here for securing the blood against being driven in the wrong direction. When any cause tends to make it move upwards, it easily separates the loose flaps, which 


\section{VEINS AND HEART.}

lie against the sides of the vein and leave it a free passage. The moment it tends to flow downwards its own movement pulls out the flaps, and its pressure forces them together, thus closing the valve against its return.

The presence of some of these valves can easily be detected in the body by making downward pressure along the large veins in the arm, when the action of valves preventing the blood from going in that direction may easily be detected by knots or swellings caused in the manner indicated at $\mathrm{Y}$ in the figure.

The onward pressure force which, in metallic pumps, is exerted by the piston, is in the veins supplied in a variety of ways.

When the muscles contract, either in severe or gentle exercise, this contraction compresses the veins between the muscles or between them and the skin, and such compression, as we have seen, tends to drive the blood always towards the heart, since it is stopped in the other direction by the valves.

Pressure from outside, as in massage or pushing, compresses the veins, and moves on the blood towards the heart.

Change of position promotes movement of the blood. Holding up the arm allows the blood to run down the veins by gravity, the valves being in the right direction for this movement.

On the other hand, holding the limb downwards causes an accumulation of blood in the 


\section{PHYSIOLOGICAL PARADOXES.}

veins. Not because it runs down them-the valves prevent that-but because in that position they are filled from their smaller tributaries so that they are distended to a larger size by the stretching of their sides. This gives the muscular and fibrous material of which the sides are composed an opportunity of contracting when the limb is raised to a natural position, and driving out the excess of blood against the now diminished pressure.

Thus, all kinds of exercise, movement, and massage contribute to assist the circulation of blood so far as the veins are concerned, and in this way help to promote the general health.

The veins end in the heart, which may be regarded as a specially enlarged part of the circulation-tubes. As the improvement of the circulation is beneficial to health, so its maintenance is essential to life; and in the heart are provided the means of keeping it up, whether the rest of the body be awake or asleep, in activity or at rest.

For this purpose it would not do to rely on the chance compressions of exercise or outside force. The means of regular and sufficient compression must be provided on the spot. Accordingly, in this part of the blood-vessels the space capacity is enormously enlarged so as to provide four chambers which answer the same purpose as the cylinders in a pump. And as we cannot have pistons, the muscular part 


\section{VEINS AND HEART.}

of the wall of the blood-vessels here receives equally enormous development, so that the heart may be regarded as little more or less than a very considerable muscle of special form and functions.

To force the blood through the arteries, arterioles, and tissues, it has to be raised to a pressure equal to that produced by a column of water nine feet high on the left side of the heart, and three feet on the right, which sends it through the lungs. And it is against this pressure that the heart has to pump it. The quantity expelled by each side of a man's heart at each stroke is about six ounces, and there are about seventy strokes a minute. Thus the work done by a strong heart in twentyfour hours is about equivalent to that of lifting a weight of two tons roo feet high. A horse-power is commonly reckoned as the work equivalent to lifting 400 tons the same height in the same time; so that a strong human heart works up to about the two-hundredth part of a horse-power. Horse-power in such measurements means the total draught-power of a strong horse; and the phrase implies no comparison here between the human and equine heart.

The work to be done, then, being so considerable, and no piston being available to force out the blood from the heart even if it were itself of the shape of a cylinder, the heart has to empty 


\section{PHYSIOLOGICAL PARADOXES.}

itself by squeezing itself together till its opposite sides touch and there is no space left to hold any blood.

It is a duplicated pump, the work of the left side being to drive the blood, when aerated, all over the body, that of the right side to drive it through the lungs to be aerated again. Each side is similar in the principle of its action to the other, so it will be sufficient to explain that principle on one side, say the left.

The left side of the heart, then, contains two chambers, one the ventricle, the strong muscular chamber whose powerful contractions drive the blood all through the body; the other, the auricle, not so strong, and used merely as a collecting chamber. If the heart, after each contraction, had to be refilled from the veins directly, this would take a long time, which is saved by having the auricle, or collecting chamber, B (Fig. 63), which receives blood from the veins $C, D$, during the time when the ventricle $A$ is expelling an earlier charge into the large artery E, called the aorta. (All the parts in this illustration are much simplified for diagrammatic purposes.)

By the time that the auricle B is filled, the ventricle $A$ has squeezed out all the previous charge of blood into the aorta E, from which it is prevented from returning by the valve $G$. This valve consists of flaps forming cups or pouches with the wall of the blood-vessel, 


\section{VEINS AND HEART.}

much in the same way as in the veins; but in this case there are three such cups, and their three flaps meet at a point in the centre of the vessel. One of them is shown at $G$, and beside it a small portion of each of the others.

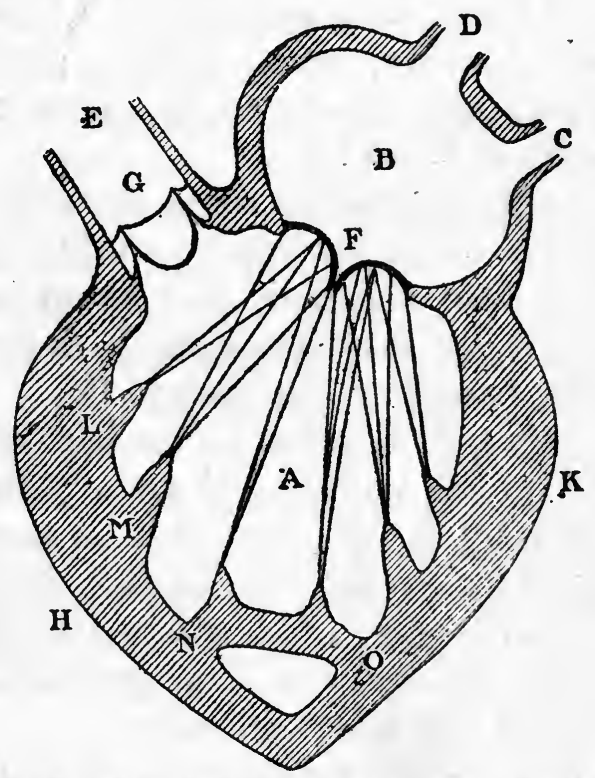

FIG. 63.-MECHANISM OF THE HEART-VALVES.

The ventricle having emptied itself by squeezing itself together, it now actively dilates to receive the next charge of blood, and in consequence of this dilatation there is very little pressure for the auricle B to overcome in emptying itself into the ventricle. It consequently needs no great strength and has no great thickness of muscle, and no special valves to 


\section{PHYSIOLOGICAL PARADOXES.}

prevent the blood flowing back into the veins, some wrinkling and folding of its inner skin as it contracts being sufficient for this purpose.

But the ventricle, having to drive the blood round the body, at a pressure equal to that of nine feet of water, must exercise great force, and consequently has a strong, thick muscular wall, shown at $\mathrm{H}$ and $\mathrm{K}$.

The most remarkable thing about the whole heart is the valve by which, during the contraction of the ventricle, the blood which is being forced out into the aorta $\mathrm{E}$, is prevented from going back into the auricle $\mathrm{B}$.

This valve, F, is called on the left side of the heart the mitral, or bicuspid valve; the latter name referring to the fact that it consists of two large flaps, which are, in fact, helped out by two small ones. The valve on the right side is very similar, but has three large flaps and is called the tricuspid valve.

The flaps of the mitral valve are shown in black at F, and it is plain how easily, when they are relaxed, the blood can push them aside and flow into the ventricle. But to allow this flow to take place rapidly, the valve-opening must be a large one. Partly for this reason, and partly because the opening is not a tubular passage with parallel walls, the arrangement of pocket-valves strong enough to resist the great pressure due to the contracting ventricle is not 


\section{VEINS AND HEART.}

possible. Accordingly, we find that the valve consists of plain flaps, supported in the very special and interesting manner shown in the diagram. On the inner walls of the ventricle stand up certain projections of muscle, shaped like ridges or columns, as at $\mathrm{L}$, and $\mathrm{M}$, or of a curious bridge-like form, as at NO. From the tips of these muscular projections small but strong fibrous cords run to various parts of the edges of each flap, where it joins the other flap, and also to numerous points over its ventricular surface. When the ventricle is contracting, and the blood-pressure tends to force the flaps towards the auricle, the support so admirably distributed over the surface of the flaps enables them to hold good against the pressure, and if the valve is not spoiled or the orifice enlarged by disease, no blood is allowed to get back into the auricle, which is meantime collecting a fresh charge from the veins.

It has just been suggested that sometimes the heart-valves are incapacitated by disease. Similarly the heart-muscle, which does the work of a piston, may be thinned, stretched, and weakened by disease or abuse. To this extent the heart is not a self-repairing pump. But for the wear and tear of ordinary work in good and healthy conditions, these parts are self-repairing, which, of course, the piston and valves of a metallic pump are not. 


\section{PHYSIOLOGICAL PARADOXES.}

'2. The Cab-horse as a Ballet Dancer.

Our inevitable perception of the close correspondence in structure between our bodies and those of other animals has naturally led to the practice of calling similar parts by the same names; but in some cases popular impressions have been at variance with the actual facts.

What we call knees in horses, cows, sheep, and other quadrupeds are by no means the joints which correspond to the knees in men.

If we look at human and equine skeletons we shall see this plainly.

First, take the human lower limb and the horse's hind leg.

In our own bodies the first part of this limb is called the thigh, and the thigh-bone, or femur, is hinged to the skeleton frame at the hipjoint.

The corresponding hip-joint in the horse is shown at $\mathrm{A}$ in Fig. 64 , as in the man it is at B.

That the diagram gives a fair representation of the skeleton structure in the two animals can easily be seen by referring to Plate VII., which gives a view of the admirable arrangement at the Natural History Museum, South Kensington, of human and equine skeletons placed together for the purpose of comparison.

The next joint below the hip-joint is that between the lower end of the femur and the 


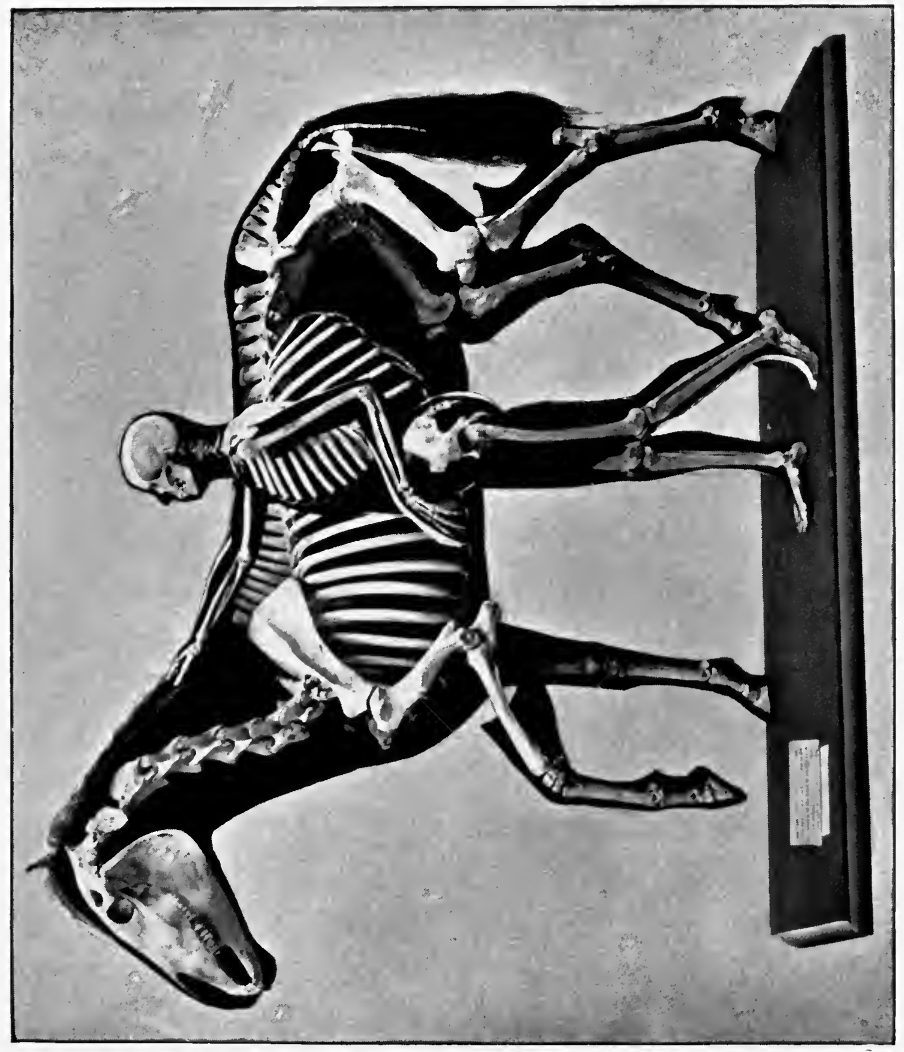

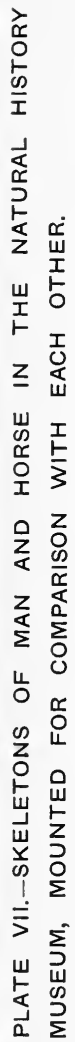





\section{THE HORSE A BALLET DANCER.}

upper end of the tibia, shown at $\mathrm{C}$ in the horse, in man at D. This is the knee in ourselves. But in horses and many other quadrupeds the femur, or thigh-bone, A C, is so short and so nearly horizontal, that the joint $\mathrm{C}$ is hardly observed in an animal in good condition; it

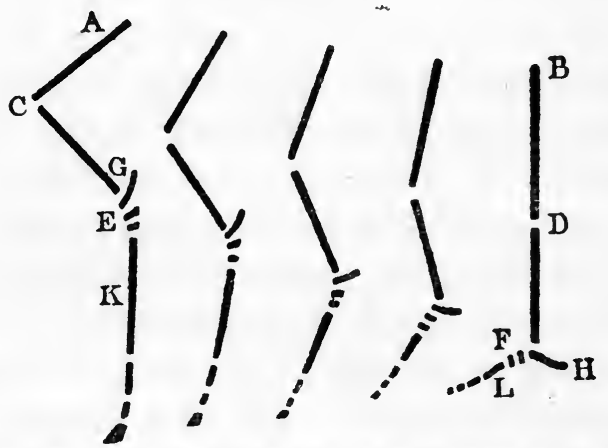

FIG. 64.- CORRESPONDENCE BETWEEN HUMAN AND EQUINE LIMBS.

appears to be part of the trunk. So little is it noticed that even when it appears, as in an emaciated animal, ordinary people, without special knowledge, would hardly know what name to give it, and those who gave it a name would probably call it the hip-joint. The real hip-joint is quite unperceived, at A.

Coming down to the next lower joint, at E, this, in the horse's hind leg, is the first joint that is reached in a position well removed from the mass of the body, and so we call it the knee, under the impression that it corresponds to the human knee; and those who have paid 


\section{PHYSIOLOGICAL PARADOXES.}

sufficient attention to the correspondences to be surprised when they fail, note with interest that in the horse the hind knee bends backwards, whereas in man it bends forwards.

The fact is that the joint at $\mathrm{E}$ is not a knee at all.

Between the diagrams of the human leg and the horse's hind-leg have been inserted in Fig. 64 three other diagrams showing intermediate conditions, the five being arranged in series. If these five be examined it will be clearly seen that in the number and succession of bones and joints each diagram corresponds strictly with those adjacent to it, having only a slight modification in the length and direction of any part. The first diagram, therefore, corresponds truly with the last, and it is impossible to deny that the joint $\mathrm{E}$ in a horse's hind leg answers to the joint $\mathrm{F}$ in the human leg.

What we commonly call a horse's knee is therefore an ankle. And its back part G corresponds to the heel $H$. Beneath this heelbone, in the horse, the same joint contains some smaller bones which represent the small bones of the tarsus in man, just in front of the ankle-joint. Then comes a fairly long bone, $\mathrm{K}$, the common bone, or, as most people call it, the shin-bone. It is, however, no shin-bone at all.

To what does it correspond in the human skeleton ? Evidently to $\mathrm{L}$, the first long bone 


\section{THE HORSE A BALLET DANCER.}

beyond the ankle-joint. But here we come upon a remarkable difference. In the horse $\mathrm{K}$ is a single bone with the most rudimentary traces of other bones down its sides. In man there are five bones side by side at L, the metatarsal bones, running down from the tarsus in front of the ankle-joint to the roots of the toes.

What is the explanation of this difference if these members in the two kinds of animals correspond?

Among ancient fossils there have recently been found a number of bones belonging to animals which were in many respects like the horse, but smaller, and possessed of a greater number of toes. An examination of them leads to the conclusion that the ancestors of our horses were originally five-toed creatures, whose descendants acquired the habit of resting more and more upon the fore part of the foot until the heel remained permanently in the air more than half-way up to the body, and the tarsus and toes obtained a similar rise in the world, so that at last the creatures were left standing, not even on the tips of the toes-not on the toes at all, but on the toe-nails, which for this purpose had become enormously developed both in size and thickness into what we call hoofs.

But the work of supporting the body was gradually concentrated more upon the long 


\section{PHYSIOLOGICAL PARADOXES.}

central toe, which grew longer and longer while the side ones grew weaker and smaller, and eventually dwindled away and disappeared, the only evidence in the modern horse of their presence in remote ancestors being ridges down. the sides of the bone in the one toe that remains, enlarged and strengthened, to do the work of the original five.

The horse's foot, then, has undergone two remarkable developments, one by which the two toes on each side of the foot have disappeared, leaving only rudiments behind; the other by which that toe has been converted practically into leg, leaving nothing but the enlarged and thickened nail to rest in contact with the ground.

In the latter respect the horse has had a modern rival in the ballet dancer, whose aim seems to be to twirl on the ball, or, if possible, on the point of the toe. The effort leads to anything but graceful and beautiful movements; but audiences are supposed to crave more for the astonishing than for the graceful and beautiful. The most successful danseuse has not yet got beyond dancing on the point of the toe ; whereas, when Madame Twirlini comes to the theatre for the performance, the horses which draw her carriage prance, not merely on the points of their toes, but on the ends of the toenails. The common cab-horse, if it does not dance in the same attitude, at any rate employs 


\section{THE HORSE A BALLET DANCER.}

it for travelling, standing, and even sleeping. If the ladies of the ballet should learn from their trainer this lesson of evolution, they might be led to redouble their assiduity in practising their steps by the prospect of developing some of their toes into mere rudiments, and so reducing the size of their feet; but a cautious teacher would not draw their attention to the extent of the overgrowth, in the horse's case, of the nails on those toes which survive.

The correspondence between the horse's fore-leg and man's arm is much the same as that between the other limbs. The upper joint of the horse's limb, corresponding to our shoulder, is not readily distinguishable from the mass of the body. The first clearly visible joint, answering to our elbow, is on a level with the bottom of the horse's chest. What we call the knee in the horse represents the human wrist and carpus. The long bone running straight down from the horse's knee takes the place of the middle metacarpal, which can be felt in the back of the human hand, our two side-bones, as before, being represented in the horse by mere ridges or rudimentary bones running down the sides of the surviving central bone. There are two more short bones, corresponding to the first and second parts of the fingers and the hoof, an enlarged and thickened nail. 


\section{PHYSIOLOGICAL PARADOXES.}

It is difficult to know which is the more striking-the remarkable harmony of structure displayed by all the vertebrate animals, or the wonderful completeness of the varieties and differences obtained by mere modification of organs originally similar. 
II 


\section{UNIVERSITY OF CALIFORNIA LIBRARY}

BERKELEY

Return to desk from which borrowed.

This book is DUE on the last date stamped below.

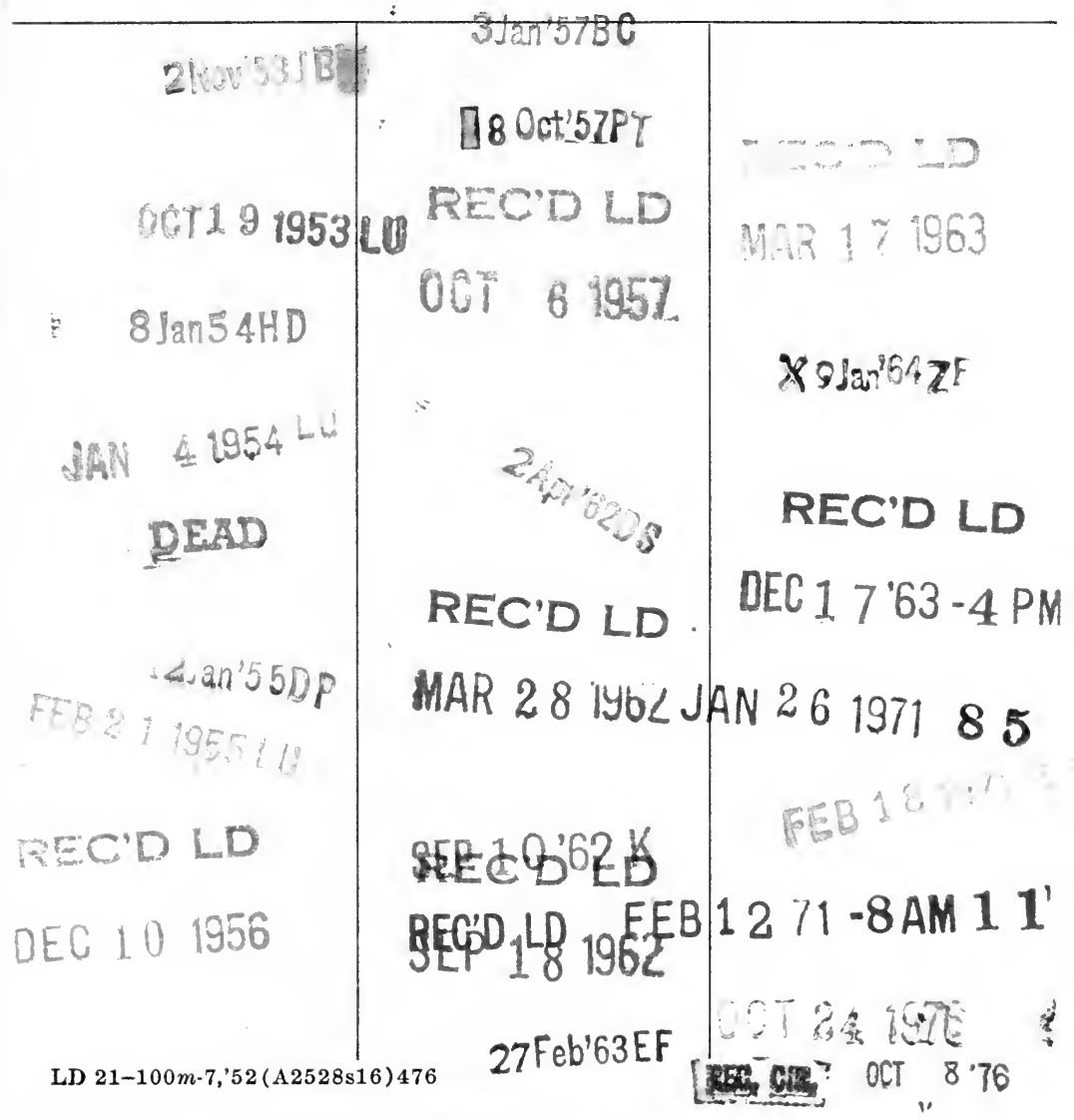




\section{YC 22543}

$\because \cdots+\cdots$ 
